\title{
Mersa Gaouasis sur la mer Rouge et les expéditions vers Pount au Moyen Empire
}

Par

\section{Claude Obsomer}

Université de Namur, Université catholique de Louvain

$\mathrm{L}$ a session 2018 des Journées de la «Société Royale Belge d'Études Orientales », consacrée aux «mers, ports et marins dans les civilisations orientales », fut pour moi l'occasion de revenir sur les expéditions envoyées vers Pount durant le Moyen Empire égyptien (vers 2030-1730 avant J.-C.). À l'époque où j'examinais la question dans le cadre de ma dissertation doctorale ${ }^{1}$, cela faisait à peine vingt ans que le Professeur Abdel Monem Sayed (Université d'Alexandrie) avait découvert près de la mer Rouge, au débouché du Ouadi Gaouasis, plusieurs documents inscrits sous le règne de Sésostris $\mathrm{I}^{\mathrm{er}}$ qui mentionnaient le pays de Pount. Nul doute pour Sayed qu'il venait d'identifier le lieu d'embarquement des expéditions navales vers Pount à la XII ${ }^{\mathrm{e}}$ dynastie : c'est là que devaient avoir été placées, à l'origine, deux stèles de la même dynastie découvertes vers 1830, l'une par James Burton, l'autre par John Gardner Wilkinson, dans un établissement gréco-romain du Ouadi Gasous à moins de dix kilomètres vers l'ouest, non loin du Bir Umm al-Huwaytat ${ }^{2}$. La plus ancienne

\footnotetext{
* Je remercie pour leur relecture Christian Cannuyer, El-Sayed Mahfouz, Daniel Malnati, Filip Taterka. Une version abrégée de cette étude vient de paraitre dans le volume XXXII des Acta Orientalia Belgica, sous le titre «Les ports de la mer Rouge et l'expédition de Sésostris I ${ }^{\mathrm{er}}$ vers Pount » (p. 31-58).

${ }^{1}$ Cf. OBSOMER 1995, p. 380-400.

${ }^{2}$ Conservées à l'Oriental Museum de l'Université de Durham, ces stèles avaient fait partie de la collection des ducs de Northumberland (Alnwick Castle). Editio princeps : BIRCH 1880, p. 267-270, pl. III-IV (nº 1934 et 1935).
} 
atteste le toponyme "Saouou » comme l'endroit où avaient abordé des bateaux revenant de Pount sous Amenemhat II, le successeur de Sésostris I ${ }^{\mathrm{er}}$. Sayed proposa d'identifier Saouou au site qu'il venait de découvrir et qu'il désigna désormais comme le « Mersa Gaouasis » ${ }^{3}$.

Si les conclusions de Sayed furent adoptées par une majorité d'égyptologues, parmi lesquels l'auteur de ces lignes, elles ne firent pas l'unanimité. Alessandra Nibbi refusa de voir dans les inscriptions et ancres retrouvées sur le site par Sayed des preuves de l'existence d'un établissement portuaire permanent à cet endroit ${ }^{4}$, tandis que Claude Vandersleyen préconisa l'itinéraire nilotique vers Pount (placé en amont de la cinquième cataracte) que Rolf Herzog avait suggéré en 1968, en interprétant également en ce sens l'inscription de l'intendant Hénou gravée au Ouadi Hammamat en l'an 8 de Mentouhotep III (XI' dynastie) ${ }^{5}$.

Les découvertes archéologiques et textuelles effectuées près de la mer Rouge à partir de 2001, non seulement au Ouadi Gaouasis mais aussi à Ayn Soukhna et au Ouadi el-Jarf, ont confirmé l'interprétation de Sayed. Elles ont permis de comprendre que trois «ports intermittents » avaient été en activité bien avant le Nouvel Empire et l'expédition d'Hatchepsout à Pount, associés à des galeries creusées au pied des collines voisines qui permettaient de conserver, d'une expédition à l'autre, les pièces détachées de bateaux. L'exposé qui suit présentera succinctement les découvertes et publications essentielles des deux dernières décennies, en s'attachant à peaufiner l'interprétation des inscriptions du Moyen Empire qui permettent de dénombrer désormais sept expéditions vers Pount datées avec précision durant cette période.

\section{Les trois « ports intermittents » de la mer Rouge}

\section{1a. Ouadi Gaouasis}

Repéré par George Murray comme l'endroit où se trouvait la Pilotéras ptolémaïque ${ }^{6}$, le site du Ouadi Gaouasis se trouve à $23 \mathrm{~km}$ au sud de Safaga et à $50 \mathrm{~km}$ au nord de Qoseir ${ }^{7}$. Lors d'une première campagne, en mars 1976, Sayed mena des fouilles au bord du plateau qui domine d'une dizaine de mètres le flanc nord du Ouadi Gaouasis, où il avait remarqué la présence çà et là de monticules formés de pierres rassemblées, ainsi que des fosses circulaires. Près de la mer, il découvrit, associées à ces structures, plusieurs stèles en calcaire, fragmentaires ou endommagées, dont certaines portaient des inscriptions : l'une d'elles notait des noms de bateaux incluant les cartouches de Sésostris $I^{\mathrm{er}}$, une autre conservait la séquence $B i 3 n(y)$ $P w n[t]$ et le nom d'un certain Imérou ${ }^{8}$. À $250 \mathrm{~m}$ à l'ouest, il trouva ensuite le monument commémoratif du chambellan du palais Ânkhou ${ }^{9}$, formé de plusieurs ancres de calcaire de réemploi : quatre ancres posées à plat constituaient un piédestal sur lequel étaient dressées trois autres ancres, amputées de leur partie arrondie et disposées en fer à cheval, qui conservaient les inscriptions d'Ânkhou, en partie effacées. On pouvait y lire encore les noms de Sésostris $\mathrm{I}^{\mathrm{er}}$, une date (Péret I de l'an 24), la séquence $m 3^{\rtimes \mathrm{C}} r$ B 3 Pwnt et nombre d'autres ter-

\footnotetext{
${ }^{3}$ SAYED 1977, p. 138-178; SAYED 1978, p. 69-71; SAYED 1979, p. 569-577; SAYED 1980, p. 154-157; SAYED 1983, p. 23-37 ; SAYED 1993, passim.

${ }^{4}$ NIBBi 1981, p. 69-74.

${ }^{5}$ VANDERSLEYEN 1988, p. 75-80 ; VANDERSLEYEN 1989, p. 148-158 ; VANDERSLEYEN 1996, p. 107-115.

${ }^{6}$ Murray 1925, p. 142.

${ }^{7}$ Coordonnées : 26³3'25" N, 3401'57" à 02'15" E.

${ }^{8}$ SAYED 1977, p. 150, pl. 12b et 13b-c ; SAYED 1979, p. 569, pl. LXXVIII ; SAYED 1993, p. 160.

${ }^{9}$ SAYED 1977, p. 157-169, fig. 2-6, pl. 13d à 14d; SAYED 1979, p. 569-570, pl. LXXIX-LXXX; SAYED 1980, p. 154-155; SAYED 1993, p. 161-179.
} 
mes et expressions des plus intéressants, en lien avec une navigation. À $200 \mathrm{~m}$ à l'ouest du monument d'Ânkhou, Sayed trouva un second monument commémoratif, composé d'une stèle dressée sur une ancre posée à plat et flanquée de deux blocs de pierre ${ }^{10}$. La stèle offrait dix lignes d'hiéroglyphes gravés dans le creux, bien conservées à part les lignes supérieures, qui mentionnaient le roi Sésostris $\mathrm{I}^{\mathrm{er}}$, son vizir Antefoqer, ainsi que le héraut Amény, connu déjà par une inscription de l'an 38 de Sésostris I ${ }^{\mathrm{er}}$ gravée au Ouadi Hammamat ${ }^{11}$. Sayed conclut que les deux monuments du Ouadi Gaouasis concernaient la même expédition.

En janvier-février 1977, Sayed poursuivit ses recherches en contrebas du monument d'Amény et d'Antefoqer. Il découvrit, près d'un abri sous roche ${ }^{12}$, trois ancres de calcaire, des pièces de bois et des mortaises, un ciseau de métal et des fragments de plusieurs autres, une jarre intacte et une quarantaine de tessons inscrits postérieurs au règne de Sésostris $\mathrm{I}^{\mathrm{er}}$, dont l'un mentionnait Pount ${ }^{13}$. Une analyse effectuée en 1980 aux Royal Botanic Gardens de Kew sur l'une des pièces de bois indiqua qu'il s'agissait de bois de cèdre datable par le radiocarbone d'environ 1975 avant J.-C. ${ }^{14}$ Une seconde analyse effectuée en 1992 au British Museum donna une fourchette plus large pour la même pièce de cèdre, entre 2200 et 1890 avant J.-C., tandis que certains éléments organiques pointaient le Nouvel Empire ${ }^{15}$. Sayed en concluait: " This results indicate that the port was in use during the New Kingdom, although no monuments or artifacts were found on the site of the port or in its vicinity dating to this time $»^{16}$.

La construction d'une voie ferrée, dans les années 1980, endommagea de façon irrémédiable la partie centrale du site, où le monument d'Ânkhou avait été découvert. Mais en 2001, Rodolfo Fattovich (Università degli Studi di Napoli "L'Orientale") et Kathryn Bard (Boston University) reprirent les recherches au Ouadi Gaouasis, menant dix missions consécutives de 2001-2002 à 2010-2011. Des tranchées et sondages effectués tant sur le plateau dominant la mer que dans la zone occidentale où avait été découvert le monument d'Amény leur permirent de mettre au jour une abondance de données nouvelles et de proposer une vision globale du site et de son utilisation ${ }^{17}$.

Il y a 4000 ans, une vaste lagune occupait l'embouchure du ouadi et offrait un accès à la mer entre deux barrières de corail ${ }^{18}$. Au sommet du plateau dominant le site au nord, les monticules de pierres étaient assemblés à des fins commémoratives ${ }^{19}$, tandis que les fosses circulaires s'avéraient être les fondations de huttes ${ }^{20}$. C'est au pied de la partie occidentale de ce plateau que les bateaux accostaient. L'on y découvrit une zone d'occupation humaine, ainsi

${ }^{10}$ SAYED 1977, p. 169-173, pl. 15d à 16b ; SAYED 1979, p. 570-571, pl. LXXXI ; SAYED 1993, p. 181-183.

${ }^{11}$ GOYON 1957, p. 17-20, 81-85 (n 61).

${ }^{12}$ Vue de la zone: SAYED 1993, p. 184. La zone examinée par Sayed correspond à la zone de fouilles WG 45-50 de la mission italo-américaine (communication d'El-Sayed Mahfouz).

${ }^{13}$ SAYED 1978, p. 70-71 ; SAYED 1983, p. 24-27 ; SAYED 1993, p. 185-190. Étude préliminaire : MAHFOUZ 2006, p. 31-34 ; MAHFOUZ 2010a, p. 431-438. Publication détaillée : MAHFOUZ 2008a, p. 267-334.

14 SAYED 1983, p. 36.

${ }^{15}$ SAYED 1993, p. 218 ; SAYED 2006, p. 209.

${ }^{16}$ SAYED 2003, p. 433.

${ }^{17}$ Notamment BARD, FAtTOVich 2007 ; BARD, FAtTOVich 2011, p. 105-129 ; BARD, FAtTOVich 2018. Voir aussi FAtTOVICH 2012, p. 1-59 ; BARD, FATtOVICH, MANZO 2013, p. 533-556 ; TALlet 2015, p. 33-36.

${ }^{18}$ BARD, FATTOVICH 2018, p. 37-38, fig. 9.

${ }^{19}$ BARD, FATTOVICH 2018, p. 126-137.

${ }^{20}$ BARD, FATTOVICH 2007, p. 44-50. 
que huit galeries et chambres creusées dans le rocher, dont l'une conservait encore 26 cordes enroulées (galerie 5) ${ }^{21}$. La fouille permit de retrouver de nombreux outils de pierre, de la céramique dont certains fragments issus des régions méridionales de la mer Rouge ${ }^{22}$, quelque 95 éléments de bateaux en bois ${ }^{23}$, une vingtaine d'ancres ${ }^{24}, 43$ boîtes de transport dont deux peintes d'une inscription de l'an 8 d'Amenemhat $\mathrm{IV}^{25}, 17$ nouveaux ostraca inscrits dont un mentionne l'an 8 d'Amenemhat $\mathrm{IV}^{26}$, un autre des bateaux dont le nom inclut le cartouche d'Amenemhat III $^{27}, 7$ fragments de papyrus et d'innombrables empreintes de sceaux ${ }^{28}$. L'on y trouva aussi 29 stèles, dont 13 inscrites, 7 notant le nom d'un roi (Sésostris II, Sésostris III ou Amenemhat III). Certaines stèles étaient encore en place dans des niches creusées près de l'entrée des galeries. Aucune inscription rupestre, car la pierre locale est impropre à la gravure, ce qui explique l'usage de stèles importées, voire le remploi d'ancres dans le cas d'Ânkhou. Pour l'approvisonnement en eau douce, les membres des expéditions pouvaient se rendre au Bir Umm al-Huwaytat, dans le Ouadi Gasous, à une dizaine de kilomètres à l'ouest.

Une chronologie de l'utilisation du site a été proposée par Bard et Fattovich à partir de l'étude typologique de la céramique et de l'analyse au radiocarbone d'éléments organiques ${ }^{29}$. La céramique date en grande majorité du début de la XII ${ }^{\mathrm{e}}$ dynastie au début de la XIII ${ }^{\mathrm{e}}$ dynastie, mais quelques tessons seraient à dater, les uns de la fin de l'Ancien Empire ou du début de la Première Période Intermédiaire (galerie 1), les autres de la fin de la Seconde Période Intermédiaire ou du début du Nouvel Empire (galerie 2). Effectuée au laboratoire de l'IFAO, l'analyse au C 14 d'une dizaine d'échantillons (bois, charbon et corde) confirme la date du Moyen Empire, hormis un morceau de charbon de l'époque ramesside. Quant aux inscriptions attestées sur les monuments commémoratifs, stèles, ostraca et boîtes en bois, elles datent exclusivement de la XII ${ }^{\mathrm{e}}$ dynastie, allant de l'an 24 de Sésostris I ${ }^{\mathrm{er}}$ à l'an 8 d'Amen- $^{-}$ emhat IV, soit de 1934 à 1800 avant J.-C. environ ${ }^{30}$.

\section{1b. Ayn Soukhna}

Situé à $65 \mathrm{~km}$ de Suez, non loin d'une source chaude qui a donné son nom à la région, le site d'Ayn Soukhna se trouve au bord de la mer Rouge au débouché d'une piste menant vers la région memphite ${ }^{31}$. Une paroi rocheuse dominant le site face à la mer, gravée d'inscriptions échelonnées de l'Ancien Empire à l'époque byzantine ${ }^{32}$, a permis à Mahmoud Abd-el-Raziq d'attirer l'attention sur le site en contrebas, qui fit l'objet de missions archéologiques à partir de 2001 grâce à un partenariat entre l'Université d'Ismaïlia (Mahmoud Abd-el-Raziq),

\footnotetext{
${ }^{21}$ Veldmeijer, ZaZZaro 2008, p. 9-39 ; BorojeVic, Mountain 2011, p. 131-141.

${ }^{22}$ MANZO 2010, p. 439-453; MANZO 2012a, p. 47-58; WALlACE-JONES 2018 ; BARD, FATTOViCH 2018, p. $100-106$.

${ }^{23}$ WARD, ZAZZARO 2010, p. 27-43 ; ZAZZARO, CALCAGNO 2012, p. 65-85 ; BARD, FATTOVICH 2018, p. 90-96.

${ }^{24}$ ZAZZARO 2011, p. 13-20 ; ZAZZARO, ABD EL-MAGUIB 2012, p. 87-103.

${ }^{25}$ MAHFOUZ 2010b, p. 165-169, fig. 1-4.

${ }^{26}$ Ostracon WG 111 : MAHFOUZ 2010b, p. 169, fig. 5-6.

${ }^{27}$ Ostracon WG 101 : MAHFOUZ 2008b, p. 258-259, fig. 10-11. La publication des autres ostraca est en cours.

${ }^{28}$ MANZO, PiRELli 2006, p. 40-100.

${ }^{29}$ BARD, FATtOVich 2011, p. 109-110, 115-117 ; BARD, FATTOVich 2018, p. 31-34.

${ }^{30}$ Pour la chronologie absolue utilisée dans cet article, voir OBSOMER 1995, p. 155.

${ }^{31}$ Coordonnées : 29॰35'02" N, 32॰20'34" E.

${ }^{32}$ AbD El-RAZIQ 1999, p. 125-131, pl. XXXIII-XXXVI ; ABD El-RAZIQ, CASTEl, TAllet, GhiCA 2002 ; TALLET 2012a, p. 194-215 (nº 211-244).
} 
l'Institut Français d'Archéologie Orientale (Georges Castel) et l'Université Paris IV-Sorbonne (Pierre Tallet) $^{33}$. Au pied du rocher aux inscriptions, dix galeries d'une longueur allant jusqu'à $24 \mathrm{~m}$ ont été mises au jour, qui servirent à entreposer des denrées alimentaires et les pièces de bateaux utilisés pour traverser la mer Rouge vers le Sinaï à l'Ancien et au Moyen Empire ${ }^{34}$. Les inscriptions de la $\mathrm{V}^{\mathrm{e}}$ dynastie qui y furent découvertes mentionnent les «Terrasses de turquoise » (Sinaï) et l'usage de bateaux- $k b n t^{35}$. Les galeries 2 et 9 contenaient encore les pièces détachées de bateaux d'environ 14-15 m de long, susceptibles d'être assemblées par des cordes et un système de tenons et mortaises ${ }^{36}$. Des analyses ont permis de déterminer que les planches sont majoritairement de cèdre, les tenons d'acacia; que la planche la plus ancienne date de la $\mathrm{V}^{\mathrm{e}}$ dynastie, la plus récente de la fin du Moyen Empire comme les cordes. C'est donc à cette époque que les bateaux ont été démontés et rangés dans les galeries, où le feu a sans doute été bouté intentionnellement. Dans la zone inférieure du site, des vestiges d'occupation humaine ont été exhumés, associés à des ateliers métallurgiques servant à traiter le minerai de cuivre ramené du Sinaï ${ }^{37}$, ainsi qu'une fosse naviforme destinée probablement à l'assemblage des bateaux.

D'après les inscriptions et empreintes de sceaux retrouvées, le "port intermittent » d'Ayn Soukhna semble avoir fonctionné à l'Ancien Empire (du milieu de la IV ${ }^{\mathrm{e}}$ dynastie au milieu de la $\mathrm{VI}^{\mathrm{e}}$ dynastie), au début du Moyen Empire (inscriptions de l'an 1 de Mentouhotep IV, de

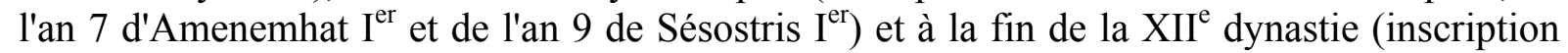
de l'an 2 d'Amenemhat III). Aucun vestige du Nouvel Empire n'a encore été identifié sur le site en relation à l'inscription rupestre d'Aménophis $\mathrm{I}^{\mathrm{er}}$. Plusieurs personnages mentionnés à Ayn Soukhna le sont également dans les sites miniers du Sud Sinaï (Ouadi Maghara, Sérabit el-Khadim $)^{38}$. Plusieurs gravures de bateaux sont visibles dans les rochers de Rod el-Air, à mi-chemin du sentier qui permet de monter au Sérabit el-Khadim.

\section{1c. Ouadi el-Jarf}

Situé non loin du monastère Saint-Paul, à $24 \mathrm{~km}$ au sud de Zafarana où débouche le Ouadi Arabah qui relie la mer Rouge à la région de Meidoum, le site du Ouadi el-Jarf fut visité vers 1830 par John Gardner Wilkinson, qui y repéra un complexe de galeries qu'il crut être d'époque gréco-romaine. Dans les années 1950, ces galeries furent retrouvées par François Bissey et René Chabot-Morisseau, pilotes du canal de Suez et archéologues amateurs, qui en dressèrent un plan provisoire; gagnant la rive de la mer sur les indications de leur guide Abouna Sidrac, du monastère Saint-Paul, ils examinèrent au lieu dit "el-Mina » les vestiges d'une jetée en forme de $\mathrm{L}$ visible à marée basse. La publication de leurs notes, en $2008^{39}$, a permis de comprendre l'intérêt de ces deux sites et a conduit à la mise en œuvre de missions archéologiques à partir de juin 2011, grâce à un partenariat entre l'Université Paris IV-

\footnotetext{
${ }^{33}$ AbD El-RAZiQ, CASTEl, TAllet 2006a, p. 3-6 ; TAllet 2006, p. 10-31; TAllet 2009, p. 698-714; ABD El-RaziQ, Castel, Tallet, Marouard 2012, p. 3-20 ; TAllet 2012c, p. 33-38; TAllet 2015, p. 37-46.

${ }^{34}$ ABD EL-RAZIQ, CASTEL, TALLET 2016.

35 TALLET 2012a, p. 215-229 (n 245-250) ; TALLET 2012b, p. 105-116.

${ }^{36}$ POMEY 2011, p. 3-12 ; POMEY 2012, p. 35-52.

${ }^{37}$ ABD EL-RAZIQ, CASTEL, TALlet, FLuZIN 2011.

${ }^{38}$ ABD EL-RAZIQ 1999, p. 125-131 ; TALLET 2002, p. 371-387 ; TALLET 2010, p. 18-22.

${ }^{39}$ LACAZE, CAMINO 2008.
} 
Sorbonne (Pierre Tallet) et l'Université d'Assiout (El-Sayed Mahfouz), auxquelles s'associa l'Institut Français d'Archéologie Orientale ${ }^{40}$.

Situées dans les collines au sud du Ouadi el-Jarf (zone 1), à environ $6 \mathrm{~km}$ du rivage, les galeries d'un nombre approchant la trentaine offrent une profondeur de 16 à $34 \mathrm{~m}$. Dix-sept galeries sont creusées autour d'une éminence rocheuse calcaire ${ }^{41}$, tandis qu'une dizaine d'autres sont localisées au sud-ouest, le long d'un petit ouadi adjacent. Devant les galeries 3 à 6 , une zone avait été aménagée au moyen de blocs de calcaire, dont certains offrent des marques à l'encre rouge, l'une incluant le cartouche de Chéops ( $\mathrm{IV}^{\mathrm{e}}$ dynastie). C'est à l'entrée de la galerie 1 que fut découvert en 2013 un lot de papyrus, au sein duquel furent identifiées les " archives de Mérer », qui donnent des précisions sur le transport de blocs des carrières de Toura au plateau de Giza à la fin du règne de Chéops ${ }^{42}$. Le site a révélé la présence de jarres de stockage, de matériaux organiques (textiles, vannerie, cordages, pièces et copeaux de bois) et, à proximité, des zones de production de céramique locale, dont des exemplaires ont été retrouvés au Sinaï, ainsi que des structures d'habitat (zones 2 à 4). Une grande pièce de coque en bois (varangue) découverte devant la galerie 5 appartenait à un bateau de 10 à $14 \mathrm{~m}$, voire de 16 à $25 \mathrm{~m}$, selon les hypothèses de restitution ${ }^{43}$.

À mi-chemin de la côte, une grande structure rectangulaire de $56 \mathrm{x} \pm 30 \mathrm{~m}$ (zone 5), datable de la $\mathrm{IV}^{\mathrm{e}}$ dynastie (Chéops et Chéphren), qui avait été repérée dès 1823 par James Burton, aurait servi à loger les membres de corps expéditionnaires ${ }^{44}$. Enfin, sur la côte ${ }^{45}$, Mina el-Jarf (site 6) présente une digue de pierre de $6 \mathrm{~m}$ de large en moyenne et de plus de $300 \mathrm{~m}$ de long, qui prend naissance sur la plage et se prolonge dans l'eau vers l'est, puis vers le sud-est ${ }^{46}$. Dans la zone ainsi définie, protégée des vents et courants dominants du nord, une vingtaine de petites ancres de bateaux gisaient au fond de l'eau. Une centaine d'autres ont été retrouvées dans les vestiges de deux bâtiments adjacents situés à $150 \mathrm{~m}$ vers l'ouest ${ }^{47}$, l'un pour le stockage, l'autre pour l'habitat, tandis qu'une structure artificielle d'une hauteur actuelle de $5 \mathrm{~m}$ offrait sans doute aux marins un point de repère visuel. Le site a livré de nombreuses empreintes de sceaux mentionnant le nom d'Horus de Chéops.

Les installations du Ouadi/Mina el-Jarf sont liées au site fortifié du Tell Ras Budran, datant de l'Ancien Empire et situé à la même latitude sur la côte du Sinaï dans la plaine d'el$\mathrm{Markha}^{48}$. Une navigation de $50 \mathrm{~km}$ à travers le golfe de Suez permettait de se rendre d'un lieu à l'autre. Du Tell Ras Budran, il était possible de gagner par voie terrestre les sites miniers du Ouadi Maghara au sud et du Ouadi Kharig au nord.

\footnotetext{
${ }^{40}$ Notamment Tallet, Marouard, Laisney 2012, p. 399-446 ; TAllet, Marouard 2014, p. 4-14 ; TALleT, MAROUARD 2016, p. 135-177. On lira avec intérêt les rapports annuels publiés dans le Bulletin de l'Institut Français d'Archéologie Orientale.

${ }^{41}$ Coordonnées : $28^{\circ} 533^{\prime} 56^{\prime \prime} \mathrm{N}, 32^{\circ} 37^{\prime} 28^{\prime \prime}$ E.

42 TALLET 2013, p. 1015-1024; TALLET 2014, p. 25-49; TALLET 2017 a.

${ }^{43}$ Selon Patrice Pomey, cité par TALlet 2017b, p. 243-246.

44 TALlet, MAROUARD 2016, p. 150-156.

${ }^{45}$ Coordonnées : 28॰53'20" N, 3240'49" E.

46 TAllet, Marouard 2016, p. 139-142.

${ }^{47}$ TALLET, MAROUARD 2016, p. 142-150.

${ }^{48}$ MumFord 2006, p. 13-67 ; MUMFORD 2012, p. 107-145 ; TALlet, MAROUARD 2016, p. 168-176.
} 


\section{1d. Chronologie de l'utilisation des "ports intermittents"}

La caractéristique essentielle des trois ports découverts près de la mer Rouge est, selon Pierre Tallet ${ }^{49}$, la présence d'un ensemble de galeries où pouvaient être entreposés, d'une expédition à l'autre, le matériel que l'on ne ramenait pas vers la vallée du Nil, de même que l'équipement et le ravitaillement nécessaires à chacune de ces expéditions. Ces sites permettaient un mouillage des bateaux dans une zone dépourvue de récifs coralliens, abritée du vent du nord et bénéficiant d'un point d'eau douce dans un rayon de $10 \mathrm{~km}$.

Toujours selon Tallet ${ }^{50}$, dans l'état actuel de la documentation, le lieu d'embarquement des expéditions navales sur la mer Rouge fut, au début de la IV $\mathrm{IV}^{\mathrm{e}}$ dynastie, le port du Ouadi el-Jarf, qui semble avoir été abondonné au profit d'Ayn Soukhna dès le règne de Chéphren. Ce nouveau port présentait l'avantage d'être directement accessible depuis Memphis, la Résidence royale de l'Ancien Empire ${ }^{51}$. Ayn Soukhna fut utilisé de nouveau à la transition des $\mathrm{XI}^{\mathrm{e}}$ et $\mathrm{XII}^{\mathrm{e}}$ dynasties (de l'an 1 de Mentouhotep IV à l'an 9 de Sésostris I ${ }^{\mathrm{er}}$ ), après quoi les expéditions navales vers Pount et le Sinaï (Sérabit el-Khadim) embarquèrent de Mersa Gaouasis. Cependant, de l'an 2 à l'an 20 d'Amenemhat III, Ayn Soukhna redevint temporairement le point de départ d'expéditions vers le Sinaï, comme il le serait de nouveau au début du Nouvel Empire.

Comme le remarque Tallet, ce séquençage chronologique ne permet pas d'expliquer un certain nombre d'expéditions attestées par ailleurs, mais certaines d'entre elles, qui avaient comme objectif le Sinaï, peuvent très bien avoir emprunté un trajet terrestre, notamment au cours des premières dynasties, mais aussi sous Ramsès III quand la Résidence royale était PiRamsès dans le Delta $\left(\mathrm{XX}^{\mathrm{e}} \text { dynastie }\right)^{52}$. Quant à l'expédition navale envoyée vers Pount par le roi Mentouhotep III de la $\mathrm{XI}^{\mathrm{e}}$ dynastie, elle est évoquée par une inscription rupestre du Ouadi Hammamat, entre Coptos et Qoseir, mais semble n'avoir laissé aucune trace sur la côte de la mer Rouge, dans l'état actuel des conaissances.

Examinons à présent les données, essentiellement textuelles, qui permettent de comptabiliser aujourd'hui sept expéditions menées vers Pount pour la période du Moyen Empire (vers 2030-1730 avant J.-C.). Il s'agira d'abord de collecter les informations sur les sources et de revoir si nécessaire la traduction des textes (points 2 et 3). L'exploitation historique de ces données, souvent minces ou partielles, sera proposée ensuite (point 4) afin de fournir une vue d'ensemble sur l'organisation et le timing de ces expéditions.

\section{Les premières expéditions du Moyen Empire vers Pount}

\section{2a. L'expédition de l'an 8 de Mentouhotep III}

La plus ancienne expédition vers Pount attestée au Moyen Empire est connue par une source unique : l'inscription de l'intendant Hénou gravée au Ouadi Hammamat. Dans les années 1840, Carl Richard Lepsius en fit une première copie, qu'il publia avec quelques autres

\footnotetext{
${ }^{49}$ TALLET 2015, p. 54-57.

${ }^{50}$ TALLET 2015, p. 59-67.

${ }^{51}$ C'est sans doute à Ayn Soukhna qu'il convient de localiser l'attaque d'Âamou contre une troupe qui était en train d'assembler des bateaux-kpnt destinés à se rendre à Pount, évoquée sous le règne de Pépy II (VI dynastie) dans l'autobiographie de Pépinakht (Urk. I, 134.13-15).

${ }^{52}$ Sur Ramsès III, voir Somaglino, TAllet 2011, p. 361-369 ; SOMAglinO, TAllet 2013, p. 511-518.
} 
dans ses Denkmaeler ${ }^{53}$. Vladimir Golenischeff en effectua une seconde copie, après sa visite du site en 1884-85 $5^{54}$. Celles-ci permirent à James Henry Breasted de fournir en 1906 une première traduction à destination de la communauté scientifique ${ }^{55}$. Enfin, en 1912, parut l'édition typographique annotée de Pierre Montet ( $\left.n^{\circ} 114\right)$, accompagnée d'une photographie en noir et blanc de Jean Couyat ${ }^{56}$. Elle a fait, depuis lors, l'objet de plusieurs traductions intégrales ou partielles $^{57}$. Je remercie le Dr. Nicolas Gauthier de m'avoir fourni d'excellentes photographies prises en février 2010 (ci-après, pages 60-61).

Une colonne de grands hiéroglyphes note la titulature du roi Mentouhotep III Séânkhkarê. À gauche de celle-ci une petite ligne aujourd'hui disparue conservait une date : « an 8, premier mois de Chémou, jour 3 ». Sous cette date, un long texte autobiographique de 15 lignes est composé de deux sections d'égale longueur: un long éloge personnel du «chancelier royal, compagnon unique et intendant Hénou » (lignes 1-8) précède son récit décrivant la mission remplie pour le roi (lignes 8-15). Voici une traduction de cette seconde section.

a) Dire : " [Mon Maître -vivant (soit-il), prospère et] en bonne santé! - [m'a] envoyé pour dépêcher ${ }^{58}$ des bateaux-kbnyt vers Pount ( $r$ sbt kbnywt $r$ Pwnt), afin de lui rapporter la myrrhe fraîche en possession des princes chefs du désert $\left(m-^{c} h k^{3} w h r y(w)-t p d \check{r} r t\right)$, en raison de la crainte qu'il suscite à travers les pays étrangers.

b) Alors je suis parti de Coptos ( ${ }^{c} h^{c} . n .(i) p r . k w(i)^{59} m$ Gbtyw) ${ }^{(9)}$ par le chemin que Sa Majesté m'avait ordonné, ayant avec moi une troupe du Sud/de Haute-Égypte, provenant des [nom]es $\left(m\left[s p^{3}\right] w t^{60}\right)$ de Ouabou et de (la zone qui va) de là (sc. Coptos) jusqu'à Ioumitérou $^{61}$ (au sud) et au nord jusqu'à Chabet $^{62}$, tous les fonctionnaires du roi, qui sont issus à la fois de la ville et de la campagne, venant à ma suite, un prospecteur et des

\footnotetext{
${ }^{53}$ LEPSIUS, II, pl. 150a.

${ }^{54}$ GOLENISCHEFF 1887, pl. XV-XVII. [non vidi]

${ }^{55}$ BREASTED 1906, p. 208-210 (§ 427-433).

${ }^{56}$ Couyat, MonTet 1912, p. 81-84, pl. XXXI.

${ }^{57}$ Notamment SCHENKEL 1965, p. 253-258 ; LICHTHEIM 1988, p. 52-54 ; VANDERSLEYEN 1989, p. 148-152 ; Goelet 1992, p. 208-209 ; Diego ESPINEL 2003, p. 76-77 ; BREYER 2016, p. 599-602 ; TATERKA 2018, p. 66-
} 67.

${ }^{58}$ Le choix de cette traduction du verbe $s$ i sera justifié plus loin (voir 4a, point 3 ).

${ }^{59}$ Les verbes pri «monter» (lignes 8 et 10$)$ et $h 3 i$ « descendre» (ligne 13) sont employés, dans le récit d'expéditions, pour fournir des indications sur les trajets aller et retour : cf. GOELET 1992, p. 209 ; OBSOMER 2007a, p. 47.

${ }^{60} \mathrm{Au}$-dessus des trois traits, on peut encore voir une petite ligne horizontale appartenant à un - $t$ du féminin. Ce passage fait penser aux col. 12-14 de l'inscription Montet 192 (an 2 de Mentouhotep IV), où on lit que le roi envoya le vizir Amenemhat « avec une troupe de 10000 hommes provenant des nomes méridionaux de HauteÉgypte au sud des domaines de Ouabou » ( $m$ sp३swt rsywt $\breve{S} m^{\top} w$ hnty prw $\left.W 3 b w\right)$. Dès lors que le nom féminin $s p^{3} w t$ semble pouvoir être restauré, de préférence au nom masculin prw préconisé par MONTET 1961, p. 52, la suite du texte énonce les régions de Haute-Égypte qui ont fourni des hommes de troupe : d'une part, le XIX nome (Ouabou) situé au sud du Fayoum; d'autre part, les nomes voisins de Coptos (comme l'a compris VANDERSLEYEN 1989, p. 151, n. 8). Il est dès lors inutile d'imaginer une séquence $w 33 w W 3 s t$ qui aurait désigné les ouabou (centres de recrutement, garnisons, troupes ?) du nome thébain. Breasted avait donc raison de voir dans ce passage la mention du nome d'Oxyrhynchos (Ouabou, XIX ${ }^{\mathrm{e}}$ nome de Haute-Égypte).

${ }^{61}$ Ioumitérou se trouve à la limite des $\mathrm{III}^{\mathrm{e}}$ et $\mathrm{IV}^{\mathrm{e}}$ nomes, non loin de Gebelein : MONTET 1961, p. 52.

${ }^{62}$ Mentionnée aussi par Ânkhtyfy de Moalla, Chabet se trouvait dans le VI ${ }^{\mathrm{e}}$ nome, non loin de Dendara : MONTET 1961, p. 90. 
policiers (smnty, $s^{3} w$-prw) ${ }^{63}$ nettoyant les routes ${ }^{(10)}$ devant moi et abattant les opposants du roi, des chasseurs (et des ?) natifs du désert étant placés en protection de ma personne, tous les conseillers (litt. : tout le conseil) de Sa Majesté étant placés sous ma supervision, alors que je faisais rapport à leur sujet à des émissaires (smi.(i) sn $n$ wpwtyw) ${ }^{64}$ en tant que commandant unique à qui une multitude obéit.

c) Je suis parti avec une troupe de 3000 hommes (Pr.n.(i) $\left.{ }^{65} m m \check{s}^{c} n(y) s 3000\right){ }^{(11)}$ et j'ai transformé le chemin en fleuve, la terre rouge en terrains fertiles de la campagne. En effet, j'ai donné une outre, un panier à pain, deux cruches d'eau et vingt pains à chacun d'entre eux, chaque jour, tandis que des ânes étaient chargés de sandales, (si bien que) lorsqu'une semelle (litt. : un pied) était usée, une autre était disponible. C'est alors que j'ai fait ${ }^{66} 12$ puits dans la zone buissonneuse (litt. : les buissons) et ${ }^{(12)} 2$ puits en Idahet ('Id’h $h$ ), l'un d'1 khet et 20 coudées, l'autre d' 1 khet et 30 coudées $^{67}$. J'en ai fait un autre en Iaheteb ('I3htb), de 10 coudées sur 10 en sa margelle $(m h 10 r 10 h r r(3) . s n b)^{68}, n s m 3 / w b$ ว $n b^{\complement} h / p$ ว $m w$ $(?)^{69}$.

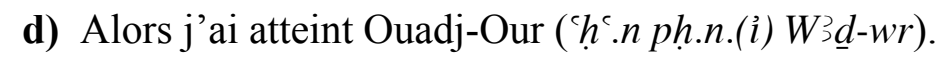

e) Alors j'ai fait/constitué cette flotte ( $h^{c} . n$ ir.n.(i) $h h^{`} w p n$ ) et je l'ai dépêchée ${ }^{70}$ en toutes choses (sb.n.(i) sw $m$ ht $n b t$ ), après avoir fait pour elle une grande offrande de taureaux, de bœufs et ${ }^{(13)}$ de gazelles.

f) Et quand on s'éloigna de Ouadj-our ( $H r$ ht.tw $m W 3 d$-wr), après que j'eus accompli ce que Sa Majesté avait ordonné, j'ai emporté pour Elle toutes sortes de produits que j'avais trouvés sur la rive de la Terre du dieu ( $h r$ idb T3-ntr).

g) Je suis revenu par Ouag et Rohanou (H3.n.(i) $h r W 3 g R(3)-h n w)$ et j'ai emporté pour Elle des pierres de qualité pour les statues de la chapelle du dieu.

\footnotetext{
${ }^{63}$ Cf. YoyotTe 1952, p. 146.

${ }^{64}$ Pour la traduction argumentée de ce passage, voir OBSOMER 1995, p. 394, n. 123.

${ }^{65}$ Il s'agit d'un second paragraphe donnant d'autres informations sur le même trajet aller.

${ }^{66}$ J'ai conservé le sens général du verbe irí. Il pourrait s'agir de puits creusés ou de citernes naturelles aménagées.

${ }^{67}$ C'est sans doute la profondeur exceptionnelle de ces deux puits que l'on a voulu indiquer. Si le terme $h t$ est bien à comprendre comme l'unité de mesure khet valant 100 coudées ( $c f$. MiCHEL 2014, p. 121), ces puits auraient 60 et $65 \mathrm{~m}$ de profondeur. Même lecture chez BrEYER, Punt, p. 601, n. 32. La stèle de Qouban de Ramsès II signale que Séthy $\mathrm{I}^{\mathrm{er}}$ avait fait creuser dans la région nubienne d'Akyta un puits de 120 coudées, mais sans parvenir à atteindre l'eau ( $c f$. OBSOMER 2012, p. 116). Par contre, KAPLONY 1969, p. 25, propose de comprendre 20 coudées $^{2}$ et 30 coudées $^{2}$. Selon Marianne Michel (communication personnelle), les données exprimées en khet et en coudées pourraient désigner des mesures différentes (profondeur et diamètre ?), ce qui expliquerait que l'on n'ait pas indiqué 120 coudées et 130 coudées en utilisant seulement cette unité de longueur.

${ }^{68}$ Les mêmes données figurent dans l'inscription Montet 191 de l'an 2 de Mentouhotep IV (col. 3-4) : hnmmt $m$-hr-ỉb int mh 10 r mh 10 hr r(3).s nb « un puits dans la vallée, de 10 coudées sur 10 coudées en sa margelle ». Il s'agit d'une mesure approximative de la superficie de l'ouverture du puits que l'on peut supposer arrondie. Dans les papyrus mathématiques, pour mesurer l'aire d'un cercle on se base sur l'aire du carré correspondant ( $c f$. MiCHEL 2014, p. 332-344).

${ }^{69}$ Traductions proposées : « in seiner ganzen Tiefe » (KAPLONY 1969, p. 25); «at all water levels » (LICHTHEIM 1988, p. 54, n. 18); pour arriver à l'eau profonde (?)» (VANDERSLEYEN 1989, p. 152); «beim Erreichen des Grundwassers? ${ }^{?}$ (BREYER 2016, p. 601). Dans l'inscription Montet 191, le puits était simplement $m h t m m w$ « rempli d'eau ». Je préfère ne pas traduire les données de l'inscription d'Hénou.

${ }^{70}$ Le choix de cette traduction du verbe sbi sera justifié plus loin (voir 4a, point 3).
} 
h) Jamais chose semblable n'avait été descendue pour les rois de la Résidence. Jamais ${ }^{(14)}$ chose semblable à cela n'avait été accomplie par aucun courtisan royal envoyé (en mission) depuis l'époque du dieu. J'ai accompli cela pour la Majesté de mon maître, tant il m'apprécie en tant qu'acteur efficace, vigilant à son heure pour son maître qui a promu sa fonction et a promu pour lui sa place en son domaine plus que (celle de) tout (autre) fonctionnaire de ce pays. ${ }^{(15)}$ Puisse à présent une chose plus grande que cela être accomplie grâce à la puissance de mon maître. Puisse-t-il être permis que son $k a$ perdure sur le grand (trône), dans la royauté des deux rives d'Horus. Je suis son serviteur, son favori, qui accomplit journellement tout ce qu'il loue. »

William Hayes attribue au même intendant Hénou la tombe thébaine n 313 située à Deir el-Bahari et datant du règne de Mentouhotep II, même si le nom est ici écrit Hénénou ${ }^{71}$. Pour Dimitri Meeks ${ }^{72}$, la stèle très fragmentaire qui se trouvait dans cette tombe «semble bien évoquer le même voyage ». Or, il est question à la ligne 9 de « faire une expédition/constituer une troupe de [...] hommes » (irt $\left.m \check{s}^{c} n(y) s[\ldots]\right)$, puis de bédouins hyrw- $\breve{s}^{c}$ et de ramener quelque chose (in.n.[...]), et à la ligne 10, après une longue lacune, Hénénou dit avoir fait des barges-wsht ('Iw ir.n.(i) wshwt). Je n'y vois pour ma part aucun lien nécessaire avec la mission décrite par l'inscription du Ouadi Hammamat, mais plutôt une activité menée au nord-est de l'Égypte, avec le transfert possible d'un butin vers Thèbes au moyen de ces barges ${ }^{73}$.

\section{2b. L'expédition de l'an 24 de Sésostris I ${ }^{e r}$}

La seconde expédition vers Pount connue pour le Moyen Empire est aussi la première à être attestée au Ouadi Gaouasis. Tout porte à croire que les inscriptions des monuments commémoratifs d'Amény et d'Ânkhou découverts sur le plateau dominant le site concernent la même expédition ${ }^{74}$. L'une décrit les activités qui ont précédé l'envoi des bateaux à Pount; l'autre a été rédigée après le retour de ces bateaux. La première mentionne la mission confiée par le roi à Antefoqer, vizir en fonction au moins depuis l'an $29 \mathrm{~d}^{\prime}$ Amenemhat $\mathrm{I}^{\mathrm{er}}$, et le rôle du héraut Amény ; la seconde conserve une date à lire comme l'« [an] 24 »de Sésostris I ${ }^{\mathrm{er}}$.

\section{L'inscription d'Amény mentionnant Antefoqer}

L'inscription se trouvait sur une stèle en calcaire de $50 \mathrm{~cm}$ de large et $15 \mathrm{~cm}$ d'épaisseur qui, au moment de sa découverte, était encore conservée sur une hauteur de $45 \mathrm{~cm}^{75}$. Le haut de la pierre d'effrita très vite, après que les hiéroglyphes qui allaient disparaître eurent été copiés. Pour Abdel Monem Sayed, il devait s'agir à l'origine d'une stèle cintrée ${ }^{76}$, ce que confirma Dominique Farout, pour qui l'épithète royale di..(w) ' $n h$ mi $R^{\varsigma}$ « doué de vie (soit-il) comme Rê » (ligne 1 de Sayed) n'appartenait pas au texte lui-même, mais accompagnait une figuration gravée dans le cintre « dont on devine quelques traces » sur la photographie ${ }^{77}$. Pour

\footnotetext{
${ }^{71}$ HAYES 1949, p. 43-49, pl. IV.

${ }^{72}$ MEEKS 2002, p. 322.

${ }^{73}$ Le terme wsht est mentionné dans Sinouhé (B 13, R 38) pour une navigation sur le Nil.

${ }^{74}$ Arguments dans SAYED 1977, p. 173 (d'ordre paléographique) ; OBSOMER 1995, p. 215-220 (d'ordre prosopographique).

${ }^{75}$ SAYED 1978, p. 70.

${ }^{76}$ SAYED 1977, p. 169.

${ }^{77}$ FAROUT 2006a, p. 43.
} 
El-Sayed Mahfouz, il pouvait s'agir d'une scène montrant le roi Sésostris $\mathrm{I}^{\mathrm{er}}$ devant le dieu $\mathrm{Min}^{78}$.

Le texte se compose donc de 9 lignes seulement, dont la première atteste le cartouche du roi, Khéperkarê, et l'ordre donné au vizir Antefoqer. La numérotation des lignes utilisée cidessous est toutefois celle des éditions et des traductions publiées jusqu'à présent ${ }^{79}$.

a) ${ }^{(2)}$ [Le Roi de Haute et de Basse-Égypte ${ }^{80}$ ] Khéperkarê, vivant (soit-il) [éternellement] !

b) $\left[{ }^{81}\right]$.

c) Sa Majesté a ordonné ${ }^{82}$ au noble prince, responsable de la ville, $\left[\ldots,{ }^{(3)}{ }^{83}\right]$ et vizir, $\left[\ldots{ }^{84}\right]$, responsable des Six Grandes Cours, Antefoqer, de charpenter cette flotte $\left(m \underline{d} h^{85} h^{c} w\right.$ pn) aux ${ }^{(4)}$ chantiers navals de Coptos $^{86}$, de gagner ${ }^{87}$ le Bia de Pount (sbt Bỉ Pwnt) pour (y) parvenir en paix et (en) revenir en paix, ${ }^{(5)}$ et de fournir (ce qui est nécessaire à) tous leurs travaux ( ${ }^{\mathrm{p}} \mathrm{pr} k^{3} \mathrm{w} t . s n n b t$ ) afin que (cela) soit parfait et réussi plus que toute (autre) chose faite en ce pays précédemment. ${ }^{(6)} \mathrm{Il}$ a agi à la perfection, conformément à ce qui lui fut ordonné dans la Majesté du Palais.

d) Voici que le héraut ${ }^{(7)}$ Amény, fils de Mentouhotep, se trouve ${ }^{88}$ sur la rive de Ouadj-Our ( $\left.h r i d b n(y) W^{3} \underline{d}-w r\right)$ à charpenter ces bateaux ( $\left.h r m \underline{d} h n n n(y) h^{c} w w\right){ }^{(8)}$ avec le Grand Conseil du nome thinite de la Tête-du-Sud ( ${ }^{3}{ }^{3}{ }^{3}$ t wrt $n(y) t$ Tp-Rsy $T$ ว-wr) qui l'accompagne.

e) Les personnes $\left({ }^{c} n h w\right)^{89}$ qui sont sur la rive de Ouadj-Our ( $h r$ idb $n(y) W^{3} \underline{d}$-wr) ${ }^{(9)}$ constituant la troupe qui accompagne le héraut ${ }^{90}:{ }^{(10)} 50$ militaires-šmsw du Maître

\footnotetext{
${ }^{78}$ MAHFOUZ 2011a, p. 55. Il précise que la stèle se trouve aujourd'hui au Musée de la Faculté des Lettres de l'Université d'Alexandrie.

${ }^{79}$ Photographie et éditions: SAYED 1977, p. 170-171 (pl. 16) ; SAYED 1993, p. 182-183, FAROUT 1994, p. 169 (pl. I) ; MAHFOUZ 2011a, p. 55. Traductions : SAYED 1977, p. 170 ; SAYED 1979, p. 571 ; GoELET 1992, p. 212-213 ; KiTCHEN 1993, p. 590 ; FAROUT 1994, p. 144 ; FAROUT 2006a, p. 44 ; FAROUT 2006b, p. 230-231; OBSOMER 1995, p. 711-712 ; Diego EsPinel 2003, p. 83 ; PhILIP-STÉPHAN 2008, p. 240-241 ; TALlet 2009, p. 695 ; MAHFOUZ 2011a, p. 55-56 ; BREYER 2016, p. 615-617 ; TATERKA 2018, p. 75.

${ }^{80} \mathrm{Si}$ on se réfère à la copie actualisée de SAYED 1993, p. 183, il n'y a rien avant le titre $n s w$-bity précédant le cartouche royal.

${ }^{81}$ La lacune est assez longue pour avoir contenu la mention d'une date, comme c'est le cas au début de l'inscription Goyon 61 laissée au Ouadi Hammamat par le même héraut Amény : « Le roi de Haute et de BasseÉgypte Khéperkarê, vivant (soit-il) éternellement! An 38, $3^{\mathrm{e}}$ mois d'Akhet, (jour) 25 » (cf. GoYON 1957, p. 81).

${ }^{82}$ L'usage de la forme $s \underline{d} m . n . f$ autonome implique de restituer un auxiliaire $i w$ devant $w \underline{d} . n$ hm.f, voire la particule proclitique $s k$ attestée devant $w \underline{d . n}$ ḥm.f dans l'une des inscriptions d'Ânkhou (SAYED 1993, p. 167, col. 2).

${ }^{83}$ Sans doute les termes $t^{3} y t y s^{3} b$ «celui-du-rideau, seigneur » qui précèdent régulièrement le titre $\underline{t}^{3} t y$ « vizir ».

${ }^{84}$ Petite lacune, pour laquelle on pourrait penser à un titre bref comme irry-Nhn "gardien de Nékhen ». Toutefois, les différentes attestations de ce titre chez Antefoqer (cf. OBSOMER 1995, p. 165) sont suivies de hm$n \operatorname{tr} M 3^{`} t$ « prêtre de Maât», pour lequel il n'y a pas de place ici.

${ }^{85}$ Le verbe $m \underline{d} h$ est mentionné également au Nouvel Empire, par exemple : Urk. IV, 1237 ; pHarris I (77.8).

${ }^{86}$ Attestée à trois reprises dans le pReisner II devant le terme whrt «chantier naval », la préposition $h r$ est à restituer à la fin de la ligne 3 devant whrwt n(yt) Gbtyw : cf. OBSOMER 1995, p. 712 (note a).

${ }^{87}$ Le choix de cette traduction du verbe sbi sera justifié plus loin (voir 4a, point 3 ).

${ }^{88}$ Le choix du présent dans la traduction se justifie par le fait qu'au moment où le monument est constitué et l'inscription gravée, Amény se trouve effectivement « sur la rive de Ouadj-our ».
} 
- vivant (soit-il), prospère et en bonne santé ! - ${ }^{(11)} 1$ intendant du (Grand) Conseil, ${ }^{(12)} 500$ soldats de la flotte du Maître - vivant (soit-il), prospère et en bonne santé !,$-{ }^{(13)} 5$ scribes du Grand Conseil, ${ }^{(14)} 3200$ soldats de la ville ${ }^{91}$.

\section{Les inscriptions d'Ânkhou}

Le monument commémoratif du chambellan du palais Ânkhou, découvert au Ouadi Gaouasis et actuellement au Musée de la Faculté des Lettres de l'Université d'Alexandrie, conserve sur les trois blocs qui le composent des inscriptions partiellement lisibles, dont les fac-similés furent édités en 1993 par Abdel Monem Sayed ${ }^{92}$.

a) L'inscription du bloc central ${ }^{93}$ comporte 14 lignes horizontales dont la partie droite notant le début des lignes est conservé :

${ }^{(1)}[\mathrm{An}] 24$, premier mois de Péret, $\left[\ldots{ }^{94}\right]$, ${ }^{(2)}\left[\right.$ responsable de $\left.{ }^{95}\right]$ la flotte, commandant des équipages, cham[bellan du palais, Ânkhou $\left.{ }^{96}\right][\ldots][\mathrm{Pou}]^{(3)} \mathrm{nt}$, au sud de Oupet-ta $(h n t W p(t)$ $\left.t^{3}\right)^{97}$ pour atteindre $(p h)[\ldots]{ }^{(4)}$ avec des troupes de recrues $[\ldots]{ }^{(5)} 1$ 'administrateur du Noun

${ }^{89}$ Le terme `nhw signifie littéralement « vivants » et désigne des « personnes », mais il concerne plus spécifiquement des soldats dans le cadre d'expéditions ( $c f$. BERLEV 1971, p. 23-48), comme le prouve l'inscription Goyon 61, qui englobe sous le terme ‘ ḩ3wty « combattant» 300 ` $n h w$ de la flotte thébaine du souverain et 700 ' $n h w$ du nome ( $c f$. GOYON 1957, p. 81). J'ai choisi de conserver ici le sens premier du terme, car la liste qui suit ne se limite pas à des militaires, en traduisant néanmoins par « soldats » les deux occurrences suivantes du terme.

${ }^{90}$ J'ai choisi de lire $m m \breve{s} c^{c} h n^{\varsigma} w h m w$ avec un « $m$ d'équivalence » (OBSOMER 1995, p. 712), suivi par TALLET 2009, p. 695. BREYER 2016, p. 616, fait de même mais il pense que les ` $n h w w n w h r i d b n(y) W \jmath$ d-wr sont des «Bewohner der Meeresküste». De son côté, Farout a préféré restaurer un signe $r$ dans l'espace entre les hiéroglyphes de la chouette et du soldat, pour comprendre imy-[r(3)] $m \breve{s}^{c} h n^{c} w h m w$ «le chef de troupe et le substitut » (FAROUT 1994, p. 144).

${ }^{91}$ S'agit-il d'une ville spécifique ? Dans l'affirmative, on pensera soit à Licht, la Résidence royale, soit à Thèbes où Amény a pu passer sa jeunesse compte tenu de la biographie de son père Mentouhotep renseignée dans l'inscription découverte en 1987 par Annie Gasse au Ouadi Hammamat (col. 13) : cf. GASSE 1988, p. 84-85.

${ }^{92}$ SAYED 1993, p. 161-179. Cette publication est restée confidentielle. Dans sa publication initiale (SAYED 1977, p. 157-162), Sayed avait transcrit les textes sans en donner visuellement leur disposition sur le monument. C'est sur la publication de 1977 que se sont basés les traducteurs : OBSOMER 1995, p. 713-715 ; DIEGO ESPINEL 2003, p. 84 ; FAROUT 2006a, p. 45-48 ; MAHFOUZ 2011a, p. 52-54 ; BREYer 2016, p. 612-615 ; E. Cruz-Uribe dans BARD, FATTOVICH 2018, p. 86-89; TATERKA 2018, p. 76-77.

${ }^{93}$ Édition : SAYED 1993, p. 169.

${ }^{94}$ La lacune doit logiquement inclure la mention de l'ordre royal : 'Iw wd.n hm.f $n$ « Sa Majesté ordonna à ». Cette séquence était-elle suivie des premiers titres d'Ânkhou ou, au contraire, précédée d'une séquence complét-

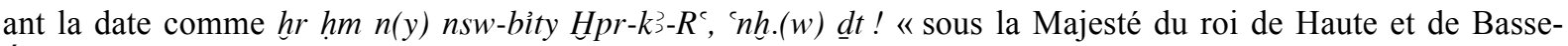
Égypte Khéperkarê, vivant (soit-il) éternellement ! ? On retiendra la première hypothèse si la rédaction de l'inscription du bloc oriental a été effectuée en même temps, car on y lit la titulature royale, dans la première colonne qui jouxte la date du bloc central et offre, à l'inverse des lignes suivantes, une inscription gravée de droite à gauche, à l'instar de l'inscription du bloc central.

${ }^{95}$ Le titre complet, (i)m(y)-r(3) hic $w$, figure dans la colonne 1 du bloc occidental. Au début de la ligne 2, on restituera le signe $r$ au-dessus de l'hiéroglyphe du bateau, le signe $m$ devant dès lors figurer à la fin de la ligne 1 .

${ }^{96}$ Restitution plus que probable.

${ }^{97}$ D'après l'édition de 1993, où l'hiéroglyphe du bateau de la copie de 1977 a été remplacé par celui des deux cornes (voir ci-après, page 63). Il ne s'agit donc pas, comme on l'avait compris jadis, du verbe hnt.n.(i) «aller vers le sud» avec le trait horizontal lu comme un $n$ (ou hntyt «die Südreise » chez BREYER 2016, p. 613). Il s'agit de l'expression hnt $W p(t)-t$ ? « en amont/au sud de l'Ouverture (mieux que "Corne") du pays/de la terre », qui justifie la présence du déterminatif de la colline à trois bosses, considérée jusque-là comme problématique. Pour la localisation de Oupet-ta, voir ci-après (4. Commentaires historiques). 
$(n n w)$, le responsable de $[\ldots]{ }^{(6)}$ l'inspecteur (?) des scribes du grenier (et) des scribes [...] ${ }^{(7)}$ le responsable des auxiliaires, le responsable des orfèvres [... ${ }^{(8)} 400$ recrues, total 400 $[+\mathrm{x}][\ldots]$.

Des lignes 9 à 14, seule la partie droite est conservée, attestant encore à deux reprises le terme $n n w$. Filip Taterka propose d'y voir les noms de bateaux ${ }^{98}$, précédés à droite d'une double colonne de texte dont le début se lit assurément $r n n(y) d p w t$ " nom des bateaux- $d p t$ ». On notera toutefois que les noms de bateaux attestés par ailleurs sur le site incluent un nom royal, celui de Sésostris I ${ }^{\mathrm{er}}$ ou d'Amenemhat III.

b) L'inscription du bloc oriental ${ }^{99}$ comportait une dizaine de colonnes, dont seules les premières sont conservées en tout ou partie. La colonne initiale, qui se trouvait immédiatement à droite du bloc central, se distingue des autres : elle est gravée pour une lecture de droite à gauche et présente une titulature royale, comme si celle-ci précédait la date et le texte du bloc central :

${ }^{(1)}[. .$.$] , aimé d'Haroëris-Rê, le Roi de Haute et de Basse-Égypte Khéperkarê, aimé de$ Khenty-khéty, le fils de Rê Sésostris, aimé d'Hathor maîtresse de Pount.

c) Le sens d'écriture (de droite à gauche) des onze colonnes d'hiéroglyphes du bloc occidental invite à lire celles-ci avant les colonnes 2 à $10 \mathrm{du}$ bloc oriental, gravées pour une lecture de gauche à droite. Ces onze colonnes du bloc occidental ne sont que partiellement lisibles $^{100}$ :

${ }^{(1)}\left[\ldots{ }^{101}\right]$ au responsable de la flotte, commandant des équipages, responsable des recrues, ${ }^{(2)}[\ldots]$ envoyé(s) $)^{102}$ vers le Bia de Pount $\left(m^{3}(w) r B \dot{\imath} \supset \text { Pwnt }\right)^{(3)}[\ldots]^{103}$. «(Je) suis revenu après avoir rapporté réellement ${ }^{(4)}\left[\ldots{ }^{104}\right]$ (pour) la Majesté du Maitre [des Deux Terres], Roi de Haute et de Basse-Égypte Khéperkarê, qui possède la vie et le pouvoir éternellement. $\left.{ }^{(5)} \mathrm{La} \mathrm{flotte}^{105}[\ldots]\right]^{3} s k^{106},{ }^{(6)}$ les pays de plaines et de montagnes ${ }^{107}\left[\ldots{ }^{108}\right]$ leur pays, les produits de la Terre du Dieu (inw T3-ntr) $m g s t^{109}{ }^{(7)}\left[\ldots{ }^{110}\right]$ Ta-tjénen en toutes

\footnotetext{
${ }^{98}$ TATERKA 2018, p. 77. Je le remercie de me permettre de mentionner son idée.

${ }^{99}$ Édition : SAYED 1978, pl. XI ; SAYED 1993, p. 167.

100 Édition : SAYED 1993, p. 171.

${ }^{101}$ Mention de l'ordre royal comme au début de l'inscription du bloc central.

${ }^{102}$ Il est préférable d'y voir un participe plutôt qu'un infinitif, ce participe se rapportant sans doute à des gens « envoyés » (cf. $W b$. II, 23.3).

${ }^{103}$ On supposera la présence d'un verbe $\underline{d} d$ « dire », introduisant un récit autobiographique d'Ânkhou.

${ }^{104}$ Quelques signes isolés.

${ }^{105}$ Début d'une proposition non-verbale, comme l'indique la présence de l'auxiliaire ỉ devant le nom. Il pourrait ne pas y avoir de lacune au-dessus de cet auxiliaire.

${ }^{106}$ Terme inconnu par ailleurs, déterminé par le triple signe de l'eau et le canal. BREYER 2016, p. 614, traduit « Meer».

${ }^{107}$ Il pourrait ne pas y avoir de lacune au-dessus de ces deux termes.

${ }^{108} \mathrm{La}$ lacune commence par $\breve{s} n$ et présente quelques signes supplémentaires dont un poussin et une triple colline.

${ }^{109}$ BREYER 2016, p. 614, propose $m g s . n$ « an unserer Seite ». L'expression $m g s t$ pourrait se révéler intéressante pour la localisation de la «Terre du dieu », mais je préfère rester prudent.

${ }^{110}$ La lacune inclut des signes à lire $k m$ ว et se termine par un signe $n b$, devant lequel Sayed place un faucon impossible à confirmer à partir de la photographie.
} 
sortes de choses de ce pays ${ }^{111}$ entendues dans (?) ${ }^{(8)}[\ldots]$ qu'ils créent ${ }^{112}$, la terre, l'eau (?) ${ }^{113}$, le sable sur la rive, ce qui est et n'est pas ${ }^{114} \cdot{ }^{(9)}[\ldots]$ dire cela $[\ldots]{ }^{(10)}[\ldots]$ ces produits $(\mathrm{inw}$ pn) qu'ils ont rassemblés comme tribut $\left(b^{3} k t\right)[\ldots]^{(11)}[\ldots]$ dont $[\ldots]$ le maitre, par $[1 \mathrm{e}$ chambellan] du palais Ânkhou ».

d) Enfin, les colonnes 2 et suivantes du bloc oriental ${ }^{115}$ énoncent ce qui suit :

${ }^{(2)}\left[\ldots{ }^{116}\right]$ en paix du maître des Deux Terres Sésostris, vivant (soit-il) comme Rê ${ }^{117}$ ! Sa Majesté a ordonné à son compagnon (smr.f), le responsable de tous les magasins du domaine royal, le chambellan ${ }^{(3)}\left[\right.$ Ânkhou] de (re)venir en paix ${ }^{118}$. Sa Majesté pense assurément qu'il est plus efficace que tout (autre) compagnon ${ }^{119}$ ayant exercé une activité dans Chen-our (ir $(w) h t m \breve{S} n-w r) .{ }^{(4)}[\ldots]$ courageux de ses bras (?), homme d'avenir qui connait les choses, ${ }^{(5)}[\ldots]$ bateaux $(d p w t)[\ldots]$ j'ai/après avoir abordé aux districts du nome de Coptos pour atteindre ${ }^{120(6)}[\ldots]$ cette flotte $\left(h^{c} w\right.$ pn) comme $[\ldots]$.

Quelques signes au bas des colonnes 6 et 7 sont tout ce qui reste de la suite de l'inscription.

S'il n'y eut qu'une seule expédition vers Pount sous Sésostris I ${ }^{\mathrm{er}}$, en l'an 24, attestée par les monuments d'Amény et d'Ânkhou, il convient de lui associer le fragment de stèle mentionnant deux noms de bateaux construits à partir du nom royal (l'un s'appelle « Sésostris est durable de vie »), voire la stèle d'Imérou attestant la séquence $B i 3 n(y) P w n[t]^{121}$.

\section{Les autres expéditions du Moyen Empire vers Pount}

Après le règne de Sésostris $\mathrm{I}^{\mathrm{er}}$, au moins cinq expéditions ont été menées vers Pount au départ de Mersa Gaouasis, pour lesquelles on dispose d'un ou de plusieurs documents offrant des données précises sur leur date ${ }^{122}$. Mais le site du Ouadi Gaouasis a également livré des stèles et ostraca, avec une date chiffrée et/ou la mention d'un roi (Sésostris III ou Amenemhat III), dont les textes, souvent endommagés, ne mentionnent pas - ou plus - la destination de l'expédition. La prudence est alors de mise, car celle-ci pourrait être aussi bien le Sinaï que

${ }^{111}$ Habituellement, $t 3$ pn désigne l'Égypte.

112 Sans doute une forme relative.

${ }^{113}$ Deux filets d'eau avec un trait horizontal entre les deux.

${ }^{114}$ Expression courante pour désigner la totalité.

${ }^{115} \mathrm{Cf}$. note 99.

${ }^{116}$ Il manque un mot devant $m$ htp. On peut clairement envisager le terme $i w t$ « venue », qui impliquerait une visite royale au Ouadi Gaouasis. Voir ci-après, point 4c (interprétation historique).

${ }^{117}$ D'après la photographie publiée par Sayed, le mot suivant est bien la particule $s k$ qui introduit ce qui suit, et non pas le terme attendu $\underline{d} t$ comme je l'avais suggéré en 1995.

${ }^{118}$ Il s'agit sans doute du retour d'Ânkhou vers la vallée du Nil.

${ }^{119}$ Littéralement : « Il est plus efficace au cœur de Sa Majesté que tout (autre) compagnon ».

${ }^{120}$ À la lumière de l'édition de 1993, je lis en effet : dmi.n.i $w w[\ldots]$ sp ‘t Gbtyw $r p h^{(6)}$ [...]. Je continue de penser qu'il ne convient pas de lire $d m i ̉ n(y) S 3 w w$ « port de Saouou », comme proposé par SAYED 1977, p. 175, n. 26, et retenu par Farout, Mahfouz et Cruz-Uribe. Il eût été intéressant de connaître le terme figurant en haut de la colonne 6 comme complément direct du verbe $p h$ « atteindre ».

${ }^{121}$ Voir ci-dessus, note 8.

${ }^{122}$ Cf. Pirelli 2010a, p. 237-238 ; BARD, FATTOVICH 2011, p. 111 ; MAHFOUZ 2011a, p. 57-65 ; MAHFOUZ 2012, p. 60-62 ; BARD, FATTOVICH 2018, p. 69-72. 
Pount, comme le suggère la stèle de Khnoumhotep (Durham N 1935) ${ }^{123}$, découverte au Ouadi Gasous et datée de l'an 1 de Sésostris II, qui affiche en son cintre une figuration de « Soped, maître de Ta-Chésémet, maître de l'Orient $\gg{ }^{124}$.

\section{3a. L'expédition de l'an 28 d'Amenemhat II}

La stèle de Khenty-khéty-our (Durham N 1934) ${ }^{125}$ montre en son cintre le roi Amenemhat II offrant des vases- $n w$ au dieu Min de Coptos. Au registre inférieur, un personnage en adoration est identifié par le texte suivant :

${ }^{(1)}$ Prier le dieu, adresser une adoration à Haroëris-Rê et à Min de Coptos ${ }^{(2)}$ par le noble prince, chancelier royal, responsable de la cour de justice $(\operatorname{im}(y)-r(3) r w y t),{ }^{(3)}$ Khentykhéty-our, après son retour en ${ }^{(4)}$ paix de Pount ( $m$-hnt iwt.f $m$ htp $m$ Pwnt), sa troupe

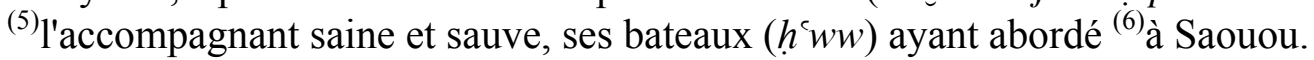

C'est sous les bras de Khenty-khéty-our que se trouve inscrite la date de l'« an $28 »$. Comme celle-ci n'est pas précédée de la préposition $m$ qui la relierait syntaxiquement au texte comme un complément de temps, il est possible qu'elle fut ajoutée au texte déjà rédigé.

\section{3b. L'expédition de l'an 2 ou 3 de Sésostris II}

Cette expédition est attestée par la stèle $n^{\circ} 29$ du Ouadi Gaouasis, découverte en 2009 près de la galerie $8^{126}$. Il s'agit d'une stèle cintrée surmontée du soleil déployant ses ailes au-dessus des noms de Sésostris II, aimé de Min de Coptos. Le texte de six lignes offre des sections difficiles à lire ; son édition finale par El-Sayed Mahfouz est en cours. Il commence par une date, l'an 2 ou l'an 3, et s'achève avec le nom d'un certain Hénénou. On notera, aux lignes 1 et 2 , l'expression « Montée de (titres) ${ }^{127}$ pour gagner le Bia de Pount », qui inclut la séquence $s b t$ $B i ̉ P$ wnt déjà rencontrée dans l'inscription d'Amény.

\section{3c. L'expédition de l'an 5 de Sésostris III}

Le lot de tessons inscrits de textes hiératiques à l'encre noire qui avait été découvert par Abdel Monem Sayed en contrebas du monument d'Amény (zone de fouilles W 45-50) a fait

\footnotetext{
${ }^{123}$ Basalte, 66 x 35 cm. Voir BIRCH 1880, p. 268-20, pl. IV ; ERMAN 1882, p. 204-205 ; NIBBI 1976, p. 50, pl. X ; SAYED 1977, p. 139 (pl. 8a) ; OBSOMER 1995, p. 387-388, 710-711; MAHFOUZ 2011a, p. 58-59 ; BREYER 2016, p. 608-609. Sur les documents relatifs à ce Khnoumhotep, fils du propriétaire de la tombe n 3 de Béni Hassan, voir FrANKE 1991, p. 51-67 ; MAHFOUZ 2008c, p. 49-54 ; ALLEN 2008, p. 29-39.

${ }^{124}$ Soped, maître de l'Orient, est le dieu du XX ${ }^{\mathrm{e}}$ nome de Basse-Égypte, non loin des lacs Amers, attesté au Sérabit el-Khadim à partir de Sésostris II ( $c f$. VALBELLE, BONNET 1996, p. 38-39). C'est la seule attestation de l'épithète « maître de Ta-Chésémet » (cf. LEITZ 2002, p. 773). On s'accorde à penser que Ta-Chésémet ou « pays de la malachite » désignerait le Sinaï où trois inscriptions attestent le terme šsmt (GARDINER, PEET, ČERNÝ 19521955 , p. 42, et $\left.n^{\circ} 121,182,200\right)$. La malachite est un carbonate de cuivre, que l'on trouve au Sinaï et dans certains sites du désert oriental ( $c f$. LUCAS, HARRIS 1962, p. 201-206). La stèle de Khnoumhotep mentionne un "gardien du cellier Nebchabet», qui est sans doute cité sur une stèle du Sérabit el-Khadim (GARDINER, PEET, ČERNÝ 1952-1955, n²25).

${ }^{125}$ Basalte, 52 x 30 cm. Voir BIRCH 1880, p. 267-268, pl. III ; ERMAN 1882, p. 203-204 ; NiBBI 1976, p. 50, pl. IX ; SAYED 1977, p. 139 (pl. 8b) ; OBSOMER 1995, p. 709-710 ; MAHFOUZ 2011a, p. 57-58 ; BREYER 2016, p. 610 .

${ }^{126}$ Grès, 72 x 47 cm. Voir BARD, FAtTOVich 2010, p. 23, fig. 9 ; BARD, FATTOVich 2018, p. 67, fig. 17.

${ }^{127}$ Formulation attestée par les stèles du Ouadi el-Houdi ${ }^{\circ} 7$ (Assouan 1472) et 144 (Caire JE 71900): $c f$. OBSOMER 1995, p. 620, 635-636.
} 
l'objet d'une étude minutieuse d'El-Sayed Mahfouz publiée en $2008^{128}$. Il s'agit de 23 étiquettes de jarres, conservées aujourd'hui au musée de la Faculté des Lettres de l'Université d'Alexandrie, qui attestent que ces jarres avaient contenu des denrées alimentaires, surtout du poisson séché, mais aussi de la bière, des côtes de bœuf, des figues, des dattes, etc. Relevons les informations les plus intéressantes pour notre propos.

L'étiquette $\mathrm{n}^{\circ} 1$ (oWG 20+22) note une date (Péret II.13 de l'an 5) et précise que le contenu de la jarre est « ce qu'a apporté le gouverneur (h`̉ty- ) Noubkaourê de Sékhem-Sénousret-maâkhérou $»^{129}$, personnage connu pour avoir exercé cette fonction à el-Lahoun sous le règne de Sésostris III ${ }^{130}$. L'étiquette $\mathrm{n}^{\circ} 2$ (oWG 06) mentionne le même personnage et Péret III.12 de l'an $5^{131}$. L'étiquette $\mathrm{n}^{\circ} 3$ (oWG 11+01) le mentionne également, mais la date n'est pas entièrement conservée ${ }^{132}$. L'étiquette $\mathrm{n}^{\circ} 4$ (oWG 39) note la date de Péret II.22 de l'an 5 et mentionne deux scribes du conseil- $\underline{d}^{3} \underline{d}^{3} t$, dont l'un se nomme Hor ${ }^{133}$. L'étiquette $n^{\circ} 7$ (oWG 15) note la date de Chémou II.16 de l'an 5 et mentionne la ville de Ioumitérou, non loin de Gébelein $^{134}$. L'étiquette $n^{\circ} 8$ (oWG 40) mentionne Pount et le domaine du héraut du portique'rryt Khenty-[khéty-our], connu aussi par un papyrus d'el-Lahoun ${ }^{135}$. Plus ancienne est l'étiquette $\mathrm{n}^{\circ} 5$ (oWG 18), qui atteste la date de Chémou III.[...] de l'an $4^{136}$. Enfin, l'étiquette $\mathrm{n}^{\circ} 6$ (oWG 2) note Chémou III d'une année qui est effacée ${ }^{137}$.

Ces jarres acheminées au Ouadi Gaouasis ont des étiquettes qui couvrent une période allant au moins de Chémou III de l'an 4 à Chémou II de l'an 5. Mahfouz en conclut qu'elles concernent la fourniture de denrées alimentaires aux ouvriers travaillant sur la côte et à ceux qui allaient voyager sur la mer Rouge, dans le cadre d'une expédition vers Pount en l'an 5 de Sésostris III ${ }^{138}$.

La stèle $\mathrm{n}^{\circ}$ 14, découverte en 2007 devant la galerie 5 (zone WG 32) ${ }^{139}$, confirme l'activité au Ouadi Gaouasis durant le règne de Sésostris III. Il s'agit d'une stèle rectangulaire surmontée d'une corniche à gorge, constituée de deux registres, dont le premier montre en trois colonnes la titulature de Sésostris III faisant face à la figuration du dieu Min de Coptos. Au second registre, on voit les traces de deux personnages figurés, associés à des légendes hélas trop partiellement conservées. Aucune mention de l'année ni aucune mention de Pount ne figure sur cette stèle, qui pourrait donc tout aussi bien être liée à une expédition au Sinaï, car

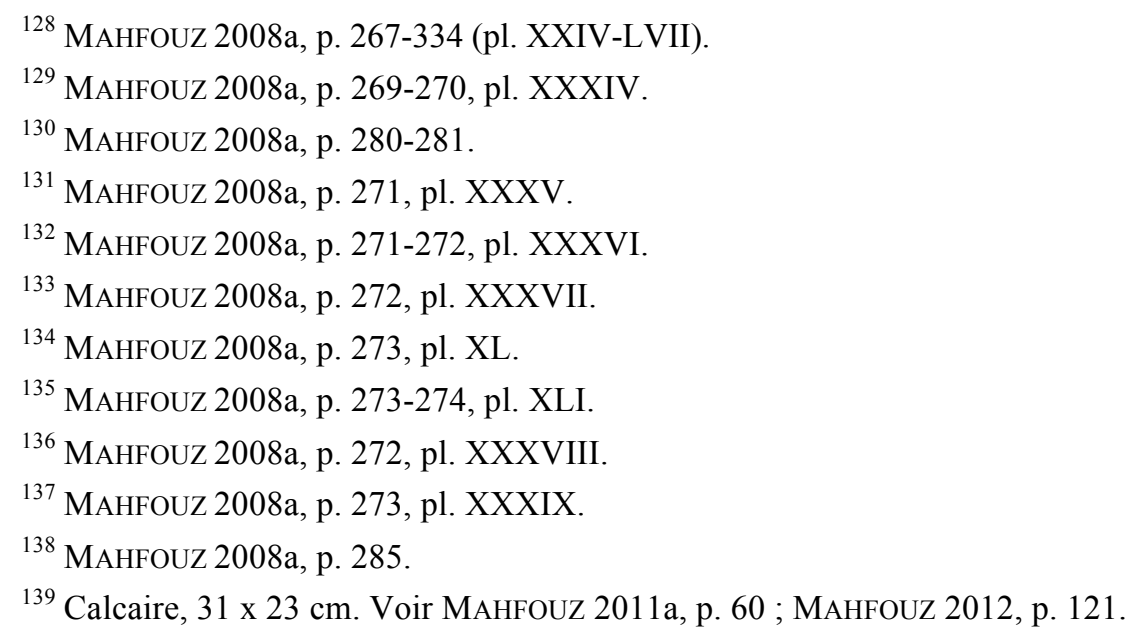


deux inscriptions attestant le nom de Sésostris III, sans toutefois mentionner l'année, sont connues au Sérabit el-Khadim ${ }^{140}$.

\section{3d. Sous le règne d'Amenemhat III}

La stèle $\mathrm{n}^{\circ} 16 \mathrm{du}$ Ouadi Gaouasis (Qift 174), découverte devant l'entrée de la galerie 4 (zone WG 33), a été inscrite au nom du «gardien du cellier du palais » (iry- ${ }^{\complement} t n(y) p r-{ }^{`} 3$ ) Amény ${ }^{141}$. Le texte offre une date, l'« an 23 sous la Majesté du Roi de Haute et de BasseÉgypte Nymaâtrê », et se poursuit par une formule d'offrande mentionnant le dieu Min de Coptos et le bénéficiaire. Étudiant le titre porté par Amény (iry- $\left.{ }^{c} t n(y) p r^{-}{ }^{`}\right)^{142}$, Mahfouz constate qu'il n'est attesté qu'au Moyen Empire, notamment dans le cadre de missions menées au Sinaï sous le règne d'Amenemhat III, pour des personnes chargées des lieux de stockage de la nourriture. Comme la stèle ne mentionne pas Pount, il se demande si elle est liée à une expédition à Pount ou au Sinaï. Pour Tallet, la présence au Sérabit el-Khadim de deux inscriptions de l'an 23 d'Amenemhat III plaide en faveur de la seconde hypothèse ${ }^{143}$.

La stèle $\mathrm{n}^{\circ} 23 \mathrm{du}$ Ouadi Gaouasis (Qift 178), découverte devant l'entrée de la galerie 5 (zone WG 55), ne comporte plus que les trois lignes gravées dans le cintre $^{144}$. On y lit une date, l'« an 41 sous la Majesté du Roi de Haute et de Basse-Égypte Nymaâtrê, [...]» (lignes 1-2), tandis que la ligne 3 présente le début de la titulature sans doute complète de ce roi. On ignore si le texte devenu illisible mentionnait une expédition à Pount ou au Sinaï. Mais la présence au Ouadi Maghara d'une inscription de l'an 41 d'Amenemhat III amène Tallet à plaider en faveur du Sinaï ${ }^{145}$.

En revanche, le toponyme Pount est mentionné à deux reprises sur une autre stèle du règne d'Amenemhat III découverte au Ouadi Gaouasis. Il s'agit de la stèle $n^{\circ} 5$ (Qift 144), trouvée devant les galeries sous la niche dans laquelle elle était placée à l'origine ${ }^{146}$. Elle a gagné aujourd'hui le Musée de la Civilisation, au Caire. Dans son cintre, le roi Amenemhat III (Nymaâtrê) offre un pain- ̌̌ $y t$ au dieu Min de Coptos, tandis que le «chambellan de la Têtedu-Sud » (imy-r(3) 'hnwty n(y) Tp-Rsy) Nebsou est figuré derrière le roi. Le corps de la stèle est séparé en deux par une ligne verticale. À droite, Nebsou est représenté une seconde fois, avec le texte suivant :

\footnotetext{
${ }^{140}$ Voir GARDINER, PEET, ČERnÝ 1952-1955, nº 81, 82. TALlet 2005, p. 144-145, qui leur associe les inscriptions $\mathrm{n}^{\circ} 146,148,151$, propose de les dater entre l'an 10 et l'an 16 sur base de considérations prosopographiques. Voir aussi SEYFRIED 1981, p. 157-158.

${ }^{141}$ Calcaire, 16 x $14 \mathrm{~cm}$. Voir MAHFOUZ 2008b, p. 253-255, fig. 2-3. J'ai préféré traduire iry-` $t$ par " gardien du cellier » plutôt que « gardien du hall », en suivant la proposition de Tallet adoptée par Mahfouz. Ce dernier se demande (p. 261-269) si ce "gardien du scellier du palais Amény » peut être identifié sur des stèles abydéniennes du Moyen Empire (FrANKE 1984, dossier 106). Il relève trois Amény différents ayant porté ce titre, mais sans disposer d'éléments pour conclure. Voir aussi MAHFOUZ 2011a, p. 61-62 ; MAHFOUZ 2012, p. 128 (fig. 8-9).

142 MAHFOUZ 2008b, p. 269-272.

${ }^{143}$ TAllet 2015, p. 61, 66. Pour les inscriptions, voir GARDINER, PeET, ČERnÝ 1952-1955, nº $102,131$. Tallet leur associe l'inscrition $\mathrm{n}^{\circ} 151$.

${ }^{144}$ Calcaire, 35 x 26 cm. Voir MAHFouz 2008b, p. 255, fig. 4-5 ; MAHFouZ 2011a, p. 62 ; MAHFouZ 2012, p. 129 (fig. 10-11).

${ }^{145}$ TAllet 2015, p. 62, 66. Pour l'inscription, voir GARDINER, PEET, ČERNÝ 1952-1955, nº 27.

${ }^{146}$ Calcaire, 38 x 26 cm. Voir PIRELli 2007, p. 88-99, pl. XVII a-b ; PIRELli 2010b, p. 1968-1970, fig. 1. Voir aussi MAHFOUZ 2008b, p. 259-261 ; MAHFOUZ 2011a, p. 62 ; MAHFOUZ 2012, p. 121-122, 127 (fig. 6-7); BREYER 2016, p. 605-606 ; BARD, FATTOVICH 2018, p. 64-65.
} 
«Sa Majesté a fait que je vienne vers le Bia de Pount (iwt.l r B $i 3$ Pwnt) avec le grand intendant Sénebef, en raison de l'excellence de mon avis. Je suis quelqu'un qui connaît son rang, à la pensée juste ». Le chambellan Nebsou, qui possède l'état de bienheureux.

À gauche son frère Amenhotep est figuré, accompagné du texte suivant :

Son frère, le scribe préposé au sceau du Trésor, Amenhotep, dit : «Sa Majesté a fait que (je) vienne pour conduire ${ }^{147}$ le grand intendant Sénebef vers Pount $(r$ sbt imy-r(3) pr wr Snb.f $r$ Pwnt), parce que Sa Majesté pense que (je) suis efficace au plus haut point ». Amenhotep, qui possède l'état de bienheureux.

Cette stèle $n^{\circ} 5$ du Ouadi Gaouasis indique que Nebsou et Amenhotep étaient au service du grand intendant Sénebef, sans doute le responsable de la mission royale. Comme le texte mentionne d'une part Bỉ Pwnt, d'autre part Pwnt, Pirelli envisage l'hypothèse de deux expéditions différentes, ce qui expliquerait pense-t-elle l'absence d'une date précise dans le règne ${ }^{148}$. Mais Mahfouz préfère y voir des références à différentes phases d'une même expédition ${ }^{149}$.

Mahfouz relève trois autres documents du Ouadi Gaouasis qui attestent le nom du roi Amenemhat III, les stèles $n^{\circ} 6$ et 8 et l'ostracon $n^{\circ} 101$, dont les textes ne permettent toutefois pas de savoir s'ils furent liés à une expédition à Pount ou au Sinaï. En voici une présentation succincte.

La stèle $n^{\circ} 6$ (Qift 155) découverte dans sa niche à l'entrée de la galerie 2, où elle était fixée grâce à un mortier, est une stèle cintrée gravée sur un bloc rectangulaire et affichant au sommet un soleil déployant ses ailes ${ }^{150}$. La première ligne présente une date partiellement conservée : l'« [an $\left.\mathrm{x}^{+}\right] 2$ sous la Majesté du Roi de Haute et de Basse-Égypte Nymaâtrê, doué de vie $[\ldots] »$. Sous cette date, un registre présente en quatre colonnes les cinq noms de la titulature d'Amenemhat III, en face d'une figuration du dieu Min de Coptos. Sous ce registre, deux personnages sont figurés face à face, séparés par quatre colonnes d'hiéroglyphes ; comme la portion inférieure de ces colonnes de textes a disparu, on ne conserve ni le nom des personnages, ni le détail de l'ordre royal adressé à chacun.

La stèle $n^{\circ} 8$ (Qift 157), découverte près de la précédente, est quasi totalement arasée, si bien qu'on n'y lit plus que le nom du roi ${ }^{151}$. En revanche, l'ostracon $n^{\circ} 101$ (Qift 159), découvert devant l'entrée de la galerie 3, offre des informations d'un tout grand intérêt ${ }^{152}$. « Le texte, composé de sept lignes et écrit en noir charbonneux, est le compte rendu du retour d'un voyage maritime. Alors que la partie droite du texte semble complète, celle de gauche est malheureusement perdue ${ }^{153}$. La première ligne commence par « Recevoir les bateaux ( $s p$

\footnotetext{
${ }^{147}$ Le choix de cette traduction du verbe sbi sera justifié plus loin (voir 4a, point 3). C'est le choix opéré par Pirelli, « to lead», et Breyer, « zu führen ».

${ }^{148}$ PiRELli 2007, p. 98.

${ }^{149}$ MAHFOUZ 2008b, p. 260-261 : « dans la vallée du Nil d'abord, sous la responsabilité de Senebef, pour préparer la logistique de l'expédition, puis les voyages au ouadi Gaouasis, sous la conduite des deux frères ; de là, l'un partit vers Pount chercher son produit principal, l'encens, l'autre se rendit aux mines de Pount pour en rapporter des métaux exotiques, comme l'or ouadj et l'électrum ».

${ }^{150}$ Calcaire, 36 x 22 cm. Voir MAHFouz 2008b, p. 256-257, fig. 6-7 ; MAHFOUZ 2011a, p. 62-63 ; MAHFOUZ 2012, p. 130 (fig. 12-13) ; BREYER 2016, p. 606-607 ; BARD, FATTOVICH 2018, p. 65-66.

${ }^{151}$ Calcaire, 21 x $14 \mathrm{~cm}$. Voir MAHFOUZ 2008b, p. 258, fig. 8-9.

${ }^{152}$ MAHFOUZ 2008b, p. 258-259, fig. 10-11.

${ }^{153}$ MAHFOUZ 2008b, p. 258.
} 
$\left.h^{c} w\right)[\ldots] »$, et les deux suivantes mentionnent les noms de deux bateaux : le bateau ( $\left.h^{c}\right)$ « Nymaâtrê-vivant comme Rê $[. .]$.$\left.» et le bateau ( { }^{c} h^{c}\right)$ " Nymaâtrê-donne [...]».

\section{3e. L'expédition de l'an 7/8 d'Amenemhat IV}

Parmi les boîtes de transport découvertes devant l'entrée des galeries, il en est deux $\left(\mathrm{n}^{\circ} 2\right.$ et $\left.n^{\circ} 21\right)$ qui présentaient une face avec une inscription peinte en noir sur un enduit de plâtre blanc où se lisait encore l'an 8 du roi Amenemhat $\mathrm{IV}^{154}$. Le contrôleur des recrues (hrp nfrw) et scribe royal Djédy est mentionné, de même que le contenu de ces boîtes : les inw $n(y) P w n t$ « produits de Pount» $\left(\mathrm{n}^{\circ} 21\right)$ et les [...] bỉ $3 y t$ Pwnt « merveilles de Pount $»\left(\mathrm{n}^{\circ} 2\right)$. Ces boîtes ont été laissées sur place sans doute parce qu'elles servaient au stockage à bord des bateaux des produits qui allaient être acheminés vers la Vallée du Nil dans des sacs transportés par des hommes ou à dos d'âne.

Mahfouz leur associe l'ostracon WG $\mathrm{n}^{\circ} 111$, qui est une étiquette de jarre découverte en 2008 dans la zone WG 47, là où Sayed avait exhumé quantité de tessons du même genre. Il mentionne l'an 8 d'Amenemhat IV et indique que la jarre avait contenu 200 poissons ${ }^{155}$.

C'est à quelque $325 \mathrm{~km}$ au sud-est de Mersa Gaouasis, devant l'entrée du temple principal de Bérénice, port connu pour avoir été établi par Ptolémée II Philadelphe ${ }^{156}$, que deux fragments d'une stèle cintrée de l'an 7 d'Amenemhat IV ont été découverts lors des fouilles menées en $2015^{157}$. Un troisième fragment, qui avait été trouvé en 1818 à l'intérieur du temple par Belzoni qui en avait publié un dessin ${ }^{158}$, permet de recomposer aujourd'hui la quasi totalité de la stèle, qui faisait environ $55 \mathrm{~cm}$ de haut sur $28,50 \mathrm{~cm}$ de large. Le registre supérieur montre le roi Amenemhat IV debout à gauche, faisant offrande à une divinité assise à droite, dont le nom n'est pas conservé ${ }^{159}$. Au registre inférieur, un personnage, inconnu par ailleurs, est identifié par quatre colonnes de texte :

${ }^{(1)}$ Le noble prince, chancelier royal et compagnon unique, ${ }^{(2)}$ préposé aux affaires confidentielles du domaine royal (hry-š́t’ $p r-n s w)$, confident de l'Horus ${ }^{(3)}$ maître du palais (imy-ỉb $\left.H r n b^{c} h\right)$, chancelier du dieu (htmty-ntr), contrôleur des recrues (hrp nfrw), ${ }^{(4)}[\ldots]$ Ptahhotep.

C'est sous le second registre qu'est notée, de façon isolée, la date de l'« an 7 ».

La stèle a été réalisée à partir d'un bloc de quartzite (ou grès silicifié), sans doute issu des carrières du Gebel Ahmar près du Caire ${ }^{160}$. Elle a pu être gravée dans la région memphite avant d'être acheminée vers sa destination ${ }^{161}$, puisqu'elle ne livre pas le compte rendu d'une mission, mais simplement les noms et titres de celui qui en serait chargé. On peut raisonnable-

\footnotetext{
${ }^{154}$ MAHFOUZ 2010b, p. 165-169, fig. 1-4.

${ }^{155}$ MAHFOUZ 2010b, p. 169, fig. 5-6.

${ }^{156}$ Dans la baie au sud du Ras Banas. Coordonnées : 2356'09" N, 35²9'00" E. Les murs du temple conservent une décoration de l'empereur romain Tibère. L'attribution à Ptolémée II figure chez Pline (Histoire naturelle, VI, 168).

${ }^{157}$ Hense, Kaper, GeErts 2015, col. 585-601. Voir aussi Hense, Sidebotham 2017, p. 41-43.

${ }^{158}$ BELZONI 1820, p. 332 ; BELZONI 1821, pl. 16. La localisation actuelle de ce fragment est inconnue.

${ }^{159}$ Pour Hense, KAPER, GeERTs 2015, col. 595, il ne s'agit pas de Min de Coptos, qui eût été figuré debout, mais sans doute de Ptah de Memphis.

${ }^{160}$ HeNSE, KAPER, GEERTS 2015, col. 593.

${ }^{161}$ HENSE, KAPER, GEERTS 2015, col. 600.
} 
ment envisager que la date fut ajoutée dans un second temps ${ }^{162}$, lors de l'installation de la stèle à l'endroit où on avait prévu de la placer. La question est de savoir à quel endroit. En effet, comment expliquer la présence de cette stèle à plus de $200 \mathrm{~km}$ de tout site du Moyen Empire connu à ce jour?

Il est clair que la stèle de Ptahhotep fut placée dans le temple gréco-romain de Bérénice comme un objet de prestige, sans doute à l'époque romaine, comme les stèles de Khéty-khétyour et de Khnoumhotep le furent dans les structures gréco-romaines du Ouadi Gasous. Mais cette stèle fut-elle acheminée à l'époque romaine du Ouadi Gaouasis vers Bérénice, à plus de $300 \mathrm{~km}$ au sud, ou bien fut-elle laissée au Ras Banas lors d'une escale de l'expédition partie de Mersa Gaouasis en l'an 7 d'Amenemhat IV et qui allait y revenir en l'an 8 ? De ces deux hypothèses, la seconde semble la plus vraisemblable ${ }^{163}$. L'hypothèse d'un site du Moyen Empire restant à découvrir aux environs du Ras Banas a même été énoncée ${ }^{164}$.

\section{Commentaires historiques}

La localisation de Pount a fait couler beaucoup d'encre, et plusieurs monographies ont paru sur le sujet ${ }^{165}$. Les hypothèses qui ont été énoncées utilisent des données archéologiques, textuelles et iconographiques. Aux informations fournies par les textes mentionnant des expéditions vers Pount s'ajoutent les produits mentionnés comme provenant de Pount, notamment la myrrhe-'ntyw utilisée lors des rituels ${ }^{166}$, la flore, la faune, le paysage et l'habitat de Pount figurés dans les peintures et reliefs, notamment à Deir el-Bahari, la physionomie des Pountites, les embarcations qu'ils utilisent, etc. L'analyse de ces données fait appel à des connaissances en botanique, zoologie, ethnographie appliquées aux régions antiques situées au sud et au sudest de l'Égypte. Mais il convient de garder à l'esprit que les produits de Pount transitaient aussi par les voies commerciales, terrestres et/ou nilotiques, avant d'entrer finalement en possession des Égyptiens.

Pount est le nom donné à une vaste contrée située aux confins sud-est du monde connu des Égyptiens, constituant la région la plus méridionale de la «Terre du Dieu » $\left(T_{3}^{3}-n \underline{t} r\right)^{167}$. Comme la relecture attentive des inscriptions d'Ânkhou a permis de le mettre en évidence ${ }^{168}$, Ânkhou localise Pount «au sud/en amont de Oupet-ta» (hnt $W p(t)-t$ ). Il s'agit de la plus ancienne attestation du toponyme Wpt-t’ (Oupet-ta), qui, selon le Wörterbuch der Aegyptischen Sprache, fut employé pour décrire l'« Extrême Sud » au Nouvel Empire ${ }^{169}$, lorsque la

\footnotetext{
${ }^{162}$ Comme c'est le cas aussi pour la date de la stèle de Khenty-khéty-our (Durham N 1934).

${ }^{163} C f$. HENSE, KAPER, GEERTS 2015, col. 599-600.

${ }^{164}$ HENSE, KAPER, GEERTS 2015, col. 596-597.

${ }^{165}$ HeRzog 1968 ; Diego ESPINEL 2011 [non vidi] ; BREYER 2016.

${ }^{166}$ Une inscription d'Hatchepsout (XVIII ${ }^{\mathrm{e}}$ dynastie) détaille comme suit les merveilles du pays de Pount
} (bi3yt hist Pwnt) et plantes de la Terre du Dieu (Urk. IV, 328-329) : des tas de résine-kmyt de myrrhe-' $n t y w$, des arbres à myrrhe fraîche, du bois d'ébène et de l'ivoire pur, de l'« or vert » d'Âmou, du bois-tỉ-šps et des aromates$\underline{h} s^{3} y t$, de la myrrhe-ỉhmt, de l'encens et du fard noir, des babouins, des singes à longue queue et des chiens, des peaux de panthères du Sud. Pour le Moyen Empire, voir MANZO 2017, p. 87-108.

${ }^{167}$ Le terme s'applique à des régions situées à l'Est de l'Égypte, là où se lève le soleil, de Byblos à Pount en passant par le Sinaï.

${ }^{168}$ Voir ci-dessus, note 97.

${ }^{169} \mathrm{~Wb}$. I, 298.3. Voir notamment Urk. IV, 138.7, 808.8, 1230.17, 1236.18, 1242.19. Les trois dernières références figurent dans la stèle de Touthmosis III au Gebel Barkal (lignes 8, 28, 49). À la ligne 8, on lit que la frontière sud de Touthmosis III va jusque Oupet-ta $\left(r\right.$ Wpt- $\left.t^{3}\right)$, jusqu'aux régions au sud/en amont de ce pays $(r$ hntyw $\left.t^{3} p n\right) », t^{3} p n$ désignant l'Égypte. Dans la stèle de Tombos de Touthmosis $\mathrm{I}^{\mathrm{er}}$, une phrase similaire atteste seule- 
frontière méridionale de l'Égypte était située à Kourgous, en aval de la cinquième cataracte du Nil. Durant le règne de Sésostris I ${ }^{\mathrm{er}}$, la frontière sud de l'Égypte se trouvait à Bouhen, au nord de la deuxième cataracte du Nil ${ }^{170}$. Mais en l'an 18 de Sésostris $I^{\mathrm{er}}$, une campagne militaire de grande envergure fut menée à travers le pays de Kouch (royaume de Kerma), permettant aux Égyptiens d'explorer la région située au sud de la troisième cataracte du Nil ${ }^{171}$. Comme cela se passa quelques années seulement avant la rédaction des inscriptions d'Ânkhou, en l'an 24, il est donc parfaitement possible que le toponyme $W p t-t^{3}$ entra en usage dès cette époque pour désigner la région qui devait s'étendre au-delà du pays de Kouch et au-delà de laquelle se trouvait Pount.

Une localisation africaine de Pount semble aller de soi. Rolf Herzog préconisa de situer Pount sur le cours supérieur du Nil, aux confluents avec l'Atbara et le Nil bleu ${ }^{172}$, mais ensuite Rodolfo Fattovich privilégia une région plus orientale, à la limite du Soudan actuel et de l'Éthiopie/Érythrée, qui était facile d'accès depuis la mer Rouge aux expéditions menées au départ de Mersa Gaouasis ${ }^{173}$. Fattovich pensa à un lieu de débarquement possible dans la baie du Ras Aqiq ${ }^{174}$, à plus de $1000 \mathrm{~km}$ au sud de Mersa Gaouasis. Récemment, Dimitri Meeks a remis à l'honneur l'idée d'une localisation de Pount dans la péninsule arabique ${ }^{175}$, plus précisément sur la côte yéménite de la mer Rouge selon Frédéric Servajean ${ }^{176}$, ce qui allonge certes le parcours de près de $700 \mathrm{~km}$. Pour le Moyen Empire, il n'y a aucun inconvénient à étendre l'appellation «Pount » de la côte africaine à la côte yéménite de la mer Rouge ${ }^{177}$, car la céramique retrouvée au Ouadi Gaouasis, contemporaine de la XII ${ }^{\mathrm{e}}$ dynastie, a révélé des tessons caractéristiques des deux régions, et de l'obsidienne ${ }^{178}$. On peut envisager que telle ou telle expédition du Moyen Empire ait pu aboutir sur la côte yéménite de la mer Rouge, au cours de sa navigation, ou à tout le moins que ses membres aient pu entendre que les fameux produits de Pount s'obtenaient également en franchissant la mer à ses latitudes les plus méridionales. Mais l'inscription découverte en 2003 par Vivian Davies dans la tombe de Sobeknakht à

ment $r$ hntyw t’ pn (Urk. IV, 85.13). Sans doute hntyw t’ pn est-il utilisé chez Touthmosis III pour expliciter ce qu'est Wpt- $t$ ? .

${ }^{170}$ OBSOMER 1995, p. 346-350.

${ }^{171}$ OBSOMER 1995, p. 311-336 ; OBSOMER 2007b, p. 58-63.

${ }^{172}$ HerzOG 1968, p. 81. À mon sens, Pount est à rechercher bien plus loin, car la région d'Atbara à Khartoum ne semble pas offrir une végétation très différente de celle qu'on observe en aval du confluent de l'Atbara.

${ }^{173}$ FATtOVich 1991, p. 257-272 ; FATTOVICH 1996, p. 15-29.

${ }^{174}$ Coordonnées : $18^{\circ} 19^{\prime} \mathrm{N}, 38^{\circ} 09^{\prime}$ E. On a proposé d'y localiser la Ptolémaïs Thérôn de Ptolémée II : $c f$. DESANGES 1978, p. 272-274. Voir aussi THIERS 2007, p. 135-142.

${ }^{175}$ MeEKS 2002, p. 267-335 ; MEEKS 2003, p. 53-80.

${ }^{176}$ SERVAJEAN 2016, p. 179-226 ; SERVAJEAN 2017, p. 103-115 ; SERVAJEAN 2018, p. 135-170.

${ }^{177}$ Voir aussi FATTOVICH 2012, p. 2 : «At present, the best candidates for the location of Punt are eastern Sudan or the northern Horn of Africa (i.e., northern Ethiopia and Eritrea) together with southern Arabia (...), or all of these regions ». En ce qui concerne le Moyen Empire, Kenneth Kitchen hésite entre l'Afrique orientale et le Sud de l'Arabie, mais, s'agissant d'une époque plus récente, il pense que l'appellation pourrait être étendue davantage vers le Sud : $c f$. KITCHEN 2004, p. 25, 30. On a proposé que le nom Pount serait à l'origine du nom grec Opôné donné à un comptoir maritime mentionné, au début de notre ère, dans le Périple de la mer Érythrée et chez Ptolémée, et localisé au Ras Hafoun au nord de la Somalie actuelle : cf. ALLiOT 1951, p. 1-7. Même si elle est abandonnée par BREYER 2016, p. 86-87, cette idée reste séduisante pour l'époque gréco-romaine, lorsque la zone sud de la mer Rouge était devenue pour sa part une région de mieux en mieux connue.

${ }^{178}$ FATTOVICH 2012, p. 12-13, qui précise : «At present, we do not know if the Egyptians were navigating along both coasts of the northern Horn of Africa and western Arabia or met South Arabs on the African coast and engaged in exchange there $»$. 
Elkab (tombe $\mathrm{n}^{\circ} 10$ ), renforce assurément la localisation africaine de Pount avant le Nouvel Empire, puisqu'il est question, à la XVII ${ }^{\mathrm{e}}$ dynastie, d'une extension du royaume de Kouch vers le Nord, « après avoir soulevé les tribus de Ouaouat, les [...] de Khent-hen-néfer, Pount et les Médjay $»{ }^{179}$.

\section{4a. Quelques termes d'interprétation délicate}

Dans les sources textuelles du Moyen Empire relevées ci-dessus, plusieurs termes nécessitent que l'on s'y arrête. Il s'agit de Ouadj-our, de Bỉ Pwnt et du verbe sbi.

1. Ouadj-our ( $W^{3} \underline{\jmath}$-wr) est mentionné deux fois dans l'inscription d'Hénou et deux fois dans celle d'Amény. Hénou dit qu'il a atteint Ouadj-Our après avoir creusé de nombreux puits le long de son itinéraire (ligne 12, d), puis qu'il s'éloigna de Ouadj-our après avoir rempli sa mission (ligne 13, f). Amény situe sur la rive de Ouadj-Our ( $h r i d b n(y) W 3 \underline{d} \underline{d}-w r$ ) son activité de charpentage de bateaux (ligne 7, d) et il dresse la liste des personnes qui s'y trouvaient en sa compagnie (ligne 8, e).

Je ne détaillerai ici pas la question de Ouadj-our, mais il est clair, depuis les travaux de Claude Vandersleyen, que ce terme ne désigne pas la mer dans un bon nombre d'occurrences. Toutefois, comme je l'ai expliqué jadis ${ }^{180}$, Amény fournit un argument décisif pour identifier Ouadj-our à la mer Rouge, dans son inscription. C'est l'emploi du démonstratif $p n$ à la ligne 3 , dans l'énoncé de la première mission confiée à Antefoqer : " charpenter cette flotte $\left(m \underline{d} h h^{c} w\right.$ pn) aux chantiers navals de Coptos ». Comme il s'agit de la première des deux mentions de bateaux que comporte l'inscription, ce démonstratif $p n$ ne peut être anaphorique, mais revêt nécessairement une valeur déictique, désignant les bateaux que l'on pouvait voir depuis l'endroit où était placé le monument d'Amény. Vandersleyen a objecté qu'il fallait d'abord prouver « que l'inscription a bien été faite en fonction du lieu où on l'a trouvée et que la flotte était bien là $\gg{ }^{181}$. Les preuves sont les suivantes : l'inscription d'Amény fut trouvée, comme celles d'Ânkhou, sur le plateau dominant la zone d'amarrage des bateaux, dans un monument installé sur une ancre au sein d'une structure de pierres plus large, à un endroit qui surplombe la zone des galeries découverte par la mission italo-américaine, qui y trouva notamment des cordes et des pièces en bois ayant appartenu à des bateaux. Parmi les stèles exhumées sur le site, il en est d'ailleurs une qui mentionne Ouadj-our: la stèle $n^{\circ} 28$, découverte en 2008 et publiée par El-Sayed Mahfouz en 2011 ${ }^{182}$. Le registre supérieur offre la formule suivante : «Puisse le roi faire que soient satisfaits Osiris de Ouadj-our, Horus ouadjou, Min maître des régions montagneuses, Haroëris-Rê. Puisse(nt)-il(s) donner une offrande invocatoire de pain et pain, viande bovine et volaille, vases d'albâtre et pièces d'étoffes pour le ka de [...]». Au registre inférieur étaient peints deux personnages aujourd'hui effacés. On notera qu'« Osiris de Ouadj-our» sera plus tard attesté au Fayoum, dans les inscriptions du cercueil d'Ânkhrouy découvert à Haouara par Petrie $\left(\mathrm{XXX}^{\mathrm{e}} \text { dynastie ou époque ptolémaïque }\right)^{183}$.

En ce qui concerne l'inscription d'Hénou, Vandersleyen pense que l'expédition pédestre a d'abord longé le Nil à partir de Coptos pour couper ensuite à travers le désert, en suivant probablement la route de Korosko vers Abou Hamed sur le parcours de laquelle les puits ont

\footnotetext{
${ }^{179}$ DAVIES 2003a, p. 52-54 ; DAVIES 2003b, p. 38-44.

${ }^{180}$ OBSOMER 1995, p. 398-399.

${ }^{181}$ VANDERSLEYEN 1996, p. 113.

${ }^{182}$ Calcaire, 18 x 10,5 cm. Musée de Suez, 174/1. MAhfouz 2011b, p. 7-14.

183 PETRIE 1889, pl. III ; VANDERSLEYEN 1999, p. 255.
} 
pu être creusés, et c'est sur le cours supérieur du Nil qu'il situe l'arrivée à Ouadj-our et la construction des bateaux-kbnyt ${ }^{184}$. Mais si la Résidence royale est la Thèbes de Mentouhotep III, on comprend mal le retour d'Hénou par le Ouadi Hammamat, où l'inscription fut gravée, ainsi que la mention de Coptos comme point de départ du trajet à pied. Hénou n'aurait-il pas eu intérêt, lors du trajet aller, à remonter le Nil en bateau jusqu'à Assouan ? On notera toutefois l'intérêt du toponyme 'Ihtb mentionné par Vandersleyen et relevé par Lepsius au temple de Soleb (Aménophis III), dans une liste de toponymes du Sud, sans localisation plus précise ${ }^{185}$.

2. Le second terme qui pose question est Bỉ Pwnt, mentionné dans cinq documents du Ouadi Gaouasis (XII ${ }^{\mathrm{e}}$ dynastie) : la stèle fragmentaire d'Imérou, qui atteste la séquence $B{ }^{3}$ 3 $n(y) P w n[t]$, indiquant une relation génitivale entre les deux termes à traduire comme « le Bia de Pount $»{ }^{186}$; dans l'inscription d'Amény, une mission du vizir est de «sbt Bỉ Pwnt, afin de $\left(l^{\prime}\right)$ atteindre en paix et d'(en) revenir en paix » (ligne $4, \mathrm{c}$ ); dans la stèle $\mathrm{n}^{\circ} 29$, il est question de la «montée » (prt) de quelqu'un pour sbt Bỉ Pwnt (lignes 1-2); dans les inscriptions d'Ânkhou, $m_{3}{ }^{\complement}(w) r$ Bỉ Pwnt, " envoyé(s) vers le Bia de Pount » se lit après une brève lacune (bloc occidental, col. 2); dans la stèle $n^{\circ} 5$ de Nebsou, on lit que «Sa Majesté a fait que je vienne vers le Bia de Pount (iwt.i r B $i ̉$ Pwnt) avec le grand intendant Sénebef ». En dehors du Ouadi Gaouasis, les termes Bia et Pount ne sont associés qu'une seule fois ${ }^{187}$, à la $\mathrm{VI}^{\mathrm{e}}$ dynastie, dans l'inscription d'Herkhouf à Assouan rapportant les propos du jeune Pépy II concernant le nain ramené de Iam : «Ma Majesté souhaite voir ce nain plus que les produits (inw) de Bia (et de) Pount ${ }^{188}$. Mais il est préférable de voir ici deux toponymes coordonnés, l'un désignant le Sinaï ${ }^{189}$, l'autre Pount, pour évoquer deux régions éloignées du Nord et du Sud dont on ramenait la production ${ }^{190}$.

Dans l'expression B $\mathfrak{\imath}$ Pwnt, le terme bỉ , qui présente 3 fois sur 5 le déterminatif de la triple colline, désigne selon toute vraisemblance une région minière à l'instar du Sinaï. Mais s'agit-il d'une désignation alternative de Pount, d'une région proche de Pount, d'une zone spécifique au sein du pays de Pount ${ }^{191}$ ? Aucune de ces propositions ne convainc compte tenu des contextes dans lesquels Bỉ Pwnt est mentionné dans les inscriptions du Ouadi Gaouasis. La solution qui s'impose à mon sens est celle de Filip Taterka, en 2018 : pour lui, B $\mathfrak{\imath} P$ wnt désigne la région littorale de la mer Rouge où se trouve Mersa Gaouasis, à savoir la région

\footnotetext{
${ }^{184}$ VANDERSLEYEN 1989, p. 154-156. Voir aussi VANDERSLEYEN 1999, p. 136-137, où il se montre plus réservé.

${ }^{185}$ En revanche, ce qu'il écrit à propos du toponyme Ibehyt attesté dans les Dépêches de Semna n'est pas pertinent puisque Ibehyt n'est pas mentionné par Hénou. Pour sa part, le toponyme Ouaâg relevé à Dehmit est de lecture incertaine : $c f$. OBSOMER 1995, p. 396, n. 128.

${ }^{186}$ Comme mis en évidence par SAYED 1979, p. 569.

${ }^{187}$ Il convient d'écarter les mentions des bỉw Pwnt « merveilles de Pount » désignant des produits venant de Pount. Il s'agit ici d'un terme $b i 3$ au singulier, attesté souvent avec le déterminatif de la triple colline.

${ }^{188}$ Urk. I, 130.14-15.

${ }^{189} C f$. GARDiner, PeEt, ČERnÝ 1952-1955, p. 1-2 (nº 53, 90, 117, 141, 409), qui relèvent l'usage récurrent de $B i$ pn «ce Bia» dans ces textes. On y ajoutera l'inscription d'Ayn Soukhna de l'an 9 de Sésostris I ${ }^{\mathrm{er}}$, qui évoque une mission $r$ Bỉ : cf. ABD EL-RAZIQ, CASTEL, TALLET, GHICA 2002, p. 57-58, fig. 28.

${ }^{190}$ BREASTED 1906, p. 161 (§ 353); GARDINER, PEET, ČERNÝ 1952-1955, p. 2 ; LiChtheiM 1975, p. 27 , n. 7 ; TATERKA 2018, p. 49-50, 410. En revanche, SAYED 1977, p. 176, n'était pas de cet avis.

${ }^{191}$ Questionnement mené par PIRELli 2007, p. 94-98; MANZO 2012b, p. 83-85 ; BARD, FATTOVICH 2018, p. 175 .
} 
minière du désert oriental à partir de laquelle on embarquait vers Pount à la XII ${ }^{\mathrm{e}}$ dynastie ${ }^{192}$. Cette proposition est étayée par la phraséologie de deux des inscriptions du Ouadi Gaouasis. En effet, la stèle $n^{\circ} 5$ indique qu'il est question pour Nebsou de venir vers le Bia de Pount, qui est donc sa destination au départ de la vallée du Nil considérée depuis l'endroit où sa stèle a été placée. Dans la stèle $\mathrm{n}^{\circ} 29$, il s'agit de monter pour $s b t$ le Bia de Pount ${ }^{193}$, le verbe pri « monter» s'utilisant quand on quitte la vallée vers sa destination. L'inscription d'Ânkhou est plus neutre, car il est sans doute question d'une ou de plusieurs personnes envoyée(s) vers le Bia de Pount. Si l'on se place du point de vue de ces Égyptiens habitant la vallée du Nil, aller vers Mersa Gaouasis était donc envisagé comme se rendre vers la région minière à partir de laquelle on pouvait embarquer vers Pount. À l'inverse, au retour de son voyage à Pount, Ânkhou déclare : "j'ai abordé $(d m i)$ aux districts du nome de Coptos pour atteindre $(p h)$ [...] » (bloc oriental, col. 5) ${ }^{194}$. C'est par rapport à la destination finale, Coptos, que le lieu de retour est ici énoncé, comme ce sera le cas aussi en ce qui concerne le retour de l'expédition pountite de Ramsès III $\left(\mathrm{XX}^{\mathrm{e}}\right.$ dynastie) : « Ils sont parvenus sains et saufs au gébel de Coptos ( hist Gbtyw) et ont accosté (mni) en paix, chargés des biens qu'ils apportaient ${ }^{195}$. Quel terme était noté, dans l'inscription d'Ânkhou, après le verbe $p h$ en haut de la colonne 6 ? Probablement un toponyme. Le toponyme Saouou est mentionné comme le lieu de mouillage des bateaux revenant de Pount dans l'inscription de Khenty-khéty-our (Durham N 1934).

3. Enfin, le troisième terme à examiner est le verbe $s b i ̉$, attesté à l'infinitif ( $s b t)$ dans quatre documents. Dans son inscription du Ouadi Hammamat, Hénou dit avoir été envoyé pour $s b t$ kbnywt $r$ Pwnt ${ }^{196}$ (ligne 8, a), et il précise plus loin que cela a été fait (ligne 12, e : sb.n.(i) sw $m$ ht $n b t^{197}$ ). Au Ouadi Gaouasis, il est question de $s b t B i 3 P w n t^{198}$ dans l'inscription d'Amény (ligne 4, c) et dans la stèle $n^{\circ} 29$ (ligne 2), tandis qu'Amenhotep, frère de Nebsou, affirme dans la stèle $\mathrm{n}^{\circ} 5$ : «Sa Majesté a fait que (je) vienne pour $s b t^{199}$ le grand intendant Sénebef vers Pount ( $r$ sbt imy-r(3) pr wr Snb.f r Pwnt). La mission d'Amenhotep allait donc commencer une fois arrivé à l'endroit où la stèle se trouve gravée.

192 TATERKA 2018, p. 410-412. Je le remercie de me permettre de présenter son point de vue sur Bia Pount, sur lequel il prépare un article. Une pratique du même genre s'observe, ajoute-t-il, dans les noms des portes de Ninive, désignées en fonction des localités vers lesquelles elles mènent. Cette pratique est on ne peut plus courante : pensons à la Porte de Namur pour des Bruxellois, à la Porte d'Orléans pour des Parisiens.

${ }^{193}$ L'expression sbt B $\mathfrak{\imath}$ P Pnt sera examinée plus loin (point 3).

${ }^{194}$ Ci-dessus, note 120 : dmi.n.i ww[...] sp 3t Gbtyw r ph ${ }^{(6)}[\ldots]$.

195 pHarris I, 77.12. Voir ERICHSEN 1933, p. 94-95 ; GRANDET 1994a, p. 338.

${ }^{196}$ Les traductions proposées varient entre (1) « envoyer » et (2) « conduire », selon que leur auteur considère qu'Hénou a pris part à l'expédition navale ou non : (1) « to dispatch a ship to Punt» (Breasted 1906 et Goelet 1992), « um Byblos-schiffe nach Punt zu schicken » (Schenkel 1965); (2) « to conduct seagoing ships to Punt » (Lichtheim 1988), " pour conduire des navires kebenyt vers la région de Pount» (Vandersleyen 1989), "para llevar barcos-kbn(y.w)t a Punt» (Diego Espinel 2003), « um kbn.t-Schiffe nach Punt zu führen » (Breyer 2016), « à guider les navires vers Pount » (Taterka 2018).

${ }^{197}$ Les traductions proposées, qui doivent tenir compte de $m$ ht $n b t$, varient entre (1) « envoyer» et (2) « charger» : (1) «I dispatch it with everything » (Breasted 1906), « ich (...) sandte sie mit allem (versehen) aus » (Schenkel 1965), «La envié con cada pertrecho » (Diego Espinel 2003); (2) « I loaded it with evrything » (Lichtheim 1988, Goelet 1992), « Je l'ai chargée de toutes choses » (Vandersleyen 1989, Taterka 2018).

${ }^{198}$ Les traductions proposées pour Amény varient entre : (1) un verbe de mouvement (Sayed 1977, 1979, Kitchen 1993, Farout 1994, 2006, Obsomer 1995, Diego Espinel 2003, Philip-Stephan 2008, Tallet 2009, Breyer 2014); (2) le verbe « envoyer» (Sayed 1977, 1979, Goelet, 1992, Mahfouz 2011, Taterka 2018).

199 Traductions proposées : « lead » (Pirelli 2007), « accompagnare » (Pirelli 2010); « führen » (Breyer 2016). 
D'après les dictionnaires ${ }^{200}$, le verbe sbi déterminé par le signe D 54 (jambes en mouvement) est attesté tant dans un sens intransitif que dans un sens transitif ${ }^{201}$. Dans l'inscription de l'an 14 de Sésostris III au Ouadi Hammamat, il fonctionne comme verbe intransitif, suivi d'un complément de direction : "Sa Majesté ordonna d'aller à Rohanou (sbt $r R(3)-h n w)$ pour rapporter $(\ldots) »^{202}$. Dans chacun des passages qui nous intéressent, sbi est un verbe transitif direct, mais son complément direct est soit une personne (imy-r(3) $p r w r$ Snb.f), soit des bateaux $(k b n y w t)$, soit un toponyme $(B i 3 P w n t)$, ce qui rend impossible une traduction identique pour ces différentes occurrences.

S'agissant de personnes, sbi signifie « envoyer» ou « dépêcher » (des gens ou une troupe $\left.m s^{c}\right)$ dans des contextes clairs où le sujet de l'action n'accompagne pas ces personnes ${ }^{203}$. Mais il est des cas, tout aussi clairs, où le sujet effectue manifestement le trajet avec eux, de sorte que la traduction «conduire» ou «acheminer» s'impose ${ }^{204}$. S'agissant de bateaux, le problème semble le même ${ }^{205}$. Il conviendra, tant pour Hénou que pour Amenhotep, de trouver des éléments externes qui soient susceptibles de rendre possible un choix ${ }^{206}$. Enfin, s'agissant de $s b t B i \jmath P w n t$, les dictionnaires ne relèvent aucun exemple où le verbe $s b i ̉$ se construit avec un toponyme comme complément direct. La stèle $\mathrm{n}^{\circ} 29$ permet d'exclure l'une des traductions proposées pour rendre sbt Bỉ Pwnt dans l'inscription d'Amény ${ }^{207}$ : «Sa Majesté a ordonné (...) de charpenter cette flotte (...), de (l') envoyer (à) B $\mathfrak{l}$ ว Pwnt ». En effet, elle nécessite d'ajouter comme complément direct un pronom qui se réfèrerait à la flotte mentionnée au préalable $\left(h^{c} w p n\right)$, ce qui est impossible dans l'inscription de la stèle $\mathrm{n}^{\circ} 29$, où il est question pour quelqu'un de monter ( $p r t)$ pour sbt Bỉ Pwnt. On privilégiera dès lors la traduction par un verbe de mouvement en dépit de l'absence, devant $B i ̉$ Pwnt, de la préposition $r$ marquant la direction. Sans doute sbi fonctionne-t-il alors comme une variante du verbe $p h$ « atteindre», « gagner » (un endroit) $)^{208}$.

\footnotetext{
${ }^{200}$ Notamment $W b$. III, 429-431 ; FAULKNER 1962, p. 219 ; HANNIG 2006, p. 2151-2154.

${ }^{201}$ Attesté avec le déterminatif du moineau, sbi est intransitif et signifie « être faible », " périr », " disparaître ».

${ }^{202}$ Inscription Montet 47. Voir aussi TALLET 2005, p. 131-132.

${ }^{203}$ Ainsi, en Sinouhé R 11, «Sa Majesté avait envoyé/dépêché (sb.n ḥm.f $m s ̌$ ) une armée au pays des Tjé-
} méhou », et dans les Devoirs du Vizir, c'est à lui qu'il revient d'envoyer tel ou tel groupe des gens pour accomplir telle ou telle mission (Urk. IV, 1113.3-5, 14). Une inscription de l'an 19 d'Amenemhat III au Ouadi Hammamat (Montet 47) omet le complément direct : Sbt hm.f $r$ int $n$.f mnw m int R(3)-hnw « Envoi (par) Sa Majesté (d'une troupe) pour lui rapporter des monuments de la vallée de Rohanou ».

${ }^{204}$ Ainsi, en Sinouhé B 245, « les Asiatiques venus à ma suite en me conduisant ( hr sbt.l) aux Chemins d'Horus »; en Sinouhé B 171, «Je suis proche du départ, lorsqu'on me conduira (sb.sn $\{n\}$ wi) vers la ville d'éternité »; en pWestcar 7.22, «Il te conduira ( $s b . f \underline{t} w$ ), en temps voulu, à tes pères ( $n$ itw. $k$ ) qui sont dans la nécropole ». Notons qu'en Urk. VII, 15.8 1, il s'agit d'acheminer des biens : «Alors, j'ai navigué vers le sud pour acheminer du minerai ( $r$ sbt bỉ 3 ) vers le port de Coptos en compagnie du noble prince, responsable de la ville et vizir Sénousret ».

${ }^{205}$ Voir, dans les Textes des Cercueils, le Spell 143 où est question pour le défunt de sbỉ la barque-hnhnw de Khépri (CT II, 176d).

${ }^{206}$ En Urk. IV, 354.17, on traduira «Il a été ordonné dans la majesté du palais à (...) Néhés(y) de conduire une troupe vers Pount ( $r$ sbt $\left.m s^{c} r P w n t\right) »$, parce qu'on sait par ailleurs que ce Néhésy accompagna l'expédition d'Hatchepsout à Pount. Il en va sans doute de même pour l'inscription 411 du Sinaï, où on lit que le roi a ordonné « de $s b t$ toute expédition ( $w \underline{d y t}$ ) vers l'Asie pour lui rapporter toutes sortes de beaux produits de cette région ».

${ }^{207}$ Voir note 198.

${ }^{208}$ Notons que sbi est bien attesté dans le sens de «passer» du temps (en Sinouhé B 172, par exemple). Par ailleurs, il est question en KRI II.889.16 de w3t sbyt, traduit «chemin de passage » par MEEKS 1982, p. 246. 


\section{4b. Les questions de timing liées aux expéditions}

Avant d'interpréter les données livrées par les inscriptions du Moyen Empire, il est important de relever les dates qu'elles offrent en examinant au préalable les questions suivantes : les vents et courants de la mer Rouge, le cycle de production de la myrrhe.

La navigation en mer Rouge dépend de vents et de courants qui varient selon les saisons ${ }^{209}$. Les auteurs du I ${ }^{\mathrm{er}}$ siècle après J.-C. recommandent d'effectuer en juillet le trajet aller vers le sud : le Périple de la mer Érythrée (§ 14) mentionne le mois d'Épiphi, qui va de fin juin à fin juillet, tandis que Pline l'Ancien (Histoire naturelle, VI, 104) indique qu'on prenait la mer au milieu de l'été, peu avant ou peu après la Canicule ${ }^{210}$. On sait en effet qu'en été, la navigation vers le Sud est facilitée par les vents dominants du Nord ${ }^{211}$ et par les courants qui se dirigent vers le $\mathrm{Sud}^{212}$. Pline précise qu'il fallait, à son époque, 30 jours pour aller de Bérénice « à Océlis d'Arabie ou à Cane de la région de l'encens ».

Les arbres à myrrhe se couvrent de fleurs à la fin de l'été, tandis que leur tronc se boursouffle de nœuds à partir desquels la myrrhe s'écoule en petites larmes jaunes, que l'on récolte une fois séchées ${ }^{213}$. La récolte avait lieu à la fin de la saison des pluies, vers septembre, ce qui permettait aux marchés d'être accessibles durant la saison sèche, de la mi-octobre à avrill ${ }^{214}$.

En ce qui concerne le trajet retour (au départ de l'Inde), Pline l'Ancien (Histoire naturelle, VI, 106) le situe aux mois de Tybi ou de Méchir, soit fin décembre ou début janvier, indiquant que l'on peut profiter en mer Rouge des vents du Sud, l'Africus (ou Lips) et l'Auster (ou Notos), pour arriver au port de Bérénice. On sait en effet que d'octobre à mai, les vents soufflent du SSE dans la partie méridionale de la mer Rouge, mais ils soufflent du NNW dans sa partie septentrionale, avec entre les deux $\left(\right.$ de $17^{\circ}$ à $\left.20^{\circ} \mathrm{N}\right)$ une aire de faible pression où règnent des brises faibles et variables ${ }^{215}$. Durant cette période, les courants de la partie méridionale de la mer Rouge vont vers le Nord, mais ils vont vers le Sud le long de la côte africaine de sa partie septentrionale ${ }^{216}$. Il était donc difficile de naviguer le long de cette côte au nord de la latitude de Bérénice ${ }^{217}$, et on devait progresser à la rame si l'on souhaitait regagner Mersa Gaouasis, ce qui peut expliquer l'intérêt de Ptolémée II à fonder le port de Bérénice à l'endroit où il se trouve.

Les dates relevées dans les inscriptions du Moyen Empire peuvent être converties comme suit dans notre calendrier grégorien ${ }^{218}$ :

- Hénou : Chémou I.3 de l'an 8 de Mentouhotep III équivaut environ au 16 août (vers 1993);

L'expression sbt Bỉ Pwnt pourrait-elle rendre l'idée que le Bia de Pount n'est qu'un lieu de transit? On notera l'expression sbi pt « le ciel » en $C T$ VII, $151 \mathrm{~d}$.

${ }^{209}$ FABRE 2005, p. 38-39, cartes p. 41.

${ }^{210}$ Référence au lever héliaque de Sothis, le 19 juillet du calendrier julien.

${ }^{211}$ SALLES 1998, p. 94.

${ }^{212}$ BRADBURY 1988, p. 129, fig. 1 (surface currents-August).

${ }^{213}$ Cf. https://fr.wikipedia.org/wiki/Arbre_à_myrrhe.

${ }^{214}$ BRADBURY 1988, p. 130, n. 16-17. Données reprises par FABRE 2005, p. 41, n. 44-45.

${ }^{215}$ Cf. SERVAJEAN 2018, p. 157-158, citant les Instructions nautiques - Mer Rouge golfe d'Aden.

${ }^{216}$ BRADBURY 1988, p. 129, fig. 1 (surface currents-October, surface currents-February). Voir aussi BARD, FATTOVICH 2018, p. 184-185.

${ }^{217}$ Cf. Rougé 1988, p. 62.

${ }^{218}$ Pour la méthode de calcul, voir OBSOMER à paraître. 
- Ânkhou : Péret I de l'an 24 de Sésostris I ${ }^{\text {er }}$ équivaut au mois d'avril (vers 1935);

- Étiquette Mahfouz 5 : Chémou III de l'an 4 (de Sésostris III) équivaut à septembre/octobre (vers 1869);

- Étiquette Mahfouz 1 : Péret II.13 de l'an 5 (de Sésostris III) équivaut environ au 27 avril (vers 1868);

- Étiquette Mahfouz 4 : Péret II.22 de l'an 5 (de Sésostris III) équivaut environ au 6 mai (vers 1868);

- Étiquette Mahfouz 2 : Péret III.12 de l'an 5 (de Sésostris III) équivaut environ au 26 mai (vers 1868);

- Étiquette Mahfouz 7 : Chémou II.16 de l'an 5 (de Sésostris III) équivaut environ au 18 août (vers 1868);

- Étiquette Mahfouz 6 : Chémou III (de Sésostris III) équivaut à septembre/octobre d'une année indéterminée ;

- Stèle de Bérénice : l'an 7 d'Amenemhat IV va de novembre à octobre (vers 1802-1801);

- Boîtes n ${ }^{\circ} 2$ et 21 : l'an 8 de Amenemhat IV va de novembre à octobre (vers 1801-1800).

Compte tenu des données récoltées, il est évident qu'une expédition vers Pount se déroulait, au Moyen Empire, à cheval sur deux années de règne ${ }^{219}$ : le trajet aller durant la période chaude de l'été, dans les premiers mois de Chémou; le trajet retour en Péret, soit au printemps de l'année suivante. Pour David Fabre ${ }^{220}$, le trajet aller devait prendre de quatre à six semaines à une moyenne de 50 à $60 \mathrm{~km}$ par jour, le trajet retour pourrait avoir pris trois mois s'il fallait ramer contre le vent du Nord.

\section{4c. Interprétation des données relatives aux expéditions}

Les documents du règne de Sésostris $\mathrm{I}^{\mathrm{er}}$ laissent entendre qu'une expédition vers Pount par la mer Rouge impliquait un ensemble d'opérations menées en plusieurs phases ${ }^{221}$, sur lesquelles nous ne disposons que d'informations partielles. En effet, comme les données disponibles sont livrées par des inscriptions privées, elles se focalisent sur les opérations effectuées par ceux qui ont fait graver ces inscriptions ${ }^{222}$. Les inscriptions de l'an 38 de Sésostris $\mathrm{I}^{\mathrm{er}}$ au Ouadi Hammamat en donnent une très bonne illustration, car l'inscription d'Amenemhat (Montet 87) ne décrit que la part du travail effectué par celui-ci dans le cadre d'une mission plus importante détaillée dans l'inscription du chef de l'expédition (Goyon 61), qui n'est autre que le héraut Amény connu au Ouadi Gaouasis ${ }^{223}$ : Amény indique que le début des travaux eut lieu en Akhet III.27, tandis qu'Amenemhat écrit qu'il est arrivé en Akhet IV.4 et que sa

\footnotetext{
${ }^{219}$ Rappelons qu'au Moyen Empire, le début d'une année de règne coïncidait avec le début de l'année du calendrier, soit Akhet I.1, les trois saisons de quatre mois se succédant comme suit : Akhet-Péret-Chémou.

${ }^{220}$ FABRE 2005, p. 38.

${ }^{221}$ Voir, par exemple, MAHFOUZ 2011a, p. 56.

${ }^{222}$ Ainsi, le récit d'Ahmès fils d'Abana à Elkab ne présente pas l'ensemble des opérations menées par le roi Amosis lors de la prise d'Avaris, mais seulement les hauts faits accomplis par Ahmès et pour lesquelles il a été récompensé.

${ }^{223} C f$. OBSOMER 1995, p. 365-374. On peut trouver à la ligne 11 une possible allusion à sa mission au Ouadi Gaouasis, lorsqu'Amény écrit à propos du roi : «Il pense mon action efficace lors de toute mission que Sa Majesté ordonne au serviteur que je suis ».
} 
mission fut de tracter 80 blocs, parmi les 210 blocs totalisés par Amény; Amény dresse la liste de tous les gens qui ont pris part à l'expédition, alors qu'Amenemhat mentionne seulement ceux qui l'accompagnèrent vers les carrières; enfin, le fait qu'Amenemhat précise la date à laquelle il atteignit la rive du Nil avec ses 80 blocs (Akhet IV.20) permet de déduire qu'il retourna ensuite au Ouadi Hammamat, car c'est là qu'il fit graver son inscription. Ce détail permet de mettre en évidence l'importance du lieu de découverte d'une inscription, qui ne peut a priori décrire des faits précis qui n'ont pas encore eu lieu au moment où elle fut gravée à cet endroit. Ces précisions étant données, réexaminons ce que l'on nous dit pour chaque expédition menée à Pount.

\section{L'expédition de l'an 8/9 de Mentouhotep III}

Comme Louise Bradbury l'a bien expliqué ${ }^{224}$, la date de l'inscription d'Hénou (Chémou I.3 de l'an 8 , soit environ le 16 août grégorien), ne permet pas d'envisager qu'en passant au Ouadi Hammamat (Rohanou), Hénou revenait d'une expédition qu'il avait conduite lui-même jusqu'à Pount. Ajoutons que son arrêt au Ouadi Hammamat a eu lieu en plein été, alors que les missions menées à Rohanou dans le but exclusif d'en rapporter des pierres s'effectuaient dans la période de janvier à mars ${ }^{225}$, quand la chaleur était moins accablante. Le passage d'Hénou aux carrières de Rohanou s'explique, non pas dans le cadre d'une expédition spécifique vers ce lieu, mais par l'opportunité qui s'offrait de s'y arrêter lors de son trajet retour vers la vallée du Nil. L'absence de mention d'un séjour à Pount par Hénou conforte l'idée de Bradbury ${ }^{226}$.

La traduction du verbe sbi attesté au début du récit (ligne 8, a) peut être précisée : la mission que le roi confia à Hénou fut de "dépêcher des bateaux-kbnyt vers Pount ", et non de les y « conduire ». Ce qu'on lit ensuite - « afin de lui rapporter la myrrhe fraîche en possession des princes chefs du désert »- apparaît dès lors comme l'objectif final de l'entreprise initiée par le roi, dont on ignore, au moment où Hénou fait graver son inscription, s'il allait ou non être atteint : l'expédition navale ne devait revenir de Pount qu'en l'an 9, à la fin d'Akhet ou au début de Péret. Quatre lignes plus loin, Hénou précise qu'il a rempli sa mission : «Alors j'ai fait/constitué cette flotte et je l'ai dépêchée en toutes choses, après avoir fait pour elle une grande offrande de taureaux, de bœufs et de gazelles » (ligne 12, e). Traduit de la sorte ${ }^{227}$, ce passage indique qu'Hénou a constitué la flotte et qu'il a fait une offrande pour lui assurer une bonne navigation avant de l'envoyer vers Pount, l'expression « en toutes choses » semblant indiquer qu'Hénou a pourvu à tous ses besoins ${ }^{228}$. Un point important sur lequel Hénou reste muet, c'est le bois avec lequel il constitua la flotte, mais il situe son activité à proximité de Ouadj-our (voir d et f), à un endroit précis qui reste toutefois à déterminer. Examinons à présent ses trajets aller et retour.

Hénou donne beaucoup d'informations sur son trajet aller (lignes 8 à 12, b et c). En résumé, il est parti de Coptos avec des ânes et une troupe de 3000 hommes, dont il précise l'origine et dont il a assuré le ravitaillement (nourriture, boisson, sandales) en sa qualité de commandant

\footnotetext{
${ }^{224}$ BRADBURY 1988, p. 127-130. Voir aussi DuHOUX 2003, p. 52-63 ; FABRE 2005, p. 39-41.

${ }^{225}$ Akhet III-IV sous Sésostris I ${ }^{\mathrm{er}}$, d'après les inscriptions de l'an 38. Avec le décalage progressif du calendrier: Chémou III sous Pépi I ${ }^{\text {er }}$, Akhet II sous Mentouhotep IV, Chémou II sous Ramsès IV, Akhet III sous Darius, Akhet I sous Xerxès.

${ }^{226}$ Contra Lichtheim 1988, p. 54, n. 21.

${ }^{227}$ Trois formes $s \underline{d m} . n . f$ : la première autonome, la seconde séquentielle, la troisième circonstancielle.

${ }^{228}$ La traduction « Je l'ai chargée de toutes sortes de choses » (cf. note 197) ne convient pas pour le verbe $s b i$. Dans le Naufragé $(146,166)$ on utilise le verbe 3’tp « charger », bien attesté lorsqu'il s'agit de charger des bateaux.
} 
en chef. La route était ouverte par des éclaireurs, de hauts fonctionnaires étaient présents et, durant le trajet, l'activité fut d'aménager treize points d'eau, dont deux en Idahet et un autre en Iaheteb avaient des dimensions importantes. Creuser des puits prend du temps et n'a d'utilité que si la nappe phréatique est atteinte ou si des pluies arrivent à les alimenter. Dans ce cas, il est probable qu'Hénou quitta Coptos plusieurs mois avant d'atteindre Ouadj-our, sans doute en hiver ou au printemps s'il s'agit de traverser une zone désertique, et il utilisa une main-d'œuvre suffisante pour aménager les points d'eau qui devaient s'avérer utiles pour ceux qui allaient ramener les produits de Pount l'année suivante. Sa troupe constitua les bateaux, avec le bois sans doute acheminé par d'autres (Hénou reste muet sur ce point), et certains membres de sa troupe ont pu prendre part au voyage à Pount dirigé par un chef de mission dont le nom reste inconnu.

Les hommes qui n'embarquèrent pas vers Pount rentrèrent en Égypte avec Hénou, dont le trajet retour est mentionné à la ligne 13 (f et g). En s'éloignant de Ouadj-our, il emporta des produits «trouvés sur la rive de la Terre du dieu », expression qui n'implique pas qu'il fût à Pount, mais à un endroit indéterminé de la rive de la mer Rouge. Dans son trajet retour, sans doute vers Thèbes via Coptos, il est passé par Ouag et Rohanou pour y prendre au passage des pierres de qualité destinées à devenir des statues. Si Rohanou est bien connu comme la zone des carrières du Ouadi Hammamat où l'on extrayait la pierre de békhen (grauwacke) destinée à la statuaire, Ouag n'est pas attesté par ailleurs. S'agit-il d'un autre endroit où l'on extrayait de la pierre ou d'un toponyme permettant de localiser l'endroit où Hénou s'écarta du trajet emprunté à l'aller pour gagner Rohanou au retour?

Des questions importantes restent à préciser : les routes empruntées par Hénou, à l'aller et au retour; l'endroit où la flotte a embarqué vers Pount. Ces questions sont intimement liées. Le départ de Coptos et le retour par le Ouadi Hammamat éliminent d'emblée le port d'Ayn Soukhna comme point de départ de l'expédition navale.

Convaincue que cette expédition ne pouvait partir que de Mersa Gaouasis, Bradbury proposa en 1988 un trajet aller différent du trajet retour ${ }^{229}$ : de Coptos, Hénou aurait rejoint la région de Qéna, emprunté le Ouadi Hammamah et gagné la mer Rouge en passant par le Gébel Semnah, les toponymes Idahet et Iaheteb étant à localiser près du Gébel Aridia et du Gébel Agharrib ; lors de son trajet retour, Hénou aurait obliqué vers le Sud aux environs du Ouadi Saqi, où elle localise Ouag, pour rejoindre le Ouadi Hammamat avant de rentrer avec des pierres vers Coptos. Comme le site du Ouadi Gaouasis n'a livré aucune preuve de la présence d'Égyptiens avant le règne de Sésostris ${ }^{\mathrm{er}}$, la proposition de Bradbury reste une hypothèse $\mathrm{e}^{230}$.

En 1995, j'avais suggéré comme alternative la route de Coptos à Bérénice ${ }^{231}$, utilisée à l'époque romaine et balisée de plusieurs puits, comme l'indique Pline l'Ancien (Histoire naturelle, VI, 102-103). Cette route fait 258000 pas romains selon Pline, soit $380 \mathrm{~km}$, et l'auteur latin précise que le trajet se faisait alors en douze jours, les déplacements ayant lieu essentiellement de nuit. Si les 15 puits d'Hénou furent creusés dans le but de ménager des pauses à l'expédition qui reviendrait de Pount avec les produits acquis, on peut envisager, en théorie, 17 étapes sur les $380 \mathrm{~km}$ de cette route. La vitesse moyenne de progression des ânes et des hommes serait dès lors de $22 \mathrm{~km}$ par jour, correspondant à la vitesse de progression des

\footnotetext{
${ }^{229}$ BRADBURY 1988, p. 131-138.

${ }^{230}$ Adoptée par BARD, FATtovich, MAnzo 2013, p. 549-553 ; BARD, FATtovich 2018, p. 12, 183-184.

${ }^{231}$ OBSOMER 1995, p. 400.
} 
troupes de Ramsès II vers Qadech ${ }^{232}$. La mention de Iaheteb au temple de Soleb, parmi les toponymes mentionnés en association à des prisonniers nubiens au pied des colonnes sud de la salle hypostyle ${ }^{233}$, est un élément qui peut plaider en faveur de cette route méridionale, mais il convient assurément de trouver des preuves plus solides. Seules de nouvelles découvertes dans le désert oriental ou au Ras Banas pourront permettre de trancher la question en faveur de l'une ou de l'autre hypothèse ${ }^{234}$.

\section{L'expédition de l'an 23/24 de Sésostris $I^{\text {er }}$}

Les inscriptions des monuments d'Amény et d'Ânkhou au Ouadi Gaouasis présentent les missions différentes que Sésostris $I^{\mathrm{er}}$ confia, l'une au vizir Antefoqer, l'autre au chambellan Ânkhou, dans le cadre de l'expédition qu'il souhaita envoyer vers Pount. Le premier fut chargé notamment de charpenter les pièces des bateaux et de les acheminer vers la côte de la mer Rouge. Le second reçut l'ordre de mener l'expédition navale jusqu'à Pount. La décision royale peut être datée de l'an 23, voire remonter à l'an 22 de son règne ${ }^{235}$.

Telle que présentée par Amény (lignes 2-6, c), la mission d'Antefoqer comporte trois phases successives : (1) charpenter une flotte aux chantiers navals de Coptos ; (2) gagner le Bia de Pount, autrement dit le débouché du Ouadi Gaouasis sur la mer Rouge ; (3) fournir ce qui est nécessaire aux travaux. En matière de construction navale, le vizir Antefoqer avait une certaine expérience, car il avait dirigé quelques années plus tôt la construction, aux chantiers navals de This, des bateaux qui allaient être utilisés lors de la campagne militaire de Sésostris $\mathrm{I}^{\mathrm{er}}$ au pays de $\mathrm{Kouch}^{236}$. Amény indique qu'Antefoqer a agi en tous points conformément à l'ordre du roi, mais on ignore s'il a effectué en personne le trajet vers la mer Rouge : il a pu déléguer à Amény ou à d'autres cette partie de sa mission. Quand Amény écrit qu'il s'agit de gagner le Bia de Pount $r$ ph $m$ htp $r$ iwt $m$ htp, « pour (y) parvenir en paix et (en) revenir en paix ", il pourrait préciser l'objectif final voulu par le roi : atteindre Pount et en revenir sans encombre. On comprend qu'Amény ne s'y attarde pas, si le roi a confié cette mission à un autre, le chambellan Ânkhou. La mission d'Antefoqer s'arrête lorsque sont achevés les travaux préalables au départ des bateaux d'Ânkhou vers Pount: on pensera non seulement à l'assemblage des bateaux, qu'Amény a supervisé puisqu'il le mentionne dans la suite de son inscription (ligne 7, d), mais aussi à l'aménagement de la baie de Mersa Gaouasis comme port d'embarquement où, de retour de Pount, les bateaux allaient être déchargés, démontés et rangés en pièces détachées dans les galeries aménagées à cette fin. Amény dispose, sur la rive de Ouadj-our, d'une troupe importante de 3700 soldats- $^{\complement} n h w$, encadrée par 50 militaires- šmsw $^{\prime}$ de l'entourage du roi (lignes 8-14, e) ; c'est parmi les « 500 soldats de la flotte du Maître » que seraient choisis les équipages destinés à se rendre à Pount. Amény mentionne également des

\footnotetext{
${ }^{232}$ HeAGREN 2010, p. 205-206 ; OBSOMER 2016, p. 85 et fig. 21.

${ }^{233}$ Voir LEPSIUS, III, pl. 88h ; ZiBELIUS 1972, p. 90. Ce toponyme ne semble pas figurer dans les photographies de SCHIFF GIORGINI 2003. Il n'est plus visible aujourd'hui in situ, comme ma visite de Soleb le 29 janvier 2019 m'a permis de le constater.

${ }^{234}$ Cf. BRUN 2018, § 3 : «During the Old and Middle Kingdom periods expeditions to Punt crossed the desert to reach ports near Aïn Sukhna, Wâdi Gawasis (ancient Saww), and, likely, at the location where Berenike was later built. » (https://books.openedition.org/cdf/5239).

${ }^{235}$ À titre comparatif, la campagne de Sésostris I ${ }^{\mathrm{er}}$ contre Kouch date de l'an 18 (stèle Florence 2540), mais les bateaux ont franchi à l'aller la première cataracte durant les hautes eaux, en Chémou de l'an 17, après avoir été construits aux chantiers navals de This dès l'an 16, car le pReisner II atteste la fourniture d'outils pour les charpentiers entre Chémou II de l'an 16 et Akhet II de l'an 17. Voir notamment OBSOMER 1995, p. 311-335.

${ }^{236}$ Voir la note précédente. Sur la carrière du vizir Antefoqer, voir OBSOMER 1995, p. 165-172, 207-222.
} 
membres du « Grand Conseil » du nome thinite, qui se compose de gens compétents délégués par la ville de This où se trouvent également des chantiers navals. Si Amény n'évoque pas l'acheminement des pièces détachées des bateaux à dos d'ânes, de Coptos à Mersa Gaouasis, c'est parce que le vizir Antefoqer avait dû confier cette tâche à un autre. En effet, Amény ne dit pas que la troupe qui était avec lui « sur la rive de Ouadj-our » était venue avec lui depuis Coptos. Il est probable que la caravane traversa le désert avec le matériel durant l'hiver qui précéda le départ d'Ânkhou (vers juillet-août) et qu'Amény n'effectua le trajet vers la mer Rouge qu'une fois les bateaux prêts à y être assemblés. Pour Bradbury ${ }^{237}$, le cartouche de Sésostris $\mathrm{I}^{\mathrm{er}}$ visible au Ouadi Atalla, à une vingtaine de kilomètres au nord du Ouadi Hammamat, a pu y être gravé lors d'une phase de cette entreprise ${ }^{238}$.

La mission d'Ânkhou est tout autre, comme ses inscriptions l'indiquent clairement malgré les lacunes qu'elles offrent. L'inscription du bloc central (a) présente Ânkhou comme le « responsable de la flotte » et le « commandant des équipages », et la mission confiée par le roi est de «[...] Pount, au sud de Oupet-ta pour atteindre [...]», avec 400 recrues et d'autres personnes, parmi lesquels figurent notamment un "administrateur du Noun », des fonctionnaires attachés au « grenier », un « responsable des orfèvres » ${ }^{239}$. La date mentionnée au début de l'inscription (Péret I de l'an 24) correspond-elle à la date où l'ordre royal a été énoncé ou à la date à laquelle l'inscription a été rédigée ? S'agissant d'un texte de la XII ${ }^{\mathrm{e}}$ dynastie, je privilégie la seconde hypothèse. Le monument a été constitué d'ancres, à un moment où celles-ci n'étaient donc plus utiles, et la date correspond au mois d'avril : deux indices qui permettent de penser que la flotte d'Ânkhou venait de revenir de Pount. Le retour de Pount est d'ailleurs décrit dans l'inscription lacunaire du bloc occidental (c) où sont évoqués les produits rapportés par la flotte.

Enfin, l'inscription du bloc oriental (d) évoque selon toute vraisemblance une visite de Sésostris $\mathrm{I}^{\mathrm{er}}$ à Mersa Gaouasis. En effet, le début du texte (col. 2) offre une brève lacune avant l'expression $m$ htp « en paix » ou "sans encombre », où il convient de restaurer sans doute un verbe de mouvement à l'infinitif, comme iwt «venir». Je propose de lire : « [Venue] en paix du maître des Deux Terres Sésostris, vivant (soit-il) éternellement!». La phrase suivante signale que le roi a ordonné à Ânkhou de « revenir en paix ». Nul doute qu'il s'agit en l'occurrence de son retour vers la vallée du Nil, puisqu'aucun détail n'est donné sur l'endroit où il est invité à se rendre. Le titre de $s m r$ « compagnon » (col.2) qui lui est conféré dans l'énoncé de l'ordre royal peut résulter d'une promotion accordée par le roi pour la réussite de la mission, comme c'est le cas pour Sinouhé lorsqu'il rentre en Égypte après son séjour en Asie ${ }^{240}$. La suite du texte (col. 3-6) énonce les qualités d'Ânkhou qui lui ont valu cette promotion, après lui avoir permis de ramener la flotte à bon port, " aux districts du nome de Coptos ». Comme il est logique, les textes d'Ânkhou ne décrivent pas le retour vers la vallée du Nil.

\footnotetext{
${ }^{237}$ BRADBURY 1988, p. 134 ; OBSOMER 1995, p. 377-378, 708.

${ }^{238}$ On notera qu'aucune mention de Pount n'est attestée dans les inscriptions du Ouadi Hammamat, hormis celle qui figure dans l'inscription d'Hénou : $c f$. GASSE 2006, p. 294-295.

${ }^{239}$ Si le Naufragé (25-27) mentionne un bateau de 120 coudées de long et 40 coudées de large ayant à son bord 120 marins, les bateaux de Mersa Gaouasis devaient faire de 20 à $30 \mathrm{~m}$ de long (40 à 60 coudées) avec un équipage de 40 à 60 personnes, suivant BARD, FATTOVICH 2018, p. 185. On envisagera dès lors une flotte de sept à dix bateaux.

${ }^{240}$ Sin. B 189, 280, 296, 307. Sésostris I ${ }^{\text {er }}$ lui attribue cette promotion pour les relations diplomatiques qu'il a pu mettre en place lors de son séjour en Asie : cf. OBSOMER 1999, p. 255.
} 
L'expédition à Pount en l'an 24 de Sésostris $\mathrm{I}^{\mathrm{er}}$ apparaît comme une entreprise de prestige. Il n'est donc pas impossible que la fameuse série de coquilles d'huîtres perlières gravées au nom de Sésostris $\mathrm{I}^{\mathrm{er}}$, les unes avec le cartouche "Sésostris», les autres avec le cartouche « Khéperkarê ${ }^{241}$, ait été produite à cette occasion pour récompenser des membres de l'expédition. Elles devaient se porter comme des pendentifs, à la façon des médailles offertes aux lauréats de nos compétitions sportives actuelles. Il s'agit de coquilles d'une dizaine de centimètres de diamètre qui, selon Pierre Lozouet (Muséum National d'Histoire Naturelle de Paris), appartiennent à l'espèce «Pinctada margaritifera (Linnaeus, 1758) » présente dans toute la mer Rouge et au-delà ${ }^{242}$.

\section{L'expédition de l'an 27/28 d'Amenemhat II}

Si Khenty-khéty-our a dressé sa stèle en l'an 28 d'Amenemhat II après son retour de Pount, c'est que le départ de l'expédition navale a eu lieu l'année précédente. Il ne porte pas de titre nautique, mais parle de $s a$ troupe et de ses bateaux, ce qui donne à penser qu'il fut le chef de cette expédition. Le titre de « responsable de la cour de justice » qu'il porte indique qu'il avait des prérogatives judiciaires, utiles pour régler les litiges potentiels entre les membres de l'expédition. Dressée pour remercier les dieux qui ont permis le succès de l'entreprise et le roi qui a ordonné celle-ci, la stèle ne donne aucune information sur la navigation, les tractations au pays de Pount et les produits rapportés.

\section{L'expédition de l'an 2 ou 3 de Sésostris II}

Dominée par le soleil ailé, qui lui confère un caractère officiel, la stèle mentionne le nom et les qualités de celui qui l'a dressée, mais elle se contente de mentionner la montée de celui-ci vers le Bia de Pount, où elle a été érigée apparemment avant le départ de l'expédition navale.

\section{L'expédition de l'an 4/5 de Sésostris III}

Les jarres sur lesquelles les étiquettes ont été notées concernent le ravitaillement acheminé à Mersa Gaouasis dans le cadre d'une expédition à Pount, qui est sans doute partie en Chémou III (septembre) de l'an 4 ( $c f$. étiquettes 5 et peut-être 6) et revenue en Péret II (avril-mai) de l'an 5 ( $c f$. étiquettes $1,2,4)^{243}$. Datée de Chémou II.16 ( \pm 18 août) de l'an 5, l'étiquette 7, qui mentionne Pount, semble pouvoir concerner une expédition menée l'année suivante ${ }^{244}$.

\section{L'expédition du règne d'Amenemhat III}

La stèle $\mathrm{n}^{\circ} 5 \mathrm{du}$ Ouadi Gaouasis, sans mention de l'année du règne d'Amenemhat III, a été laissée par deux frères, Nebsou et Amenhotep, engagés dans une même entreprise, dont le chef était le grand intendant Sénebef. Nebsou, chambellan de la Tête du Sud, indique qu'il accompagna Sénebef vers le Bia de Pount, soit Mersa Gaouasis. Amenhotep indique qu'il

\footnotetext{
${ }^{241}$ Voir notamment CORTEGGIANI 1973, p. 144-146, pl. XIIIA ; BOURRIAU 1988, p. 153.

${ }^{242}$ Je le remercie de l'information communiquée le 18 janvier 2019 et remercie Cécile Callou de nous avoir mis en contact. Il convient d'écarter l'appellation «avicula (meleagrina) margaritacea » diffusée dans la littérature égyptologique.

${ }^{243}$ Les jarres des étiquettes 1 et 2 contenaient du poisson séché fourni par Noubkaourê d'el-Lahoun. Il en va de même pour la jarre de l'étiquette 3 (sans date).

${ }^{244}$ Cette jarre provient de Ioumitérou.
} 
conduisit $^{245}$ Sénebef vers Pount, sa qualité de « scribe préposé au sceau du Trésor » donnant à penser qu'il fut chargé de la gestion des biens et marchandises embarqués.

\section{L'expédition de l'an 7/8 d'Amenemhat IV}

Les documents du règne d'Amenemhat IV confirment qu'une expédition à Pount se déroulait, au Moyen Empire, sur deux années civiles consécutives. La stèle de Bérénice, qui porte la date de l'an 7, a visiblement été laissée lors d'une escale au Ras Banas durant le trajet aller sur la mer Rouge ${ }^{246}$. Cette stèle mentionne le chef de l'expédition navale, Ptahhotep, dont les titres révèlent un proche du roi, qui opérait en l'occurrence en tant que "chancelier du dieu » et " contrôleur des recrues ». C'est un autre "contrôleur des recrues », Djédy, qui a laissé son nom sur les boîtes de l'an 8 trouvées au Ouadi Gaouasis, qui avaient contenu les produits rapportés de Pount. L'inscription de l'ostracon WG 111 indique que sa jarre contenait 200 poissons, mais elle ne donne aucune information sur leur provenance : il peut dès lors s'agir de poissons pêchés en mer Rouge lors du trajet retour.

\section{Conclusion}

À la XII ${ }^{\mathrm{e}}$ dynastie, la frontière sud de l'Égypte était établie sur la deuxième cataracte du Nil, à Bouhen sous Sésostris $\mathrm{I}^{\mathrm{er}}$, à Semna sous Sésostris III, où de puissantes forteresses ont été bâties. L'expédition militaire de l'an 17/18 de Sésostris ${ }^{\mathrm{er}}$ contre le royaume de Kerma a permis aux Égyptiens d'obtenir des produits de Pount à travers un tribut que les Kouchites devaient leur livrer, comme attesté dans l'inscription d'Amenemhat II à Memphis ${ }^{247}$. Mais les rois de la XII ${ }^{\mathrm{e}}$ dynastie décidèrent aussi, dès l'an 23/24 de Sésostris I ${ }^{\mathrm{er}}$, d'envoyer des expéditions navales sur la mer Rouge pour atteindre directement le pays de Pount producteur de la myrrhe. Les inscriptions de cette époque ne livrent toutefois aucune information sur l'aspect du pays de Pount ou les tractations commerciales qui furent menées par les chefs d'expédition.

Le port de Mersa Gaouasis fut opérationnel sur une durée de plus de 130 ans, entre l'an 23 de Sésostris ${ }^{\text {er }}$ et l'an 8 d'Amememhat IV, soit entre 1936 et 1800 avant J.-C. environ. Les inscriptions découvertes in situ évoquent les opérations mises en œuvre pour mener à bien ces expéditions: la construction des pièces de bateaux aux chantiers navals de Coptos, leur assemblage sur la côte de la mer Rouge, l'envoi de l'expédition navale durant l'été et le retour au printemps suivant avec les produits rapportés de Pount. Il est probable que les bateaux du règne de Sésostris $\mathrm{I}^{\mathrm{er}}$ ont été réutilisés lors de plusieurs expéditions sous les règnes suivants, puisque les galeries permettaient d'en entreposer les pièces d'une expédition à l'autre. En revanche, des incertitudes subsistent autour de l'expédition du règne de Mentouhotep III, vers 1993 avant J.-C., soit près de 60 ans avant la mise en activité du port de Mersa Gaouasis. Quel fut le lieu d'embarquement de l'expédition maritime qu'Hénou a dépêchée vers Pount? Cette expédition connut-elle le succès ou fut-elle un échec ? Les informations font défaut.

Au Nouvel Empire, le "portique de Pount» du temple d'Hatchepsout à Deir el-Bahari offre des textes et des reliefs qui n'évoquent ni la préparation des bateaux, ni le lieu d'embarquement, ni le trajet effectué pour se rendre à Pount, vers 1470 avant J.-C. En revanche, on montre ces bateaux et l'aspect qu'offrait le pays de Pount, ainsi que la rencontre avec les

\footnotetext{
${ }^{245}$ Cette traduction du verbe sbi semble s'imposer lorsque le complément direct est un individu précis et non une troupe ou des bateaux.

${ }^{246}$ Dans la mesure où des bateaux étaient disponibles dans les galeries du Ouadi Gaouasis, on n'envisagera pas le Ras Banas comme le point de départ de la navigation.

${ }^{247}$ Texte égyptien : AltenMüLlER 2015, p. 34-37.
} 
Pountites et les produits qui furent rapportés, tout cela dans le but de démontrer la capacité du roi Hatchepsout à mener à bien une mission ordonnée par son père Amon. On mesure le prestige qu'une telle expédition a pu présenter pour une Hatchepsout en quête de légitimité. En ce qui concerne l'expédition à Pount du règne de Ramsès III, vers 1165 avant J.-C., le récit qu'en donne le pHarris I donne à penser, avec Pierre Grandet ${ }^{248}$, qu'elle embarqua aux environs de Suez, mais il précise qu'elle aborda au retour au « Gébel de Coptos », en raison sans doute des vents et courants contraires qui ont pu l'empêcher de progresser davantage vers le Nord. On ignore le lieu précis où furent débarquées les marchandises qui allaient être chargées ensuite sur des ânes : la région de Qoseir ou l'ancien port de Mersa Gaouasis (Saouou) ? Des cartouches de Ramsès III dans les rochers du Ouadi Saqi et du Ouadi Atalla semblent plaider en faveur de la seconde hypothèse. Une fois arrivées en caravane à Coptos, ces marchandises furent ensuite chargées dans des bateaux- $h^{\complement} w$ pour gagner, par la voie fluviale, la Résidence de Pi-Ramsès.

${ }^{248}$ GRANDET 1994b, p. 255-260 (note 931). 


\section{BIBLIOGRAPHIE}

ABD EL-RAZIQ 1999 : Mahmoud ABD EL-RAZIQ, « New inscriptions at El Ein el-Sukhna », Memnonia, 10, p. 125-131, pl. XXXIII-XXXVI.

AbD el-RaziQ, Castel, Tallet 2006a : Mahmoud AbD el-RaziQ, Georges Castel, Pierre TALLET, « Ayn Soukhna et la mer Rouge », Égypte, Afrique \& Orient, 41, p. 3-6.

Abd el-RaziQ, Castel, Tallet 2016 : Mahmoud AbD el-RaziQ, Georges Castel, Pierre TALlet, Ayn Soukhna III. Le complexe de galeries-magasins. Rapport archéologique (Fouilles de l'Institut Français d'Archéologie Orientale, 74), Le Caire.

Abd el-RaziQ, Castel, Tallet, Fluzin 2011 : Mahmoud AbD el-RaziQ, Georges Castel, Pierre Tallet, Philippe Fluzin, Ayn Soukhna II. Les ateliers métallurgiques du Moyen Empire (Fouilles de l'Institut Français d'Archéologie Orientale, 66), Le Caire.

AbD el-RaziQ, Castel, Tallet, Ghica 2002 : Mahmoud AbD el-RaziQ, Georges Castel, Pierre TAllet, Victor GHICA, Les inscriptions d'Ayn Soukhna (Mémoires publiés par les membres de l'Institut Français d'Archéologie Orientale, 122), Le Caire.

Abd el-RaziQ, Castel, Tallet, Marouard 2012: Mahmoud AbD El-RaziQ, Georges CAstel, Pierre TAllet, Grégory Marouard, «The Pharaonic Site of Ayn Soukhna in the Gulf of Suez. 20001-2009 Progress Report», dans Pierre TAllet, El-Sayed Mahfouz, The Red Sea in Pharaonic Times. Recent Discoveries along the Red Sea Coast. Proceedings of the Colloquium held in Cairo / Ayn Soukhna, 11th-12th January 2009 (Bibliothèque d'Étude, 155), Le Caire, p. 3-20.

Allen 2008 : James P. Allen, « The Historical Inscription of Khnumhotep at Dahshur: Preliminary Report », Bulletin of the American Schools of Oriental Research, 352, p. 29-39.

Alliot 1951 : Maurice Alliot, « Pount-Pwāne, l'Opôné du géographe Ptolémée », Revue d'Égyptologie, 8, p. 1-7.

Altenmüller 2015: Hartwig AltenMüller, Zwei Annalenfragmente aus dem frühen Mittleren Reich (Studien zur altägyptischen Kultur. Beihefte, 16), Hambourg.

BARd, FAtTovich 2007 : Kathryn A. BARD, Rodolfo FAtTovich (éd.), Harbor of the Pharaohs to the Land of Punt: Archaeological Investigations at Mersa/Wadi Gawasis, Egypt, 2001-2005, Naples.

BARD, Fattovich 2010 : Kathryn A. BARD, Rodolfo FAtTovich, « Mersa/Wadi Gawais 2009-2010 », Newsletter di Archeologia CISA 1, p. 7-35.

Bard, Fattovich 2011 : Kathryn A. Bard, Rodolfo Fattovich, "The Middle Kingdom Red Sea Harbor at Mersa/Wadi Gawasis », Journal of the American Research Center in Egypt, 47, p. 105-129.

Bard, Fattovich 2018 : Kathryn A. BARD, Rodolfo Fattovich, Seafaring expeditions to Punt in the Middle Kingdom: Excavations at Mersa/Wadi Gawasis, Egypt (Culture and History of the Ancient Near East, 96), Leyde, Boston.

Bard, Fattovich, Manzo 2013 : Kathryn A. BARd, Rodolfo Fattovich, Andrea Manzo, « The ancient harbor at Mersa/Wadi Gawasis and how to get there: new evidence of Pharaonic seafaring expeditions in the Red Sea », dans Frank Förster, Heiko RiemER (éd.), Desert Road Archaeology in Ancient Egypt and beyond, Cologne, p. 533-556. 
Belzoni 1820 : Giovanni Battista Belzoni, Narrative of the Operations and Recent Discoveries within the Pyramids, Temples, Tombs, and Excavations in Egypt and Nubia; and of a Journey to the Coast of the Red Sea, in Search of the Ancient Berenice, Londres.

Belzoni 1821 : Giovanni Battista Belzoni, Atlas des voyages, recherches et découvertes de G. Belzoni en Égypte et en Nubie, Paris.

Berlev 1971 : Oleg D. BERlEV, «Les prétendus «citadins » au Moyen Empire », Revue d'Égyptologie, 23, p. 23-48.

BIRCH 1880 : Samuel BIRCH, Catalogue of the Collection of Egyptian Antiquities at Alnwick Castle, Londres.

Borojevic, Mountain 2011 : Ksenija Borojevic, Rebecca Mountain, " The Ropes of Pharaohs: the Source of Cordage from "Rope Cave" at Mersa/Wadi Gawasis revisited ", Journal of the American Research Center in Egypt, 47, p. 131-141.

Bourriau 1988 : Janine Bourriau, Pharaohs and Mortals. Egyptian art in the Middle Kingdom, Cambridge.

BRADBURY 1988 : Louise BRADBURY, « Reflections on Traveling to "God's land" and Punt in the Middle Kingdom », Journal of the American Research Center in Egypt, 25, p. 127-156.

BREASTED 1906 : James Henry BREASTED, Ancient Records of Egypt, vol. I, Chicago.

Breyer 2016 : Francis Breyer, Punt: die Suche nach dem "Gottesland" (Culture and History of the Ancient Near East, 80), Leyde, Boston.

BRUN 2018 : Jean-Pierre BRUN, « Chronology of the Forts of the Routes to Myos Hormos and Berenike during the Graeco-Roman Period », dans J.-P. BRUN et alii (éd.), The Eastern Desert of Egypt during the Greco-Roman Period: Archaeological Reports, Paris (https://books.openedition.org/cdf/5239).

Corteggiani 1973 : Jean-Pierre Corteggiani, Documents divers (I-IV), Bulletin de l'Institut Français d'Archéologie Orientale, 73, p. 143-153, pl. XII-XIII.

Couyat, Montet 1912 : Jean Couyat, Pierre Montet, Les inscriptions hiéroglyphiques et hiératiques de Ouâdi Hammâmât (Mémoires publiés par les membres de l'IFAO, 34), Le Caire.

CT II : Adriaan De Buck, The Egyptian Coffin Texts, II, Chicago, 1938.

CT VII : Adriaan De Buck, The Egyptian Coffin Texts, VII, Chicago, 1961.

DAVIES 2003a: Vivian DAVIES, «Kush in Egypt: a new historical inscription », Sudan \& Nubia, 7, p. 52-54.

DAVIES 2003b : Vivian DAVIES, « Kouch en Égypte. Une nouvelle inscription historique à ElKab », Bulletin de la Société Française d'Égyptologie, 157, p. 38-44.

Desanges 1978 : Jehan Desanges, Recherches sur l'activité des Méditerranéens aux confins de l'Afrique (VIe siècle avant J.-C. - IVe siècle après J.-C.), Rome.

Diego EsPinel 2003 : Andrés Diego EsPinel, « Los contactos commerciales entre Egypto y Pount durante el Reino Medio (Dinastías XI-XIII) », Boletín de la Asociación Española de Egiptologia, 13, p. 67-108.

Diego Espinel 2011, Andrés Diego Espinel, Abriendo los caminos de Punt: contactos entre Egipto y el ámbito afroárabe durante la Edad del Bronce [ca. 3000 a.C.-1065 a.C.], Barcelone. 
Duhoux 2003 : Yves Duhoux, Des Minoens en Égypte? "Keftiou” et "les îles au milieu du Grand Vert" (Publications de l'Institut orientaliste de Louvain, 52), Louvain-la-Neuve.

ERICHSEN 1933 : Wolja ERICHSEN, Papyrus Harris I. Hieroglyphische Transkription (Bibliotheca Aegyptiaca, V), Bruxelles.

ERMAN 1882 : Adolf ERMAN, « Stelen aus Wâdi Gasus bei Qosêr », Zeitschrift für Ägyptische Sprache und Altertumskunde, 20, p. 203-204.

FABRE 2005 : David FABRE, Le destin maritime de l'Égypte ancienne, Londres.

Farout 1994 : Dominique Farout, «La carrière du whmw Ameny et l'organisation des expéditions au ouadi Hammamat au Moyen Empire », Bulletin de l'Institut Français d'Archéologie Orientale, 94, p. 143-172.

FAROUT 2006a: Dominique FAROUT, «Des expéditions en mer Rouge au début de la XII dynastie », Égypte, Afrique \& Orient, 41, p. 43-52.

Farout 2006b : Dominique Farout, « Men on the Red Sea under Senusret I », dans Essam EL-SaEed, El-Sayed Mahfouz, Abdel Monem Megahed (éd.), The Festschrift volume: A collection of studies presented to Professor Abdel Monem Abdel Haleem Sayed (...) On the Occasion of his $80^{\text {th }}$ Birthday, Alexandrie, p. 229-273 (aussi : Abgadiyat, 11, 2016, p. 2236).

Fattovich 1991 : Rodolfo Fattovich, « The problem of Punt in the light of recent field work in the eastern Sudan », dans Sylvia SchOSKE (éd.), Akten des vierten Internationalen Ägyptologen Kongresses München 1985, vol. IV, Hambourg, p. 257-272.

Fattovich 1996 : Rodolfo Fattovich, «Punt: the Archaeological Perspective », Beiträge zur Sudanforschung, 6, p. 15-29.

Fattovich 2012 : Rodolfo FatTovich, «Egypt's trade with Punt: new discoveries on the Red Sea Coast », British Museum Studies in Ancient Egypt and Sudan, 18, p. 1-59.

FAULKNER 1962 : Raymond O. FAULKNER, A Concise Dictionary of Middle Egyptian, Oxford.

Franke 1984 : Detlef Franke, Personendaten aus dem Mittleren Reich (Ägyptologische Abhandlungen, 41), Wiesbaden.

Franke 1991 : Detlef Franke, « The Career of Khnumhotep III of Beni Hasan and the Socalled "Decline of the Nomarchs" ", dans Stephen Quirke, Middle Kingdom Studies, New Malden, p. 51-67.

Gardiner, Peet, Černý 1952-1955 : A.H. Gardiner, T.E. Peet, J. ČernÝ, The Inscriptions of Sinai, Oxford.

GASSE 1988: Annie GASSE, "Amény. Un porte-parole sous le règne de Sésostris $\mathrm{I}^{\mathrm{er}}$ ", Bulletin de l'Institut Français d'Archéologie Orientale, 88, p. 83-93, pl. VI.

Gasse 2006 : Annie Gasse, "The Wadi Hammamat on the Road to Punt », dans Essam ELSaeed, El-Sayed Mahfouz, Abdel Monem Megahed (éd.), The Festschrift volume: A collection of studies presented to Professor Abdel Monem Abdel Haleem Sayed (...) On the Occasion of his 80 $0^{\text {th }}$ Birthday, Alexandrie, p. 293-312 (aussi : Abgadiyat, 11, 2016, p. 4450).

Goelet 1992 : Ogden Goelet, «W $3 \underline{d}$-wr and Lexicographical Method », dans Ulrich LufT (éd.), The Intellectual Heritage of Egypt: Studies presented to László Kákosy by Friends and Colleagues on the Occasion of his 60th Birthday (Studia Aegyptiaca, 14), Budapest, p. 205-214. 
GOLENISCHEFF 1887 : Vladimir GOLENISCHEFF, «Êpigrafičeskie rezul'taty poezdki v Uadi Hammamât », ZVO, II, p. 65-79, XVIII planches.

GoYON 1957 : Georges GoYOn, Nouvelles inscriptions rupestres du Wadi Hammâmât, Paris.

Grandet 1994a : Pierre Grandet, Le Papyrus Harris I, vol. I (Bibliothèque d'Étude, 109.1), Le Caire.

Grandet 1994b: Pierre Grandet, Le Papyrus Harris I, vol. II (Bibliothèque d'Étude, 109.2), Le Caire.

HanNig 2006 : Rainer HANNIG, Ägyptisches Wörterbuch, II. Mittleres Reich und Zweite Zwischenzeit, Mayence.

Hayes 1949 : William C. HAYes, « Career of the Great Steward Henenu under Nebhepetre“ Mentuhotpe », Journal of Egyptian Archaeology, 35, p. 43-49, pl. IV.

Heagren 2010 : Brett H. Heagren, The Art of War in Pharaonic Egypt: An Analysis of the Tactical, Logistic, and Operational Capabilities of the Egyptian Army (Dynasties XVII$X X)$, thèse de doctorat, Auckland.

Hense 2018 : Martin Hense, « The Great Temple of Berenike », dans J.-P. BrUN et alii (éd.), The Eastern Desert of Egypt during the Greco-Roman Period: Archaeological Reports, Paris (https://books.openedition.org/cdf/5244).

Hense, Kaper, Geerts 2015 : Martin Hense, Olaf E. KaPer, Roderick C.A. GEERTS, « A stela of Amenemhet IV from the main temple at Berenike », Bibliotheca Orientalis, 72, p. 585-601.

Hense, Sidebotham 2017 : Martin Hense, Steven Sidebotham, « A Middle Kingdom Text from a Graeco-Roman Red Sea Port », Egyptian Archaeology, 51, p. 41-43.

Herzog 1968 : Rolf Herzog, Punt (Abhandlungen des Deutschen Archäologischen Instituts Kairo. Ägyptologische Reihe, 6), Glückstadt.

KAPLONY 1969 : Peter KAPLONY, «Bermerkungen zu fünf Texten der Ersten Zwischenzeit und der späteren 11. Dynastie », Mitteilungen des Deutschen Archäologischen Instituts, Abteilung Kairo, 25, p. 22-32.

Kitchen 1993 : Kenneth A. Kitchen, «The Land of Punt», dans Thurstan Shaw, Paul Sinclair, Bassey Andah, Alex OKPOKO (éd.), The Archaeology of Africa: Food, Metals and Towns, Londres, New York, p. 587-608.

Kitchen 2004 : Kenneth A. Kitchen, «The Elusive land of Punt revisited », dans Paul Lunde, Alexandra Porter (éd.), Trade and Travel in the Red Sea Region: Proceedings of Red Sea Project 1, held in the British Museum, October 2002, Oxford, p. 25-31.

Lacaze, Camino 2008 : Ginette Lacaze, Luc Camino, Mémoires de Suez. François Bissey et René Chabot-Morisseau à la découverte du désert oriental d'Égypte (1945-1956), Pau.

LEITZ 2002 : Christian LEITZ, Lexikon der ägyptischen Götter und Götterbezeichnungen, III (Orientalia Lovaniensia Analecta, 112), Louvain.

LEPSIUS : Carl Richard LEPSIUS, Denkmaeler aus Aegypten und Aethiopien, Berlin.

LichtheIM 1975 : Miriam LichtheIM, Ancient Egyptian Literature, I. The Old and Middle Kingdoms, Berkeley.

LiCHTHEIM 1988: Miriam LichtHeIM, Ancient Egyptian Autobiographies chiefly of the Middle Kingdom (Orbis Biblicus et Orientalis, 84), Göttingen. 
LUCAS, HARRIS 1962 : Alfred LuCAS, Ancient Egyptian Materials and Industries, 4 éd. par James R. HARRIS, Londres.

MAHFOUZ 2006 : El-Sayed MAHFOUZ, « Les ostraca hiératiques du Ouadi Gaouasis », Égypte, Afrique \& Orient, 41, p. 31-34.

MAHFOUZ 2008a : El-Sayed MAHFOUZ, « Les ostraca hiératiques du Ouadi Gaouasis », Revue d'Égyptologie, 59, p. 267-334.

MAhFouZ 2008b : El-Sayed MAHFouZ, «Amenemhat III au Ouadi Gaouasis », Bulletin de l'Institut Français d'Archéologie Orientale, 108, p. 253-279.

MAHFOUZ 2008c : El-Sayed MAHFOUZ, «A-t-il existé une voie de communication entre le Ouadi Gaouasis et les sites miniers du Sud Sinaï ?», Abgadiyat, 3, p. 48-55.

MAhfouz 2010a : El-Sayed MAhfouz, «L'expédition de Sésostris III au pays de Pount », dans Włodzimierz GodLEWSKI, Adam ŁAJTAR (éd.), Between the Cataracts: proceedings of the 11th Conference for Nubian Studies, Warsaw University, 27 August-2 September 2006, Part 2, p. 431-438.

MAHFouz 2010b : El-Sayed Mahfouz, «Amenemhat IV au Ouadi Gaouasis », Bulletin de l'Institut Français d'Archéologie Orientale, 110, p. 165-173.

Mahfouz 2011a : El-Sayed Mahfouz, «The Maritime Expeditions of Wadi Gawasis in the Twelfth Dynasty », Abgadiyat, 6, p. 51-67.

MAhfouz 2011b: El-Sayed MAhfouz, «Osiris de Ouadj-Our : une nouvelle attestation provenant du ouadi Gaouasis au bord de la mer Rouge », Bulletin de la Société Française d'Égyptologie, 180, p. 7-14.

MAHFOUZ 2012 : El-Sayed MAHFOUZ, « New epigraphic material from Wadi Gawasis », dans Pierre Tallet, El-Sayed Mahfouz, The Red Sea in Pharaonic Times. Recent Discoveries along the Red Sea Coast. Proceedings of the Colloquium held in Cairo / Ayn Soukhna, 11th-12th January 2009 (Bibliothèque d'Étude, 155), Le Caire, p. 117-132.

Manzo 2010 : Andrea MAnzo, «Exotic Ceramic Materials from Mersa Gawasis, Red Sea, Egypt », dans Włodzimierz GodlewsKi, Adam LAJTAR (éd.), Between the Cataracts: proceedings of the 11th Conference for Nubian Studies, Warsaw University, 27 August-2 September 2006, Part 2, Varsovie, p. 439-453.

MANZO 2012a : Andrea MANZO, « Nubians and the Others on the Red Sea. An Update on the Exotic Ceramic Materials from the Middle Kingdom Harbour of Mersa/Wadi Gawasis, Red Sea, Egypt », dans Dionisius A. Agius, John P. CoOPER, Athena TrakadAs, Chiara ZAZZARO (éd.), Navigated spaces, connected places: proceedings of Red Sea Project V, held at the University of Exeter, 16-19 September 2010, Oxford, p. 47-58.

MANZO 2012b: Andrea MANZO, «From the sea to the deserts and back: new research in Eastern Sudan », British Museum Studies in Ancient Egypt and Sudan, 18, p. 75-106.

MANZO 2017 : Andrea MANZO, «Bỉw Pwnt in the archaeological record: preliminary results and perspective of research », dans Ilaria Micheli (éd.), Cultural and linguistic transition explored: proceedings of the ATrA closing workshop Trieste, May 25-26, 2016, Trieste, p. 87-108.

Manzo, Pirelli 2006 : Andrea Manzo, Rosanna Pirelli, «The sealings from Marsa Gawasis $(S 3 w)$ : preliminary considerations on the administration of the port », dans Essam EL-SaEed, El-Sayed Mahfouz, Abdel Monem Megahed (éd.), The Festschrift volume: A collection of studies presented to Professor Abdel Monem Abdel Haleem Sayed (...) On the 
Occasion of his $80^{\text {th }}$ Birthday, Alexandrie, p. 40-100 (aussi : Abgadiyat, 11, 2016, p. $92-$ 126).

Meeks 1982 : Dimitri Meeks, Année lexicographique. Égypte ancienne. Tome 3 (1979), Paris.

Meeks 2002 : Dimitri Meeks, «Coptos et les chemins du Pount», dans M.-F. Boussac, M. Gabolde, G. Galliano (éd.), Autour de Coptos. Actes du colloque organisé au Musée des Beaux-Arts de Lyon (17-18 mars 2000) (Topoi, Supplément 3), Paris, p. 267-335.

Meeks 2003 : Dimitri MeEks, «Locating Punt», dans David O'Connor, Stephen Quirke (éd.), Mysterious Lands, Londres, p. 53-80.

MiCHEL 2014 : Marianne MiCHEL, Les mathématiques de l'Égypte ancienne (Connaissance de l'Égypte ancienne, 12), Bruxelles, 2014.

Montet 1961 : Pierre Montet, Géographie de l'Égypte ancienne, vol. II, Paris.

MumFord 2006 : Gregory MumFord, « Tell Ras Budran (Site 345): Defining Egypt's Eastern Frontier and Mining Operations in South Sinai during the Late Old Kingdom (Early EB IV/MB 1) », Bulletin of the American Schools of Oriental Research, 342, p. 13-67.

MumFord 2012 : Gregory MuMFord, « Ras Budran and the Old Kingdom trade in Red Sea shells and other exotica », British Museum Studies in Ancient Egypt and Sudan, 18, p. 107145.

Murray 1925 : George W. Murray, « The Roman Roads and Stations in the Eastern Desert of Egypt », Journal of Egyptian Archaeology, 11, p. 138-150.

NibBI 1976 : Alessandra NiBBI, « Remarks on the Two Stelae from the Wadi Gasus », Journal of Egyptian Archaeology, 62, p. 45-56.

NiBBi 1981 : Alessandra NiBBI, «Some remarks on the two monuments from Mersa Gawasis », Annales du Service des Antiquités de l'Égypte, 64, p. 69-74.

OBSOMER 1995 : Claude OBSOMER, Sésostris $I^{e r}$. Étude chronologique et historique du règne (Connaissance de l'Égypte ancienne, 5), Bruxelles.

OBSOMER 1999 : Claude OBSOMER, « Sinouhé l'Égyptien et les raisons de son exil », dans Le Muséon, 112, p. 207-271.

OBSOMER 2007a: Claude OBSOMER, «Les expéditions d'Herkhouf ( $\mathrm{VI}^{\mathrm{e}}$ dynastie) et la localisation de Iam », dans Marie-Cécile BrUwIER (éd.), Pharaons Noirs. Sur la Piste des Quarante Jours, Mariemont, p. 39-52.

OBSOMER 2007b : Claude OBSOMER, «L'empire nubien des Sésostris : Ouaouat et Kouch sous la XII ${ }^{\mathrm{e}}$ dynastie », dans Marie-Cécile BrUwIER (éd.), Pharaons Noirs. Sur la Piste des Quarante Jours, Mariemont, p. 53-75.

OBSOMER 2012 : Claude OBSOMER, Ramsès II (Les grands pharaons), Paris.

OBSOMER 2016 : Claude OBSOMER, « La bataille de Qadech de Ramsès II. Les n'arin, sekou tepy et questions d'itinéraires ", dans Christina KARLSHAUSEn, Claude OBSOMER, De la Nubie à Qadech. La guerre dans l'Égypte ancienne (Connaissance de l'Égypte ancienne, 17), Bruxelles, p. 81-170.

OBSOMER à paraître : Claude OBSOMER, « Se déplacer sur le cours nubien du Nil à l'époque des Sésostris (XII ${ }^{\mathrm{e}}$ dynastie) », à paraître dans les actes du Colloque « Le roi et le fleuve », Paris, 16-17 décembre 2015.

Petrie 1889 : William M. Flinders Petrie, Hawara, Biahmu, and Arsinoe, Londres. 
Philip-StÉPhAn 2008: Alexandra Philip-StÉPHAn, Dire le droit en Égypte pharaonique (Connaissance de l'Égypte ancienne, 9), Bruxelles.

PiRelli 2007 : Rosanna Pirelli, «Two New Stelae from Mersa Gawasis », Revue d'Égyptologie, 58, p. 87-109.

Pirelli 2010a : Rosanna PiRelli, «Epigraphic documents from Mersa Gawasis: a Reassessment », dans Francesco Raffaele, Massimiliano NuZzolo, Ilaria InCORdino (éd.), Recent Discoveries and latest Researches in Egyptology. Proceedings of the First Neapolitan Congress of Egyptology, June 18th-20th 2008, Wiesbaden, p. 237-244.

Pirelli 2010b: Rosanna Pirelli, «Le stele del Medio Regno egiziano e il cosidetto "silhouette style" », dans Franco MAzzeI, Patrizia CARIOTI (éd.), Oriente, Occidente e dintorni... Scritti in onore di Adolfo Tamburello, IV, Naples, p. 1967-1985.

Pomey 2011 : Patrice Pomey, « Les bateaux d'Ayn Soukhna. Les plus vieux vestiges de navires de mer actuellement connus », Égypte, Afrique \& Orient, 64, p. 3-12.

Pomey 2012 : Patrice PomeY, «Ship Remains at Ayn Soukhna », dans Pierre TAllet, ElSayed Mahfouz, The Red Sea in Pharaonic Times. Recent Discoveries along the Red Sea Coast. Proceedings of the Colloquium held in Cairo / Ayn Soukhna, 11th-12th January 2009 (Bibliothèque d'Étude, 155), Le Caire, p. 35-52.

Rougé 1988 : Jean RougÉ, « La navigation en mer Érythrée dans l'Antiquité », dans L'Arabie et ses mers bordières, I. Itinéraires et voisinages. Séminaire de recherche 1985-1986 (Travaux de la Maison de l'Orient, 16), Lyon, p. 59-74.

SAlles 1998 : J.-F. SALleS, La mer Rouge, du VI siècle avant J.-C. au milieu du premier siècle de notre ère, dans Dominique VAlbelle, Charles Bonnet, Le Sinaï durant l'antiquité et le Moyen-Âge, Paris, p. 93-101.

SAYED 1977 : Abdel Monem A.H. SAYED, « Discovery of the site of the 12th Dynasty port at Wadi Gawasis on the Red Sea shore (preliminary report on the excavations of the Faculty of Arts, University of Alexandria, in the Eastern Desert of Egypt - March 1976) », Revue d'Égyptologie, 29, p. 138-178.

SAYed 1978 : Abdel Monem A.H. SAYED, «The Recently Discovered Port on the Red Sea Shore », Journal of Egyptian Archaeology, 64, p. 69-71.

SAYED 1979 : Abdel Monem A.H. SAYED, « Discovery of the site of the 12th Dynasty port at Wâdi Gawâsîs on the Red Sea shore », dans Walter F. REINEKE (éd.), Acts: First International Congress of Egyptology, Cairo October 2-10, 1976, Berlin, p. 569-577.

SAYED 1980 : Abdel Monem A.H. SAYED, «Observations on recent discoveries at Wâdî Gawâsîs », Journal of Egyptian Archaeology, 66, p. 154-157.

SAYed 1983 : Abdel Monem A.H. SAYed, « New Light on the Recently Discovered Port on the Red Sea Shore », Chronique d'Égypte, 58, p. 23-37.

SAYed 1993 : Abdel Monem A.H. SAYED, The Red Sea and its Hinterland in Antiquity, Alexandrie (en arabe).

SAYed 2003 : Abdel Monem A.H. SAYed, «The Land of Punt: Problems of the Archaeology of the Red Sea and the Southeastern Delta », dans Zahi HAWASS, Lyla Pinch BROCK (éd.), Egyptology at the dawn of the twenty-first century: proceedings of the Eighth International Congress of Egyptologists, Cairo, 2000, vol. I, Le Caire, p. 432-439. 
SAYED 2006 : Abdel Monem A.H. SAYED, « On the Non-Existence of the Nile-Red Sea Canal all over the Pharaonic Time, and its Existence from the Persian Period Onwards », dans Hedvig GYÖRY (éd.), Aegyptus et Pannonia II: Acta Symposii anno 2004, Budapest, p. 207-226.

SCHENKEL 1965 : Wolgang SCHENKel, Memphis, Herakleopolis, Theben (Ägyptologische Abhandlungen, 12), Wiesbaden.

Schiff Giorgini 2003 : Michela Schiff Giongini, Soleb, IV. Le temple. Plans et photographies, Le Caire.

SERVAJEAn 2016 : Frédéric ServaJeAn, « Les dimensions des navires d'Hatchepsout et autres remarques sur la navigation en mer Rouge », Égypte Nilotique et Méditerranéenne, 9, p. 179-226.

Servajean 2017 : Frédéric Servajean, «Les radeaux de Pount », Égypte Nilotique et Méditerranéenne, 10, p. 103-115.

SERVAJEAn 2018 : Frédéric SERVAJEAn, «Les citernes de la mer Rouge et le voyage au pays de Pount », Égypte Nilotique et Méditerranéenne, 11, p. 135-170.

SEYFRIED 1981 : Karl-Joachim SEYFRIED, Beiträge zu den Expeditionen des Mittleren Reiches in die Ost-Wüste (Hildesheimer ägyptologische Beiträge, 15), Hildesheim.

Somaglino, Tallet 2011 : Claire Somaglino, Pierre TAllet, « Une mystérieuse route sudorientale sous le règne de Ramsès III », Bulletin de l'Institut Français d'Archéologie Orientale, 111, p. 361-369.

Somaglino, Tallet 2013 : Claire Somaglino, Pierre Tallet, «A road to the Arabian Peninsula in the reign of Ramesses III », dans Frank FÖRSTER, Heiko RIEMER (éd.), Desert Road Archaeology in Ancient Egypt and beyond, Cologne, p. 511-518.

TAllet 2002 : Pierre TAllet, « Notes sur le ouadi Maghara et sa région au Moyen Empire », Bulletin de l'Institut Français d'Archéologie Orientale, 102, p. 371-387.

Tallet 2005 : Pierre TAllet, Sésostris III et la fin de la XII dynastie (Les grands pharaons), Paris.

TAllet 2006 : Pierre TAllet, «Six campagnes archéologiques sur le site d'Ayn Soukhna, golfe de Suez », Bulletin de la Société Française d'Égyptologie, 165, p. 10-31.

TALlET 2009 : Pierre TALlET, « Les Égyptiens et le littoral de la Mer Rouge à l'époque pharaonique ", Comptes rendus des séances de l'Académie des Inscriptions \& Belles-Lettres, 153.2, p. 687-719.

TAllet 2010 : Pierre TAllet, «Prendre la mer à d'Ayn Soukhna au temps du roi Isési », Bulletin de la Société Française d'Égyptologie, 177-178, p. 18-22.

TAllet 2012a: Pierre TAllet, La zone minière pharaonique du Sud-Sinaï - I. Catalogue complémentaire des inscriptions du Sinaï (Mémoires publiés par les membres de l'IFAO, 130), Le Caire.

TAllet 2012b : Pierre TAllet, « New Inscriptions from Ayn Soukhna 2002-2009», dans Pierre Tallet, El-Sayed Mahfouz, The Red Sea in Pharaonic Times. Recent Discoveries along the Red Sea Coast. Proceedings of the Colloquium held in Cairo / Ayn Soukhna, 11th-12th January 2009 (Bibliothèque d'Étude, 155), Le Caire, p. 105-116.

Tallet 2012c : Pierre Tallet, «A New Pharaonic Harbour in Ayn Sokhna (Gulf of Suez)», dans Dionisius A. Agius, John P. Cooper, Athena Trakadas, Chiara Zazzaro (éd.), 
Navigated spaces, connected places: proceedings of Red Sea Project $V$, held at the University of Exeter, 16-19 September 2010, Oxford, p. 33-38.

TAllet 2013: Pierre TAllet, «Les papyrus de la Mer Rouge (Ouadi el-Jarf, Golfe de Suez) », Comptes rendus des séances de l'Académie des Inscriptions \& Belles-Lettres, 157.2, p. 1015-1024.

TAllet 2014 : Pierre TAllet, « Des papyrus du temps de Chéops au ouadi el-Jarf (golfe du Suez) », Bulletin de la Société Française d'Égyptologie, 188, p. 25-49.

TALLET 2015 : Pierre TALLET, «Les “ports intermittents" de la mer Rouge à l'époque pharaonique : caractéristiques et chronologie », dans Bruno ARGÉMI, Pierre TALLET (éd.), Entre Nil et mers. La navigation en Égypte ancienne, Nehet 3, p. 31-72.

Tallet 2017a: Pierre TAllet, Les papyrus de la mer Rouge, 1. Le "journal de Merer" (Papyrus Jarf A et B) (Mémoires publiés par les membres de l'IFAO, 136), Le Caire.

Tallet 2017b : Pierre Tallet, « Des serpents et des lions : la flotte stupéfiante de Chéops en mer Rouge ", dans Nathalie Favry et alii, Du Sinaï au Soudan. Itinéraires d'une égyptologue (Mélanges offerts à Dominique Valbelle), Paris, p. 243-253.

TAllet, Marouard, 2014 : Pierre TAllet, Grégory Marouard, « The Harbor of Khufu on the Red Sea Coast at Wadi al-Jarf, Egypt », Near Eastern Archaeology, 77.1, p. 4-14.

TAllet, Marouard, 2016 : Pierre TAllet, Grégory Marouard, « The Harbor Facilities of King Khufu on the Red Sea Shore: The Wadi al-Jarf/Tell Ras Budran System », Journal of the American Research Center in Egypt, 52, p. 135-177.

Tallet, Marouard, Laisney 2012 : Pierre Tallet, Grégory Marouard, Damien Laisney, « Un port de la IV dynastie au Ouadi al-Jarf (mer Rouge) », Bulletin de l'Institut Français d'Archéologie Orientale, 112, p. 399-446.

TATERKA 2018 : Filip TATERKA, Les expéditions au pays de Pount sous la XVIII dynastie égyptienne. Essai de compréhension du rôle idéologique des expéditions " commerciales", thèse de doctorat inédite, Poznan et Paris.

ThIERs 2007 : Christophe ThIERs, Ptolémée Philadelphe et les prêtres d'Atoum de Tjékou. Nouvelle édition commentée de la « Stèle de Pithom » (CGG 22183), Montpellier.

Urk. I : Kurt SETHE, Urkunden des Alten Reiches (Urkunden des ägyptischen Altertums, I), Berlin, 1932-1933.

Urk. IV : Kurt Sethe, Wolfgang Helck, Urkunden der 18. Dynastie (Urkunden des ägyptischen Altertums, IV), Leipzig, Berlin, 1906-1961.

Urk. VII : Kurt SeTHE, Historisch-biographische Urkunden des Mittleren Reiches (Urkunden des ägyptischen Altertums, VII), Berlin, 1935.

Valbelle, Bonnet 1996 : Dominique Valbelle, Charles Bonnet, Le sanctuaire d'Hathor maîtresse de la turquoise, Paris.

VAndersleyen 1988 : Claude VAndersleyen, « Pount sur le Nil », Discussions in Egypto$\log y, 12$, p. $75-80$.

VANDERSLEYEN 1989 : Claude VANDERSLEYEN, «Les inscriptions 114 et 1 du Ouadi Hammamât (11 ${ }^{\mathrm{e}}$ dynastie) », Chronique d'Égypte, 64, p. 148-158.

VANDERSLEYEN 1996 : Claude VANDERSLEYEN, «Les monuments de l'Ouadi Gaouasis et la possibilité d'aller au pays de Pount par la Mer Rouge », Revue d'Égyptologie, 47, p. 107-115. 
VANDERSLEyen 1999 : Claude VANDERSLEYen, Ouadj our $W^{3} \underline{d}$ wr : un autre aspect de la vallée du Nil (Connaissance de l'Égypte ancienne, 7), Bruxelles.

Veldmeijer, ZazZaro 2008 : André J. Veldmeijer, Chiara ZazZaro, « The 'Rope Cave' at Mersa/Wadi Gawasis », Journal of the American Research Center in Egypt, 44, p. 9-39.

WALLACE-JONES 2018 : Sally WALLACE-JONES, Egyptian and imported pottery from the Red Sea port of Mersa Gawsis, Egypt (Archaeopress Egyptology, 20), Oxford.

WARD, ZAZZARo 2010 : Cheryl WARD, Chiara ZAZZARo, « Evidence for Pharaonic Seagoing Ships at Mersa/Wadi Gawasis, Egypt », International Journal of Nautical Archaeology, 39.1, p. 27-43.

Yoyotte 1952 : Jean Yoyotte, «Un corps de police de l'Égypte pharaonique », Revue d'Égyptologie, 9, p. 139-151.

ZAZZARo 2011 : Chiara ZAZZARo, «Les ancres de Mersa Gawasis », Égypte, Afrique \& Orient, 64, p. 13-20.

Zazzaro, Calcagno 2012 : Chiara Zazzaro, Claire Calcagno, « Ship Components from Mersa Gawasis: Recent Finds and their Archaeological Context », dans Pierre TALLET, ElSayed Mahfouz, The Red Sea in Pharaonic Times. Recent Discoveries along the Red Sea Coast. Proceedings of the Colloquium held in Cairo / Ayn Soukhna, 11th-12th January 2009 (Bibliothèque d'Étude, 155), Le Caire, p. 65-85.

ZazZaro, ABd el-Maguib 2012 : Chiara ZazZaro, Mohammed Abd El-Maguib, « Ancient Egyptian Stone Anchors from Mersa Gawasis », dans Pierre TAllet, El-Sayed MAHFOUZ, The Red Sea in Pharaonic Times. Recent Discoveries along the Red Sea Coast. Proceedings of the Colloquium held in Cairo / Ayn Soukhna, 11th-12th January 2009 (Bibliothèque d'Étude, 155), Le Caire, p. 87-103.

ZiBeLIUS 1972 : Karola ZIBELIUS, Afrikanische Orts- und Völkernamen in hieroglyphischen und hieratischen Texten (Beihefte zum Tübinger Atlas des Vorderen Orients, Reihe B. Geisteswissenschaften, 1), Wiesbaden. 


\section{ILLUSTRATIONS}

\section{Cartes et sites}

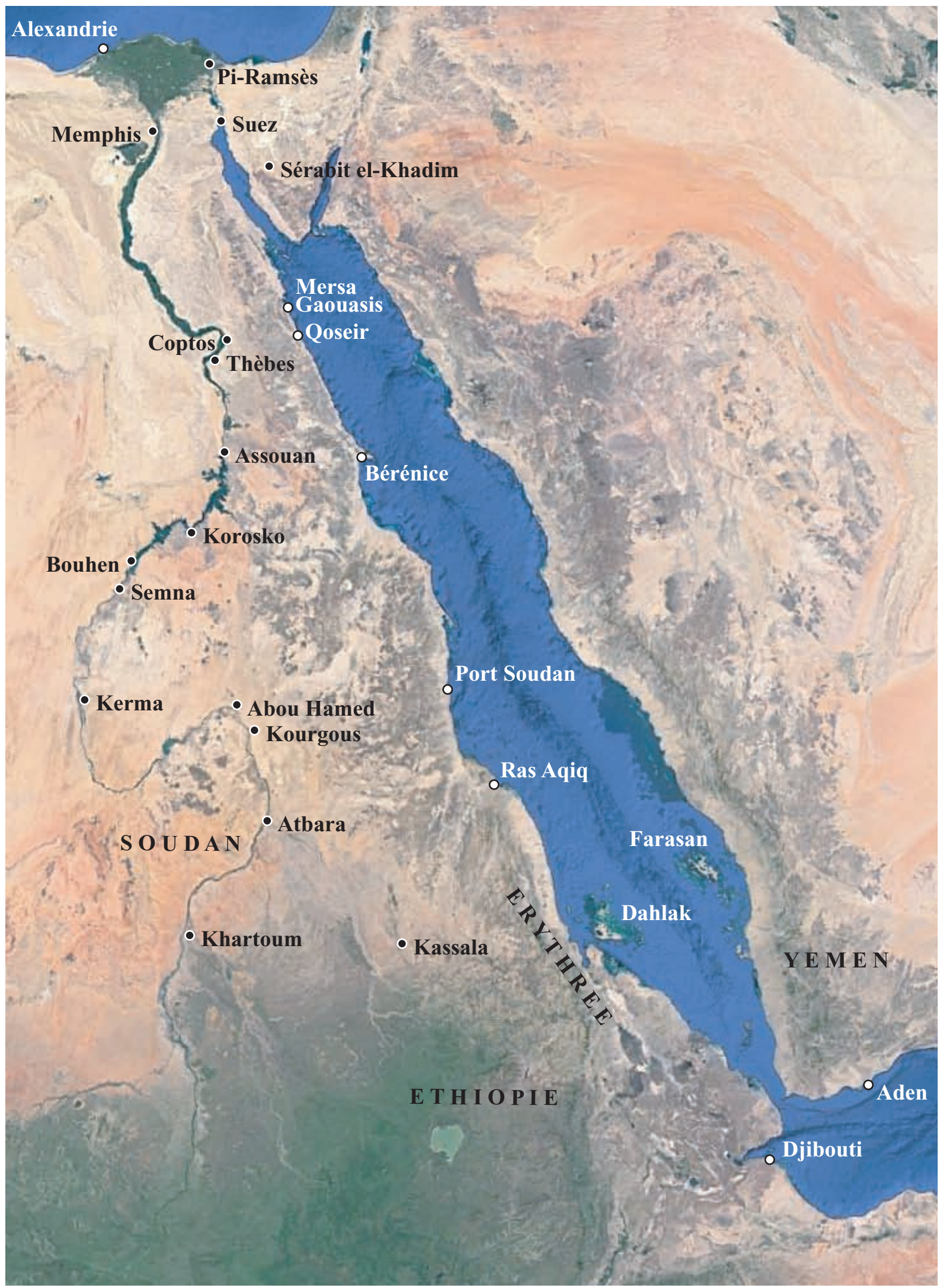

La mer Rouge et les territoires circonvoisins 


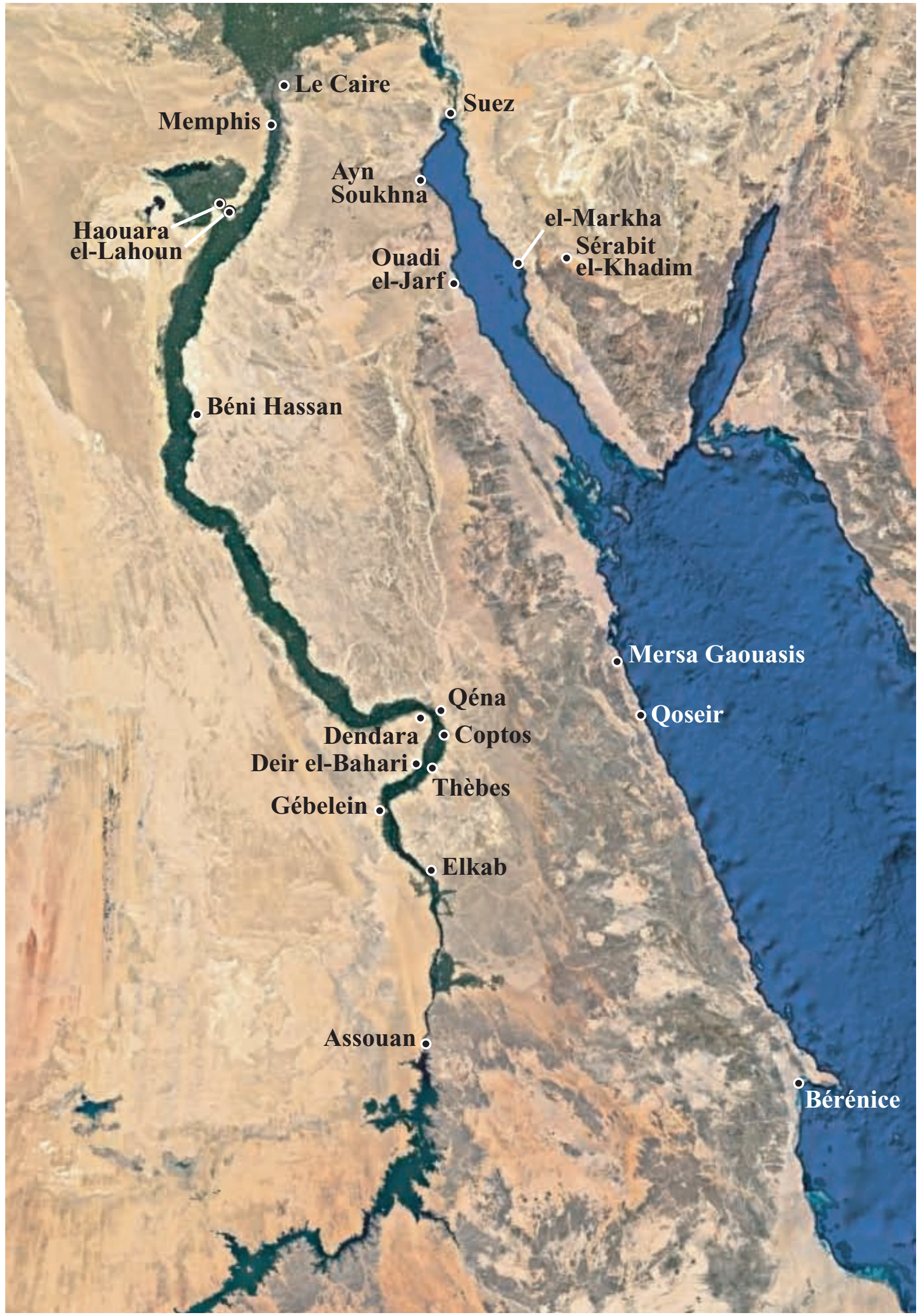

L'Égypte et les ports de la mer Rouge 


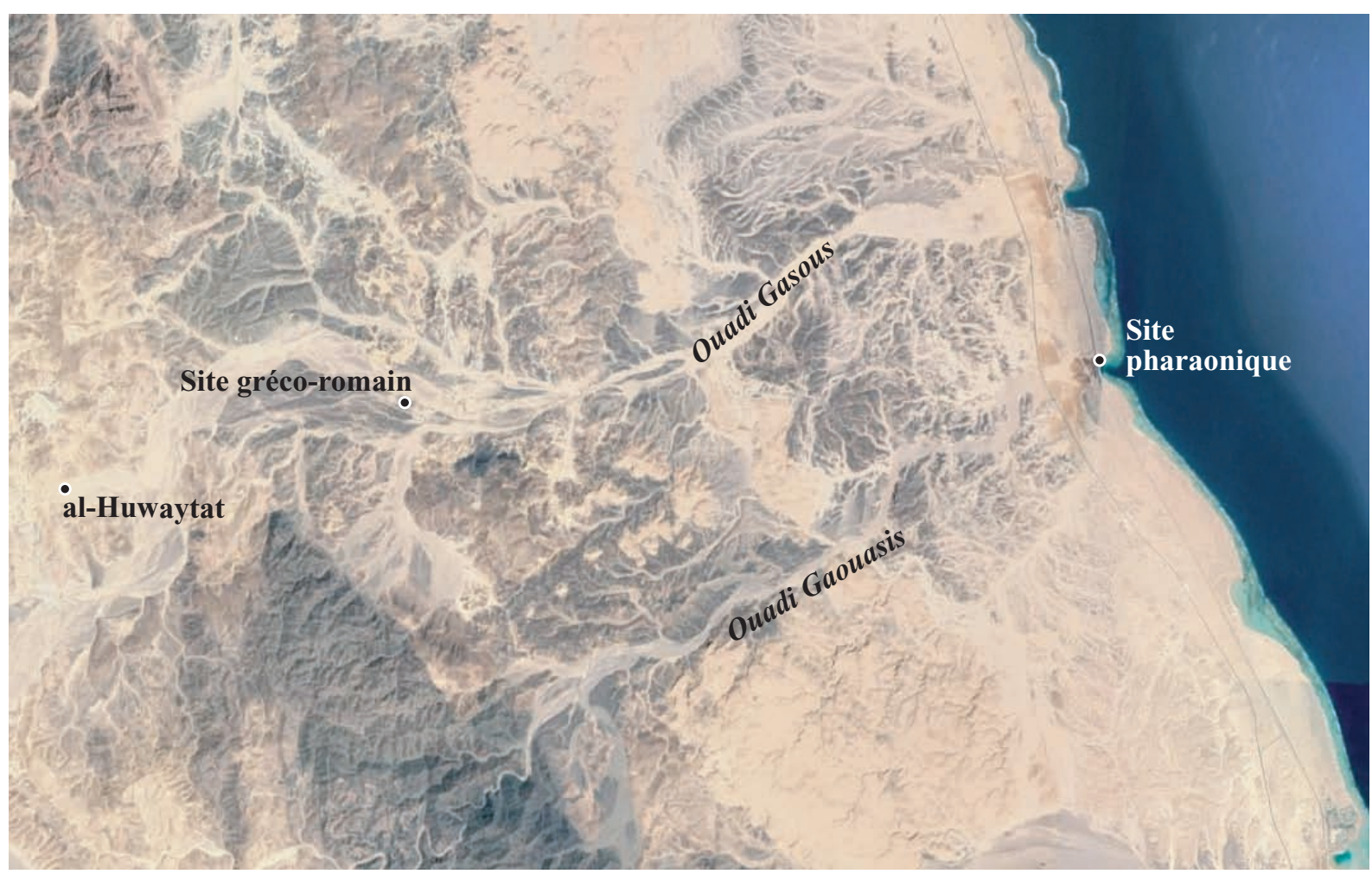

Les Ouadi Gasous et Ouadi Gaouasis

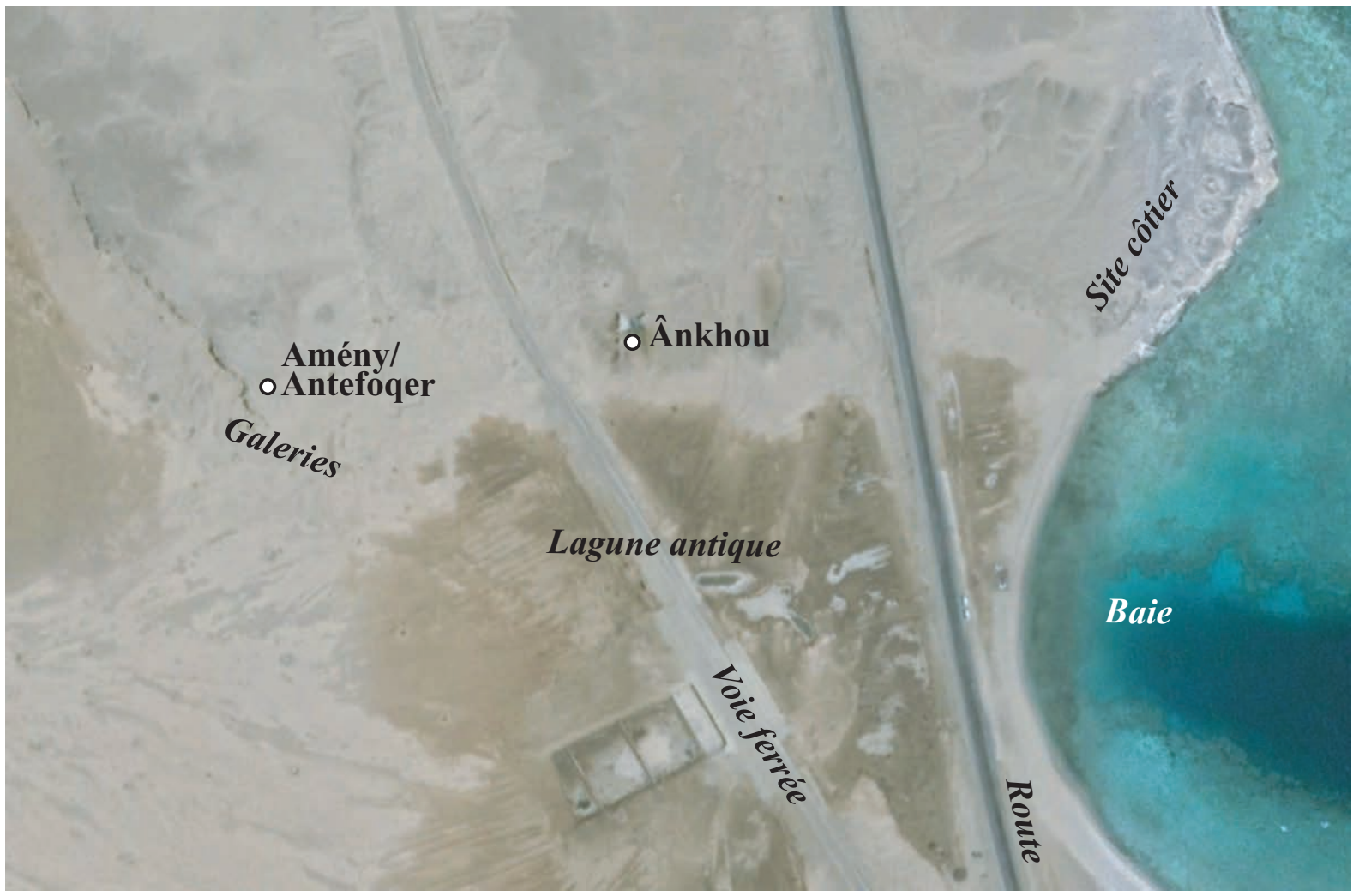

Le site pharaonique de Ouadi / Mersa Gaouasis 


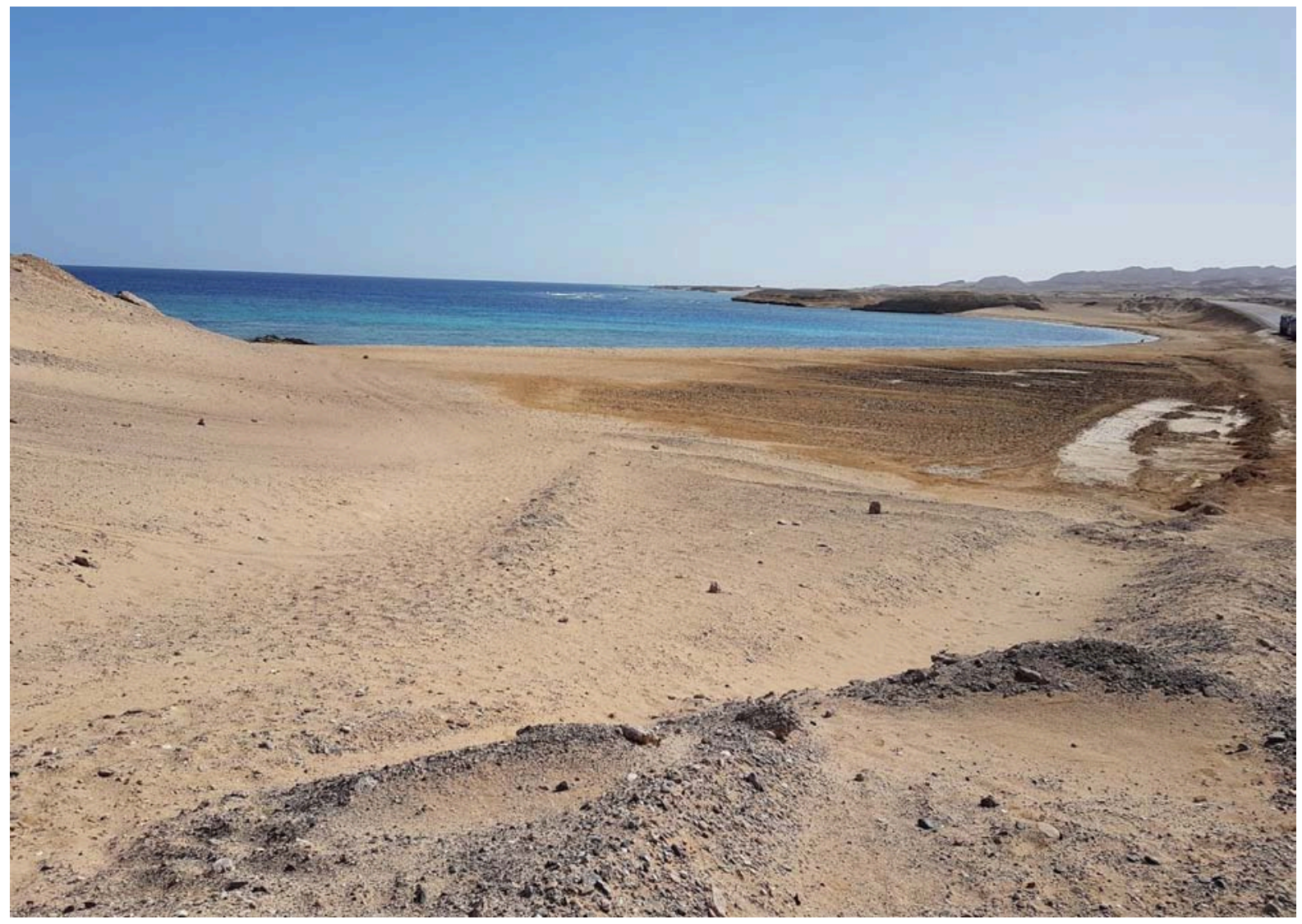

La baie de Mersa Gaouasis (photographie de Romy Kirsch, 27 février 2019)

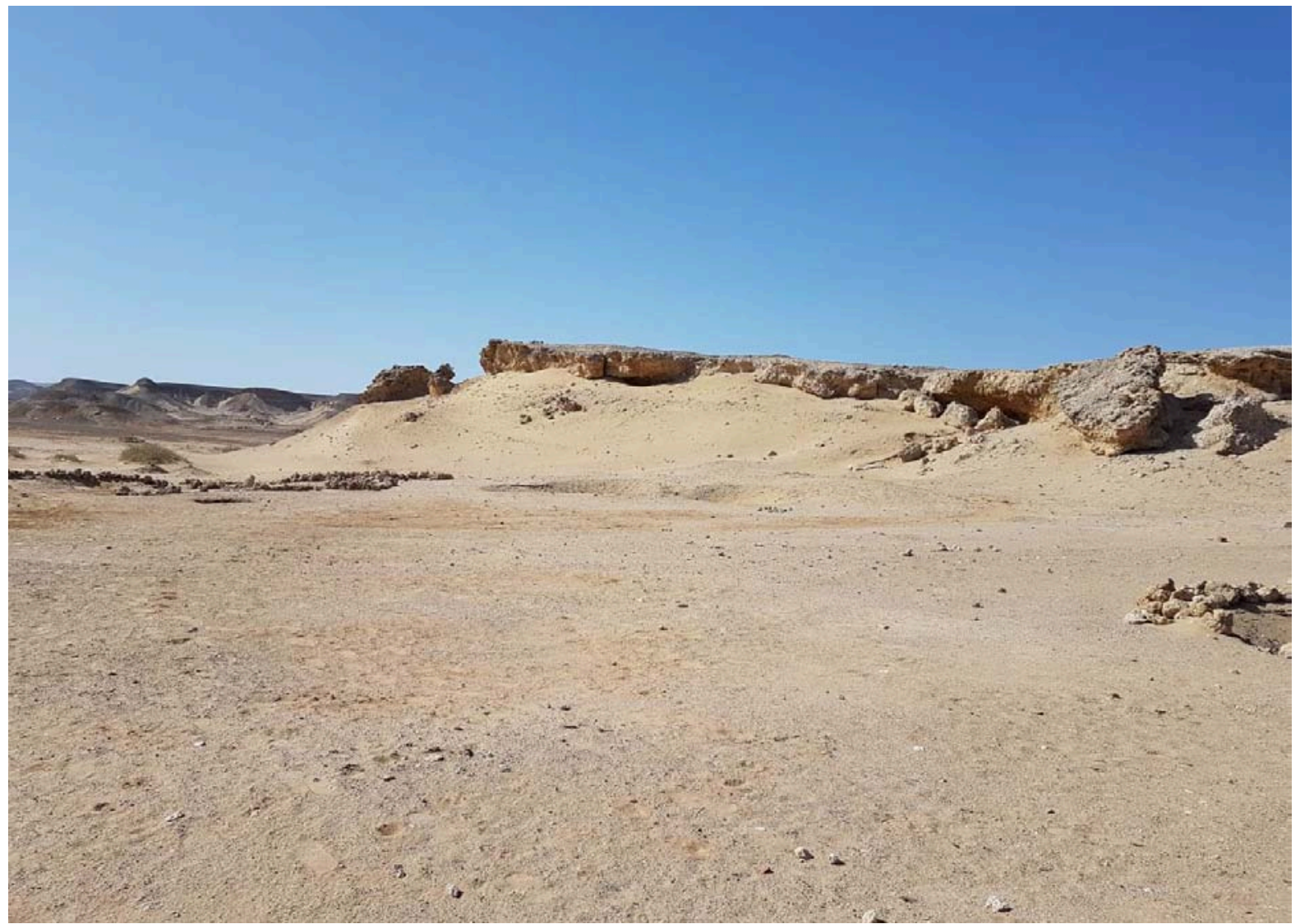

Le plateau surmontant les galeries (photographie de Romy Kirsch, 27 février 2019) 


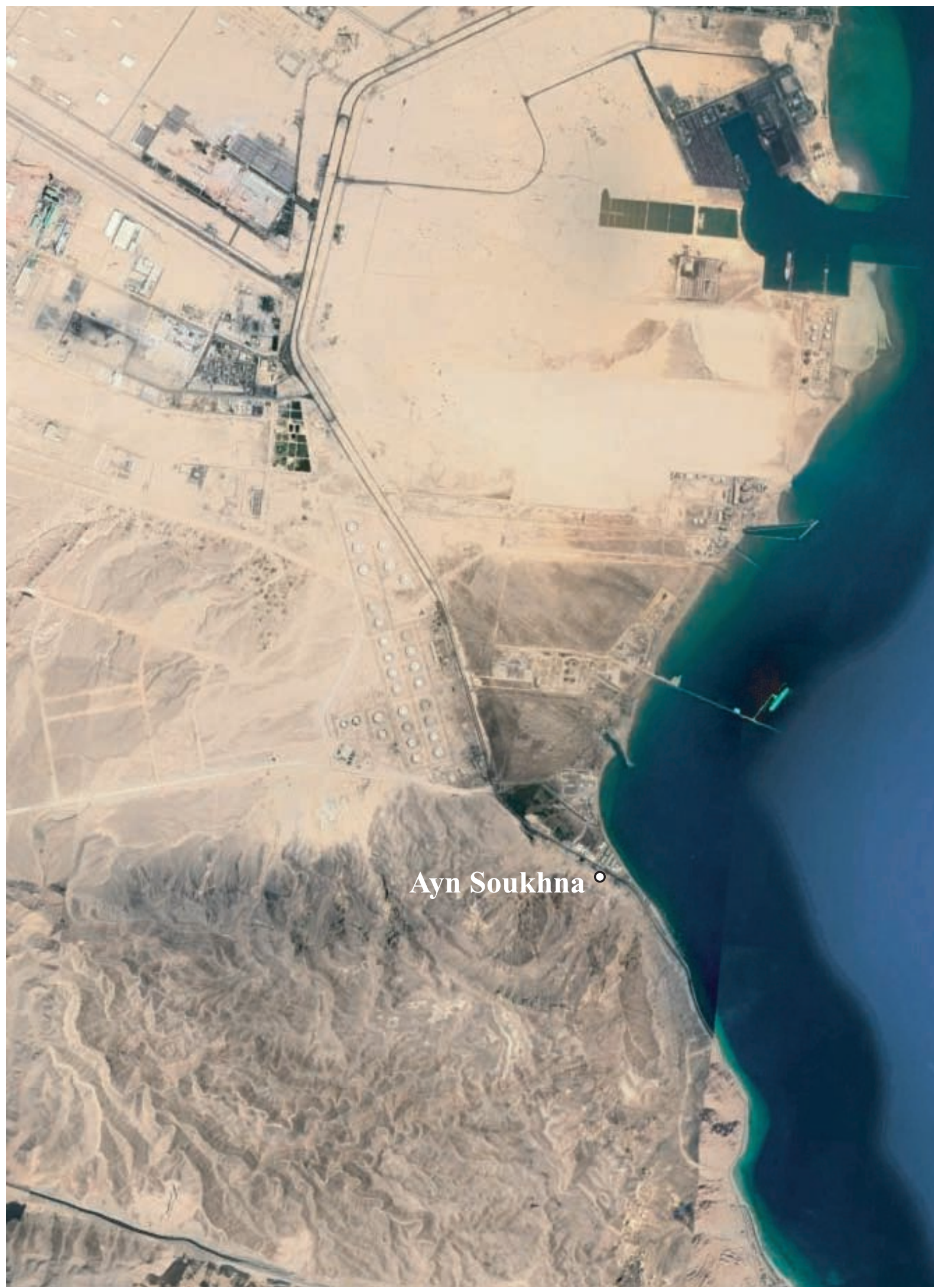

Le site pharaonique d'Ayn Soukhna 


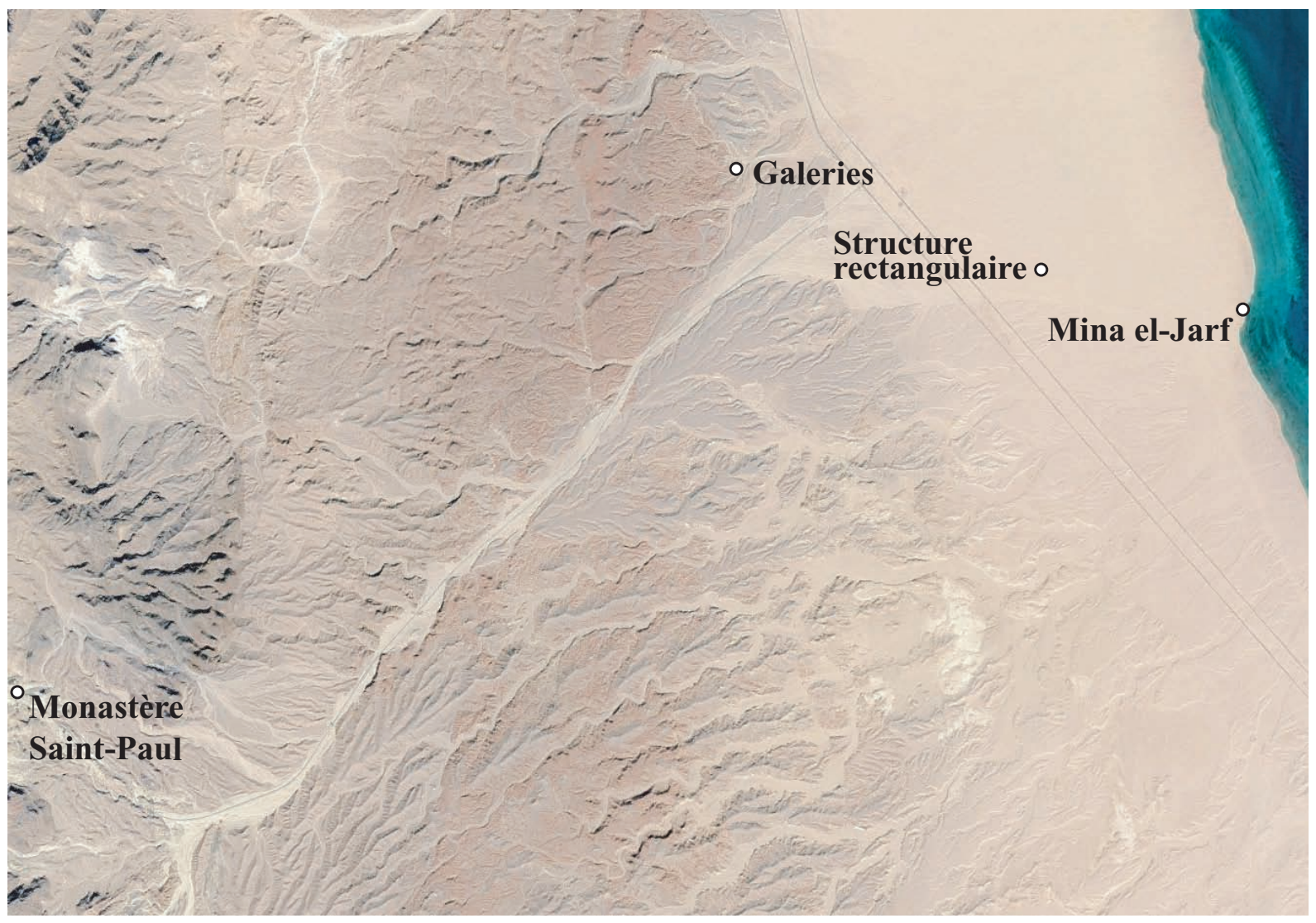

Les sites pharaoniques du Ouadi el-Jarf

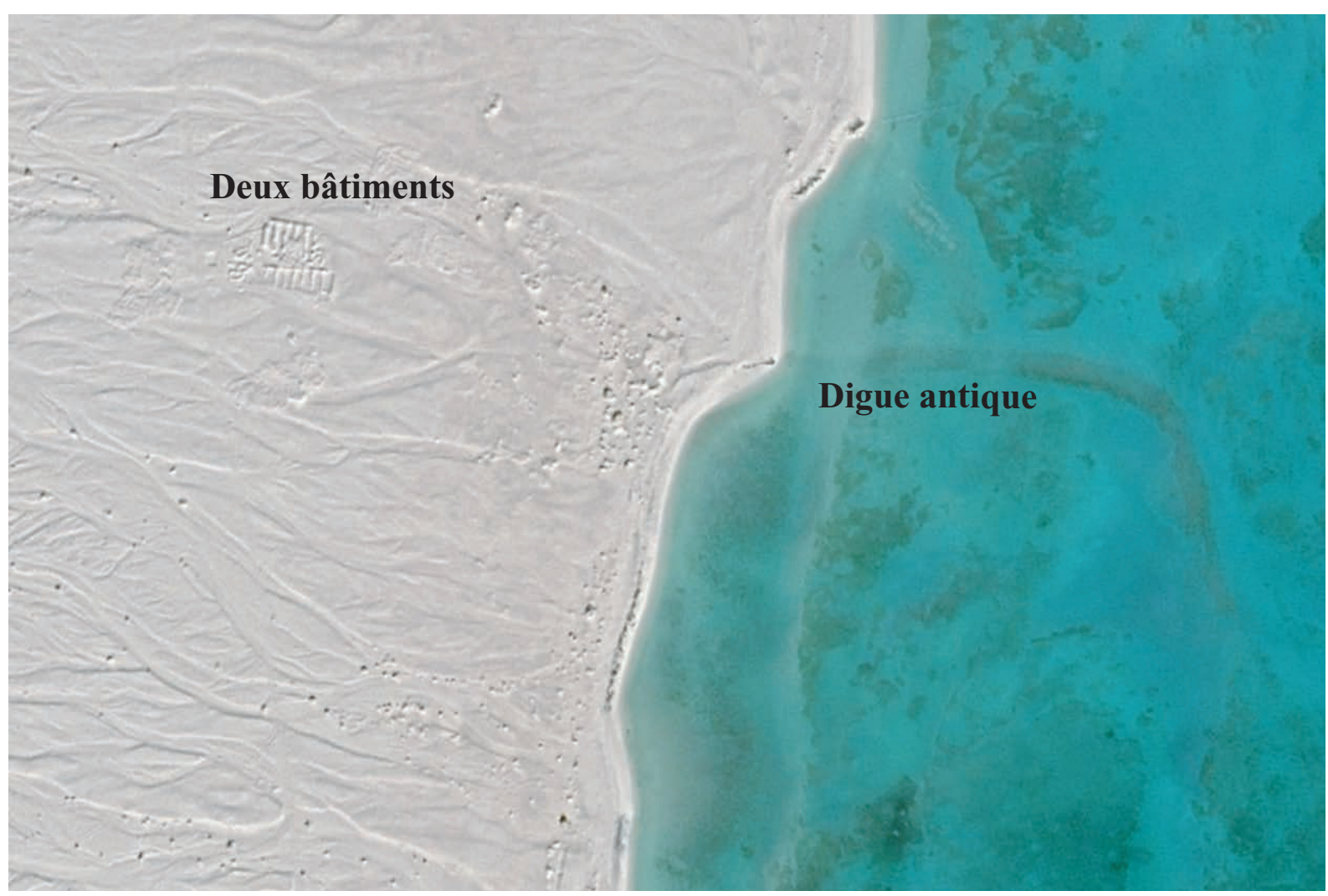

Les vestiges de Mina el-Jarf 


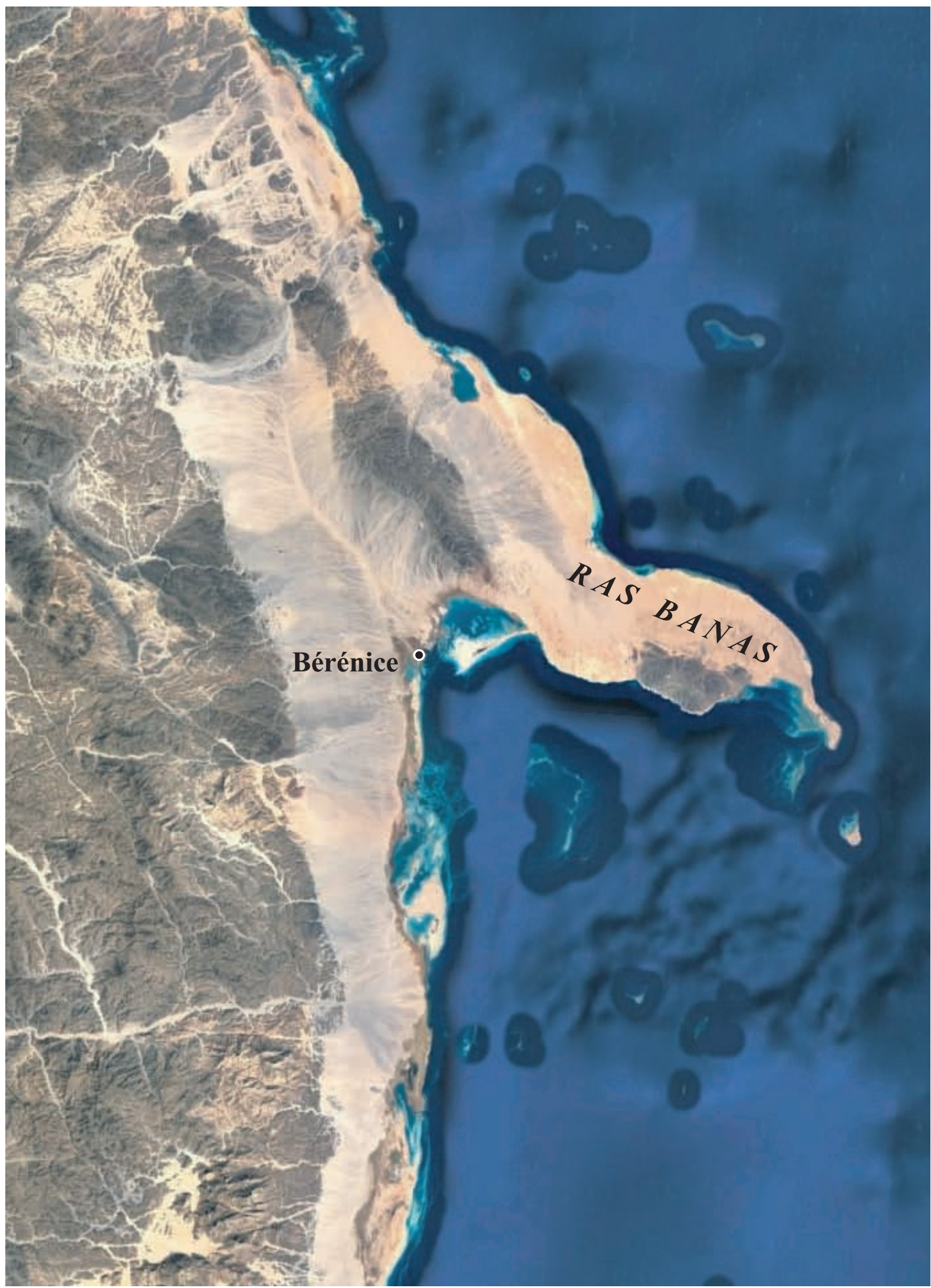

Le Ras Banas et le site de Bérénice 


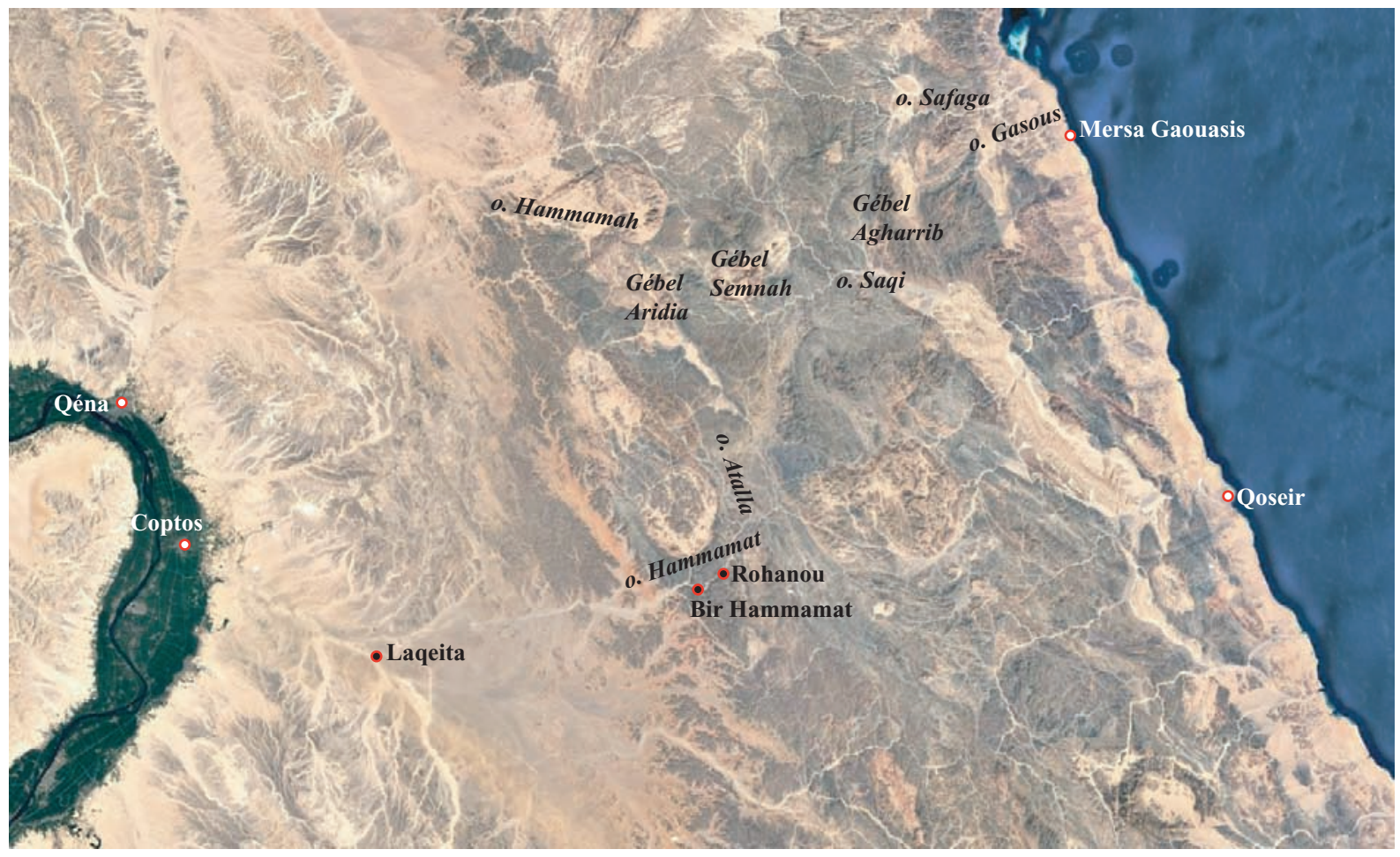

Le désert oriental, de Coptos à Mersa Gaouasis

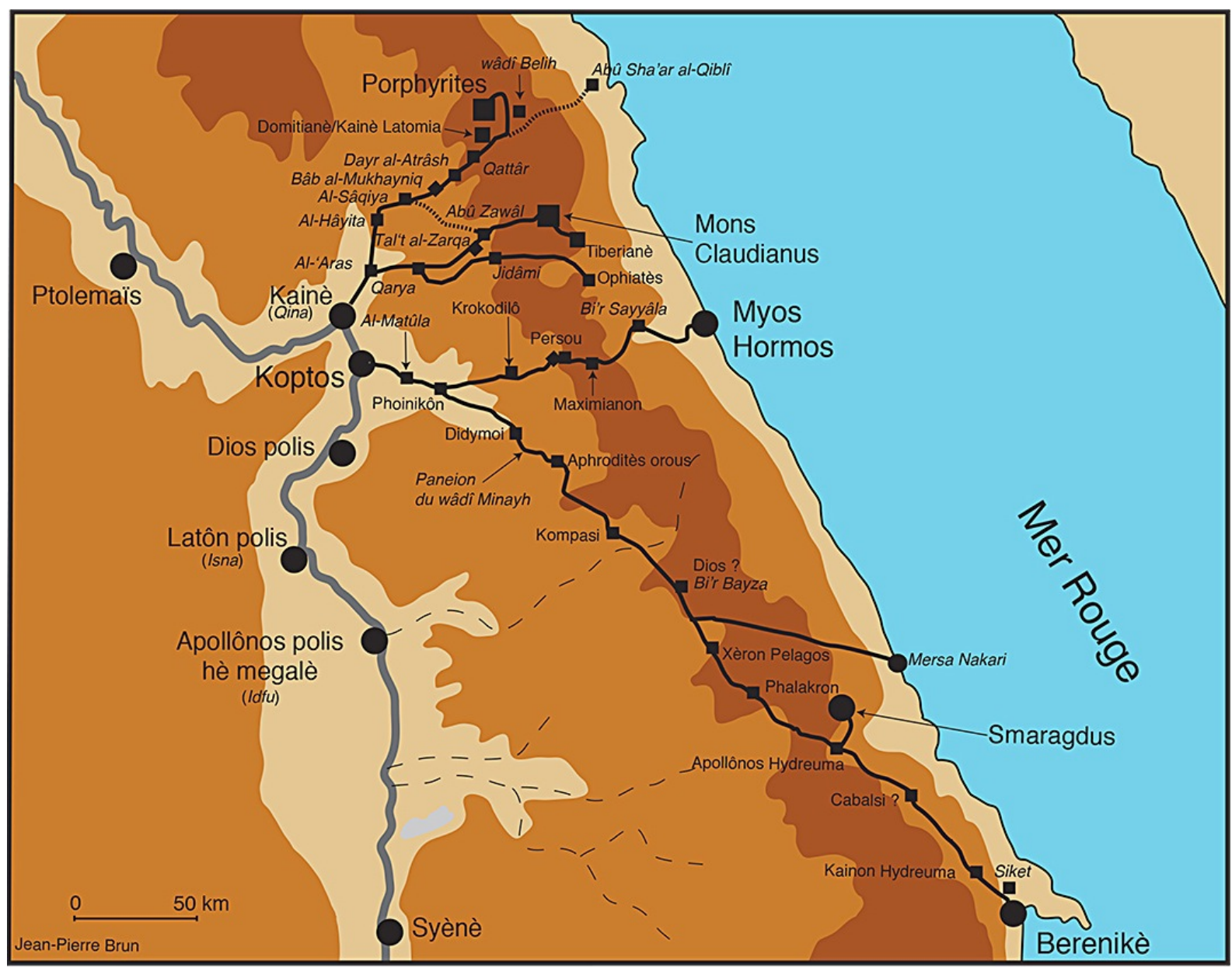

Les routes du désert oriental à la fin du $\mathrm{I}^{\mathrm{er}}$ siècle après J.-C. (carte de Jean-Pierre Brun, https://books.openedition.org/cdf/5239, fig. 11) 


\section{Textes du Moyen Empire}

\subsection{Au Ouadi Gasous}

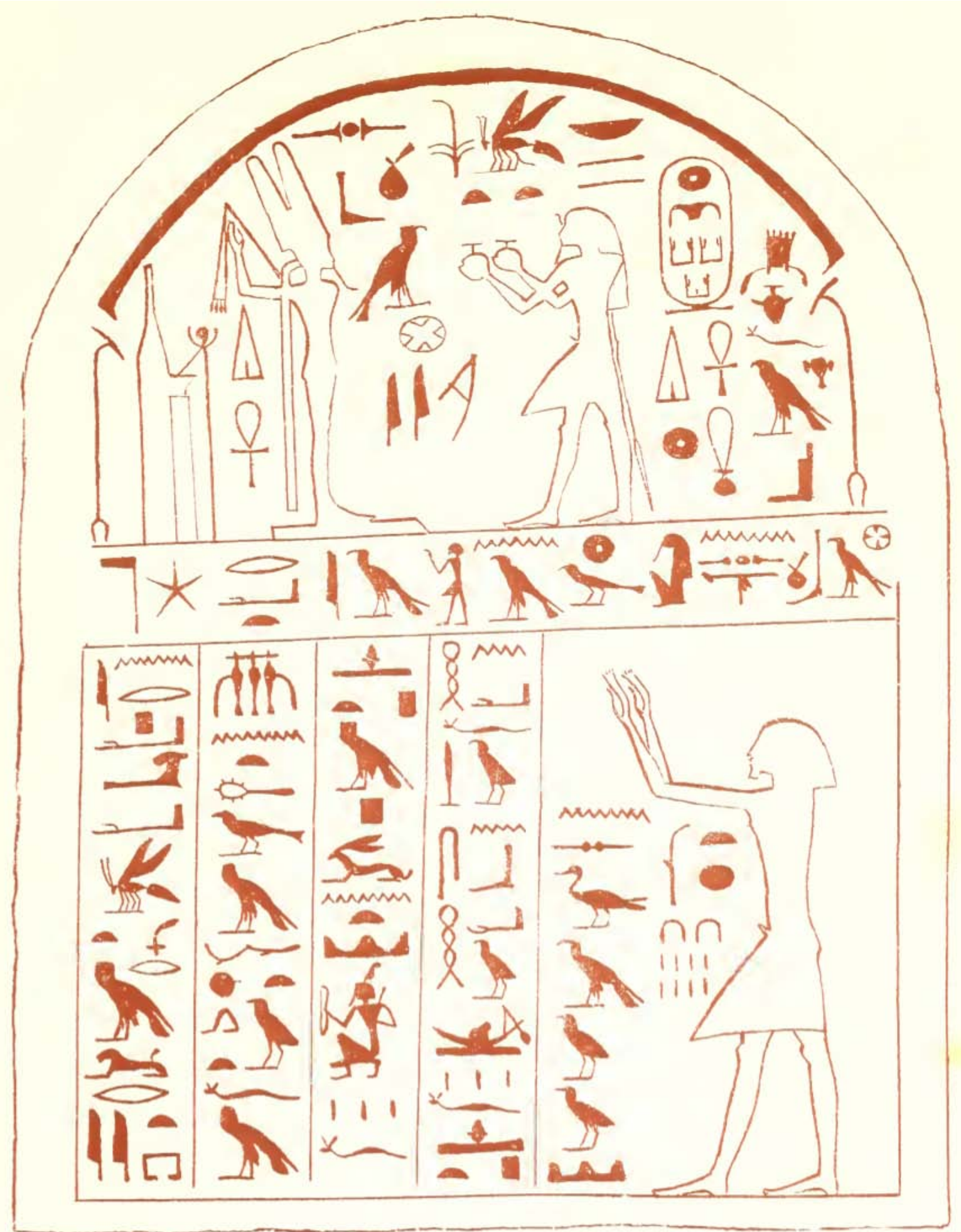

La stèle Durham N 1934 (BIRCH 1880, pl. III) 


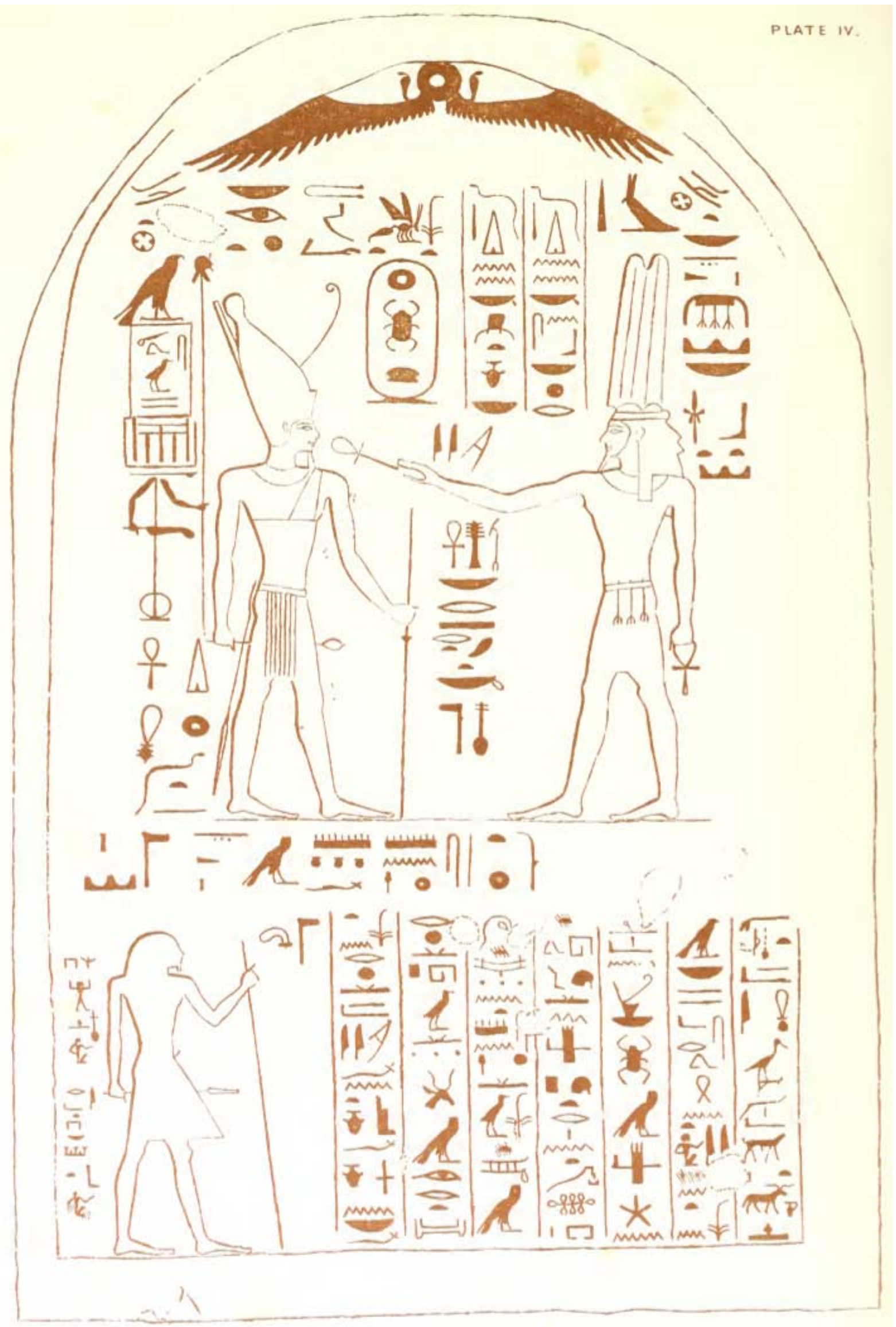

La stèle Durham N 1935 (BIRCH 1880, pl. IV) 


\subsection{Au Ouadi Hammamat}

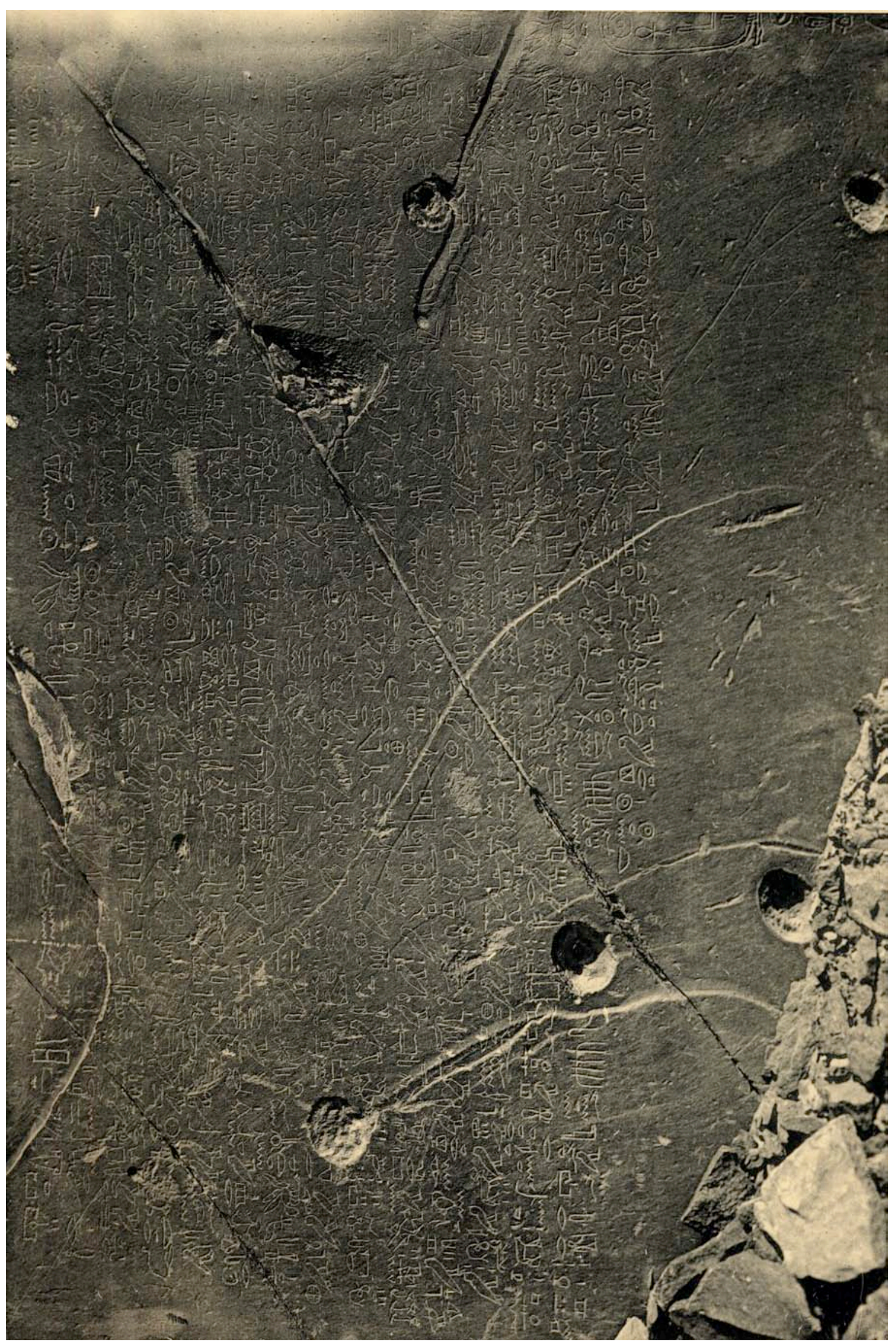

L'inscription d'Hénou M 114 (COUYAT, MonTET 1912, pl. XXXI) 


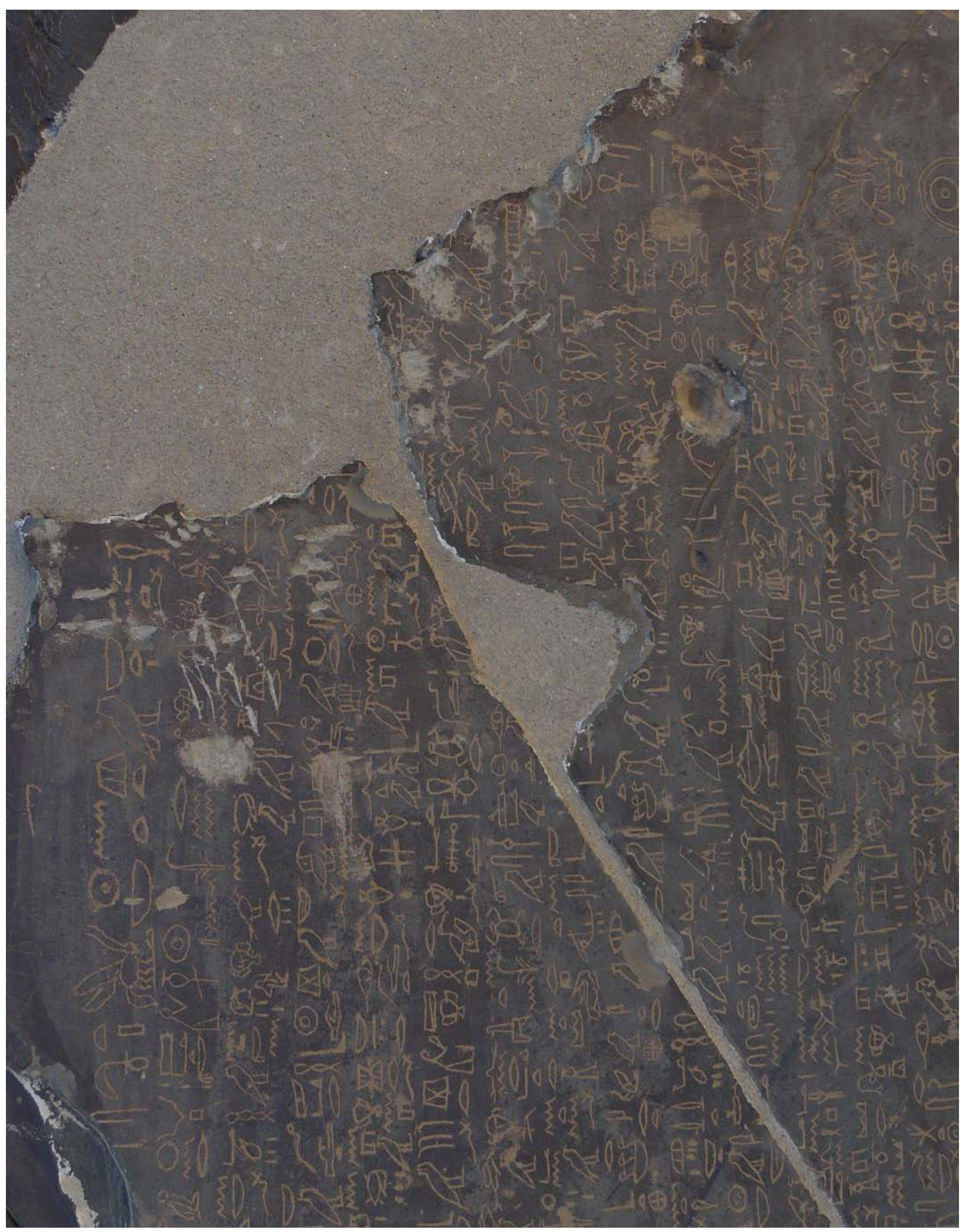

L'inscription d'Hénou M 114 (photographie de Nicolas Gauthier, 5 février 2010) 


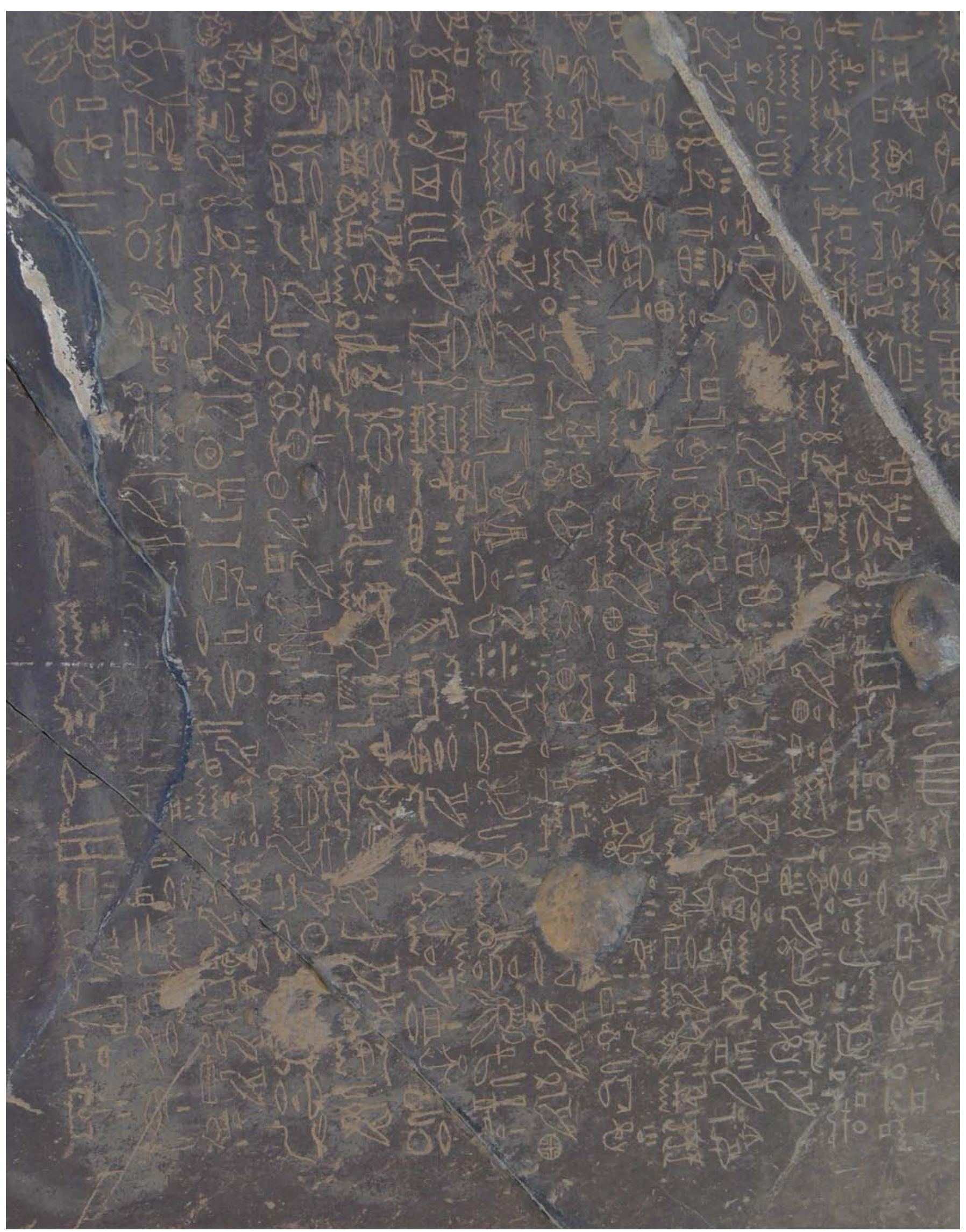

L'inscription d'Hénou M 114 (photographie de Nicolas Gauthier, 5 février 2010) 


\subsection{Au Ouadi Gaouasis}

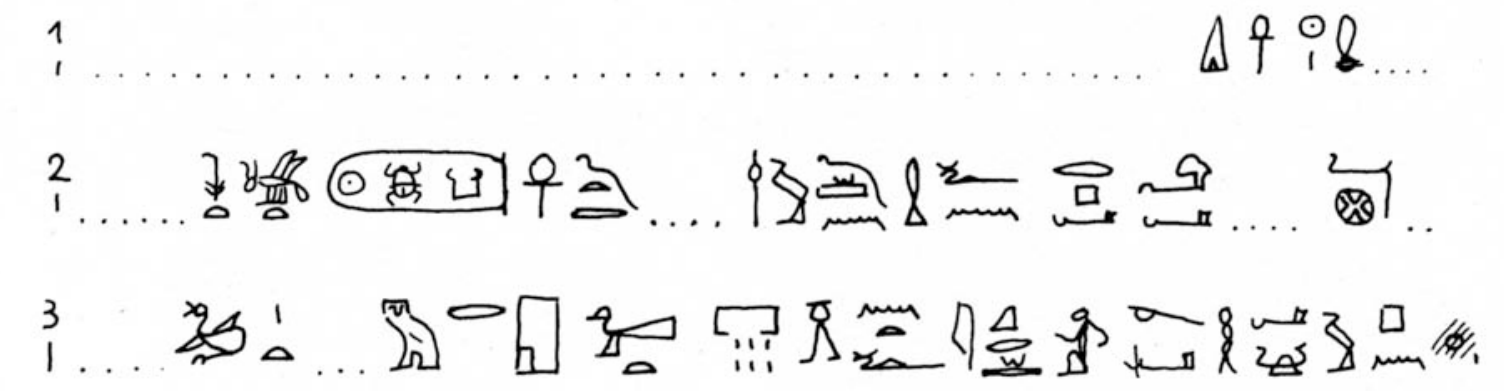

a

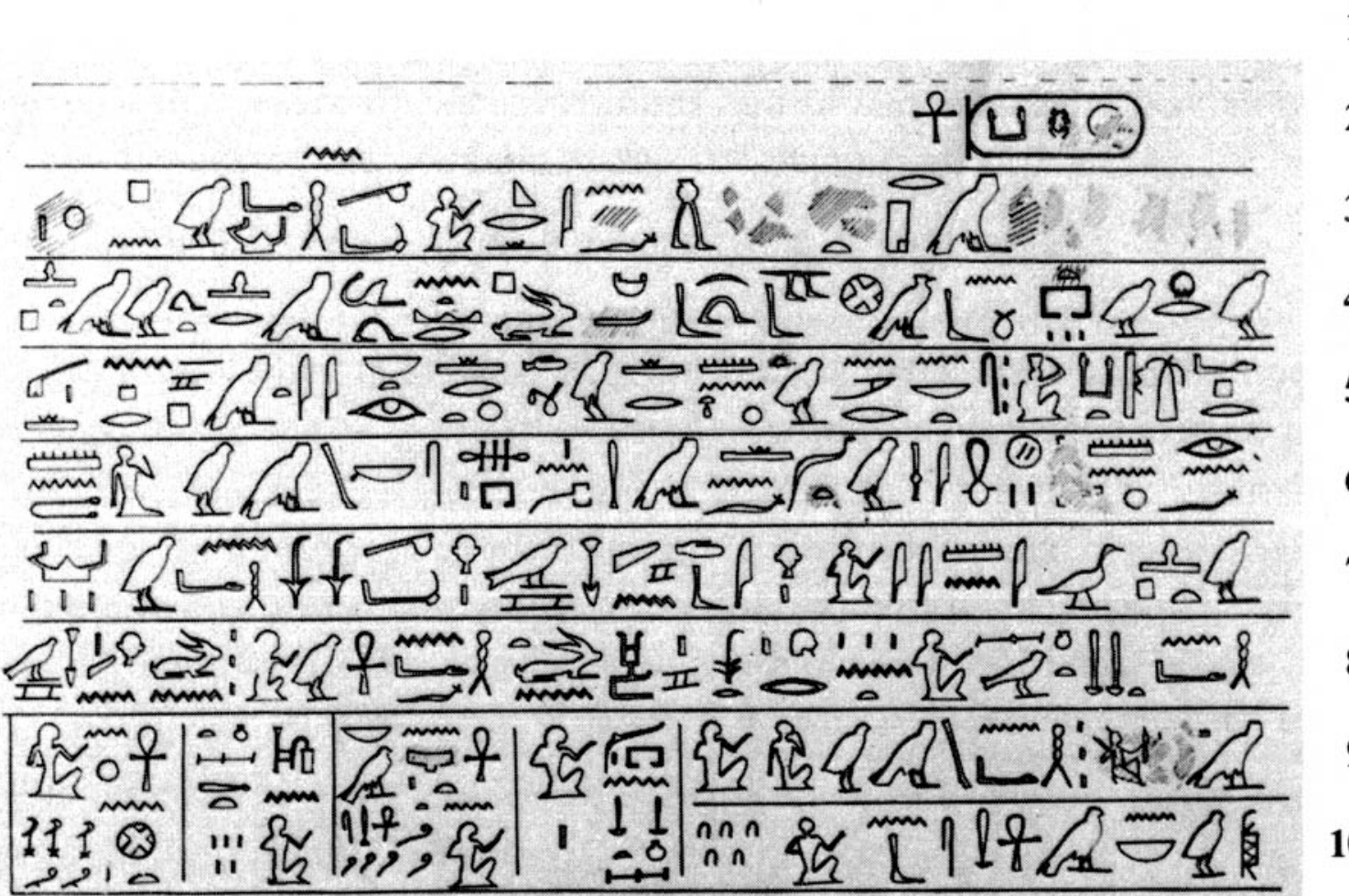

b

L'inscription du monument d'Amény au Ouadi Gaouasis

a. Les hiérogyphes des premières lignes (SAYED 1977, p. 170)

b. L'édition du texte préservé (SAYED 1977, p. 171, pl. 16b) 


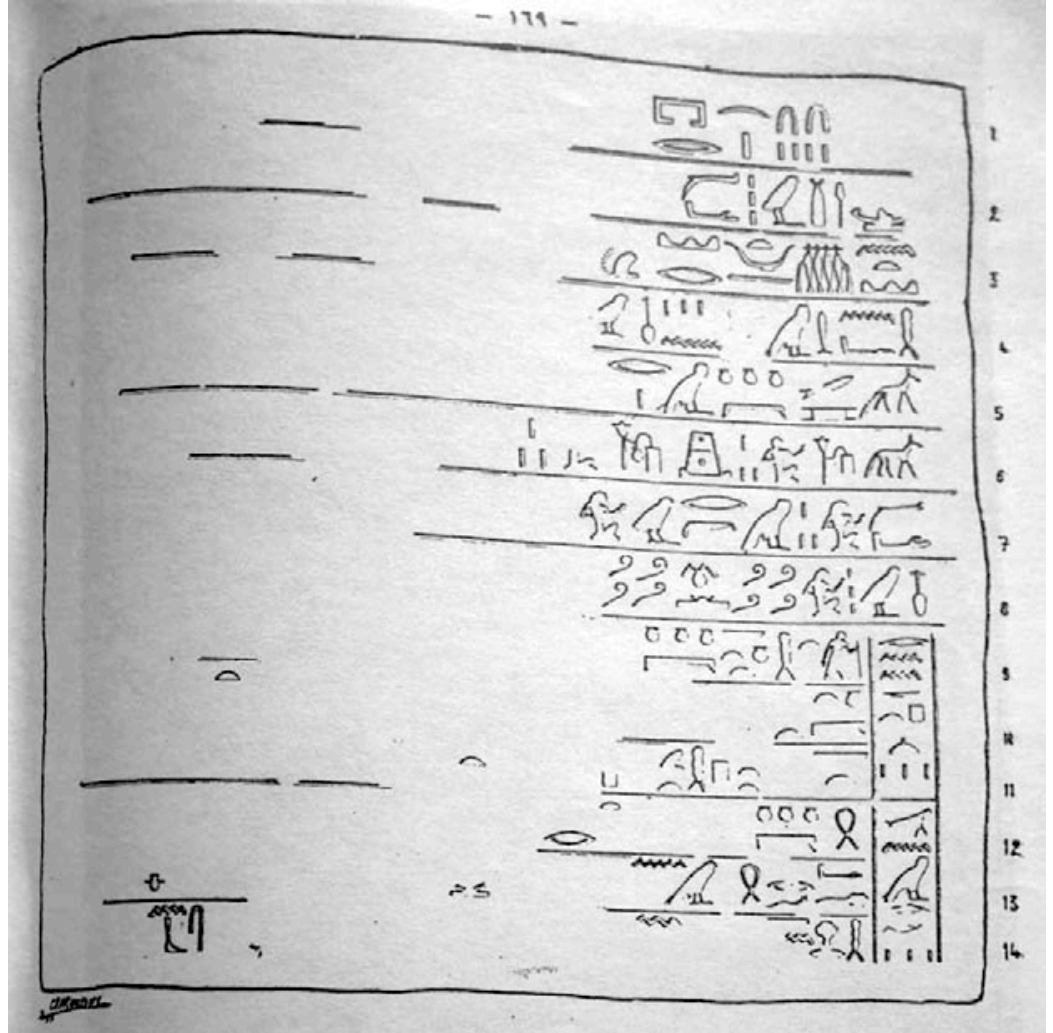

a

b c 1......n...

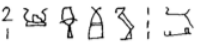

31 䇺

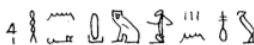

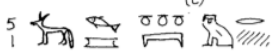

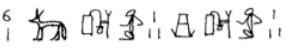

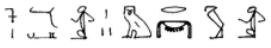

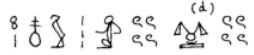

9 있

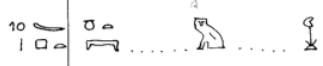

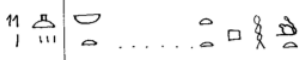

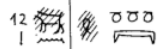

$\vec{s}$

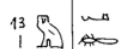

$14 \underset{14018}{10}$
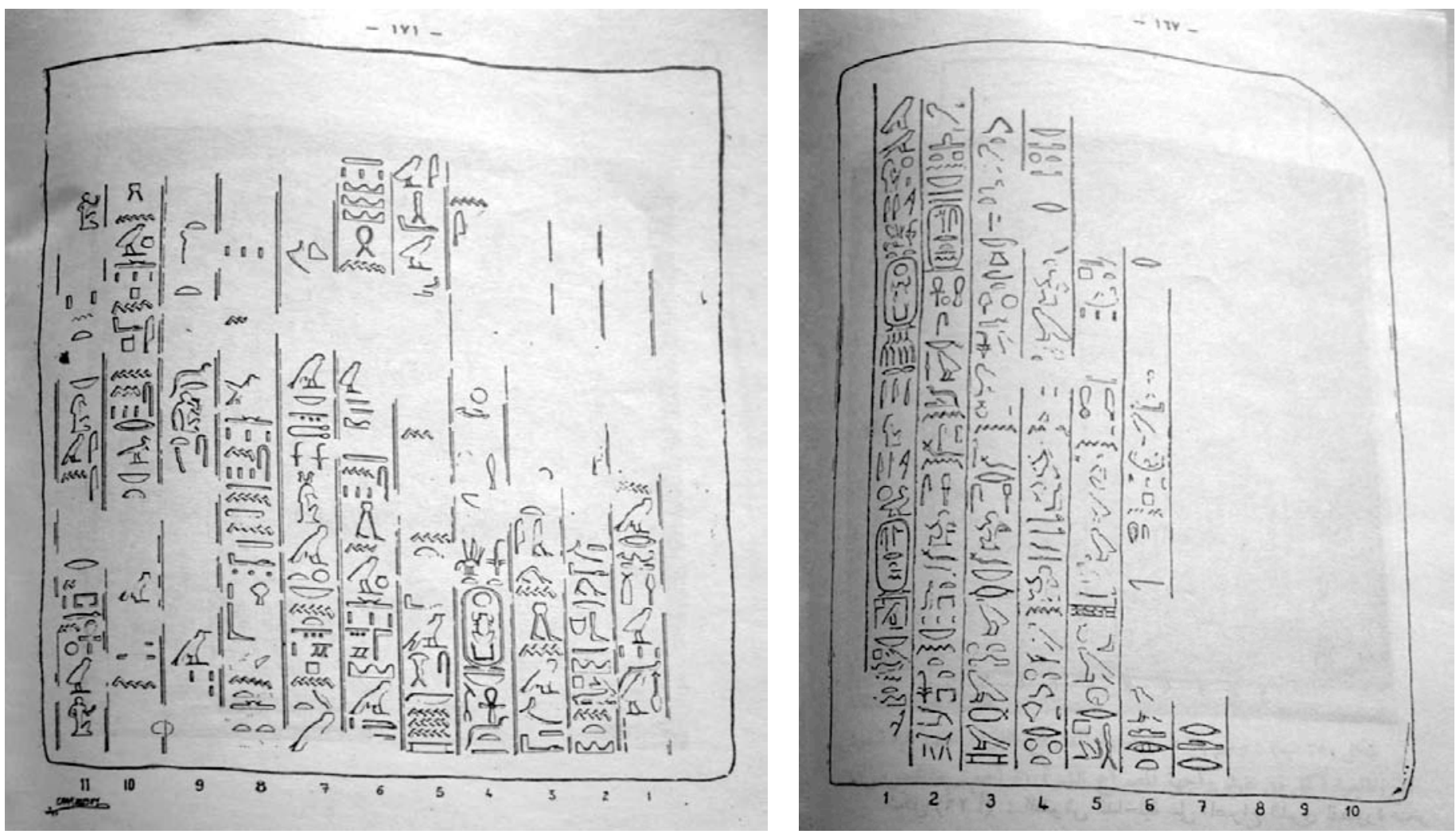

Les inscriptions du monument d'Ânkhou au Ouadi Gaouasis

a. Inscription du bloc central (à gauche, SAYED 1993, p. 169; à droite, SAYED 1977, p. 161)

b. Inscription du bloc occidental (SAYED 1993, p. 171)

c. Inscription du bloc oriental (SAYED 1993, p. 167) 


\subsection{Au Ras Banas (Bérénice)}
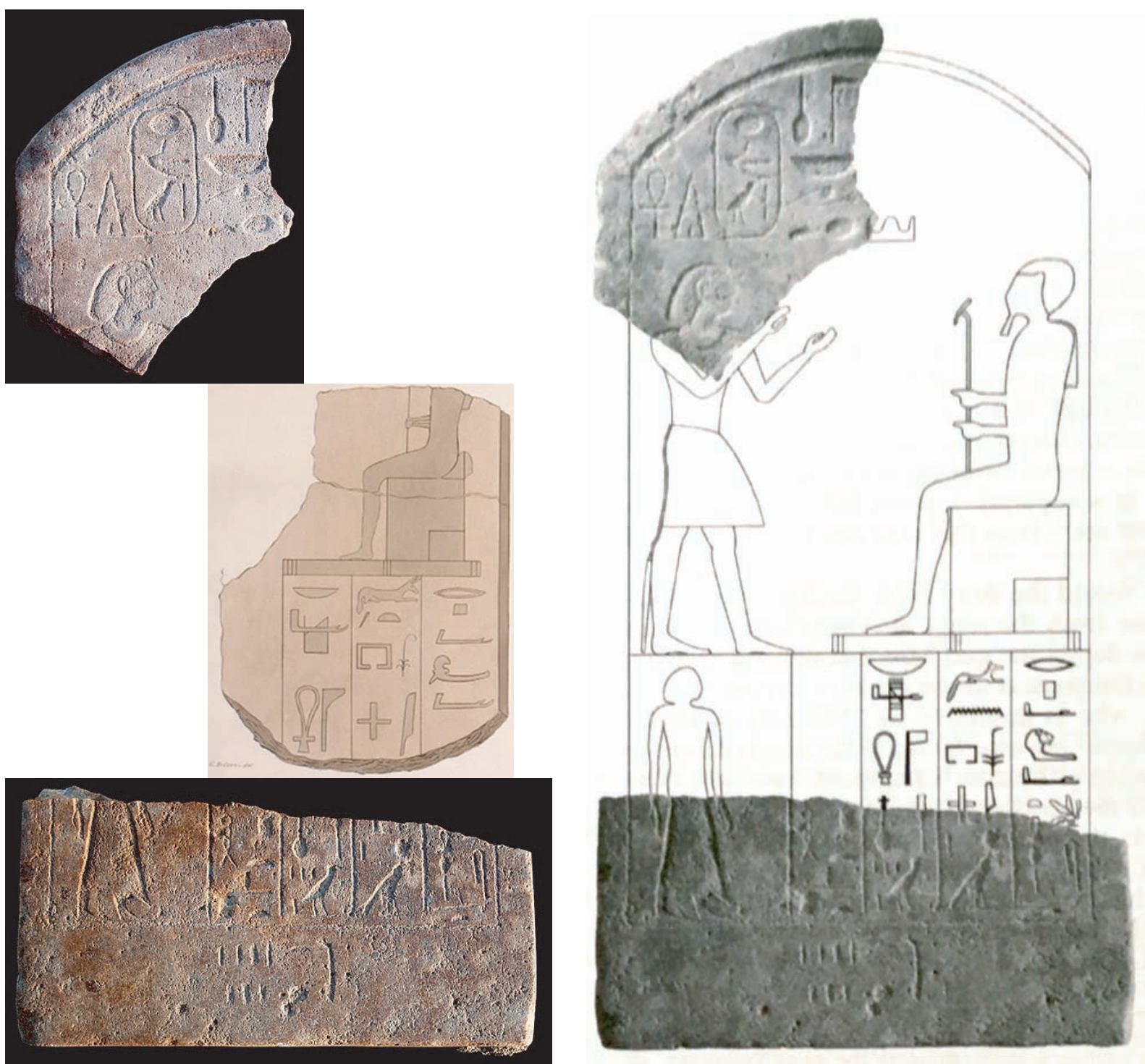

Fragments de la stèle de Ptahhotep

À gauche : les fragments retrouvés en 2015 (photographies de Steven E. Sidebotham, d'après https://books.openedition.org/cdf/5244, fig. 9)

et le fragment découvert en 1818 par Belzoni (BELZONI 1821, pl. 16)

À droite : restitution de la stèle par Martin Hense (HENSE, KAPER, GEERTs 2015, col. 594) 